الملامح العمرانية والمعمارية لمدينة أم درمان الأثرية

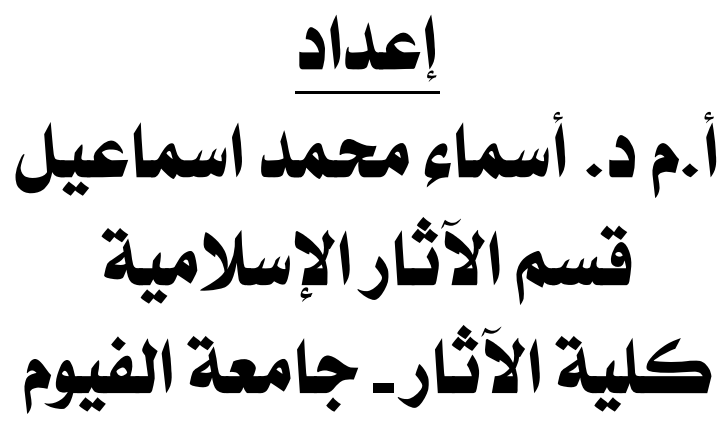




\section{الملامح العمرانية والمعمارية لمدينة أم درمان الأثرية}

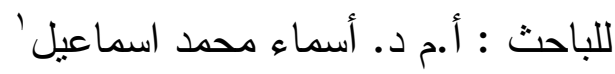

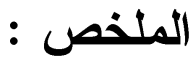

لُعد مدينة أم درمان العاصمة التاريخية لدولة المهدية، واحدة من المدن القديمة في

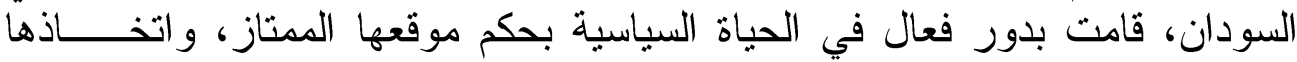

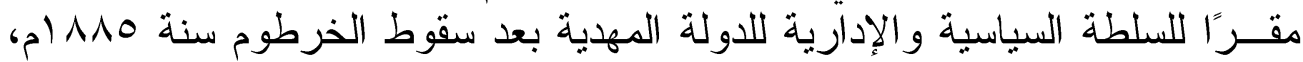

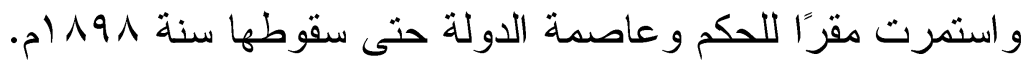

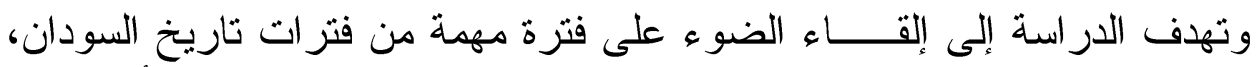

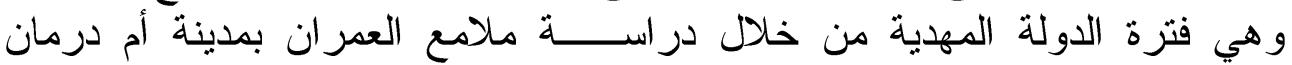

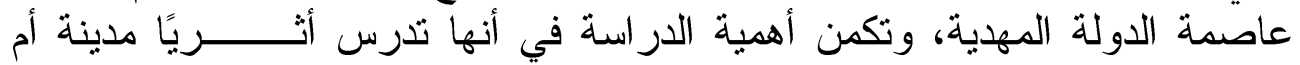

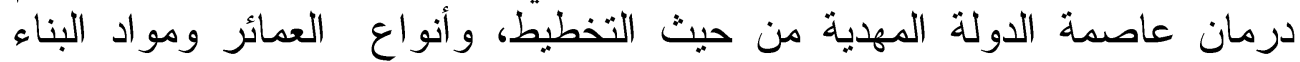

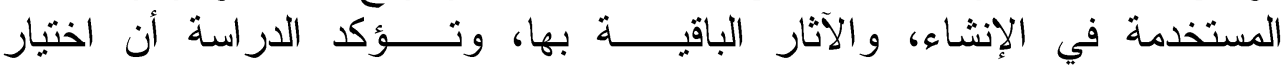

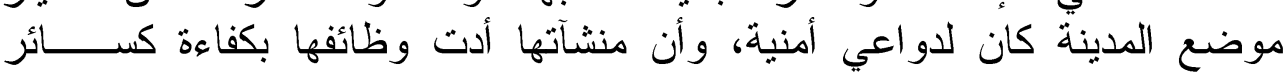
المدن الإسلامية.

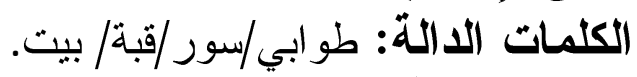

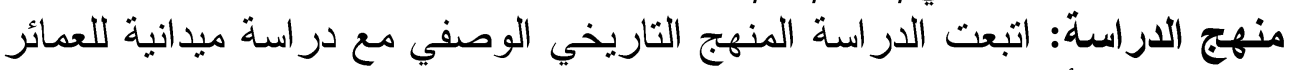
الباقية بمدينة أم درمان. مباحث الار اسة: قسمث الدر اسة إلى ثلاثثة مباحث هي :

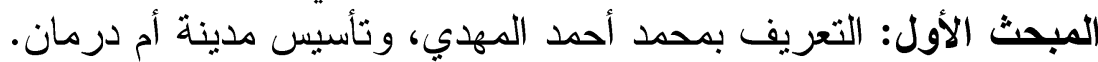

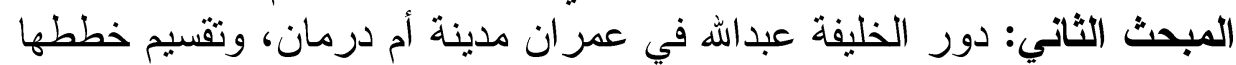
المبحث الثالث: الدر اســـــة التاريخية و الأثرية للعمائر الباقية بمدينة أم درمان. 


\section{Urban and Architectural features of the Archeological city of Omdurman}

\section{Abstract :}

Om Dorman city was the historical capital of Máhdia state, it was considering one of ancient cities in Sudan, it played an effective role in political life, as it has an excellent site and it Itwas become the seat of government "authority"in thestate of Mahdia, until its falling in 1898.

The research aims to study the most important period of modern Sudan which Called Mahdia State, by studying its Capital - Om Dorman- urban, city planning, remain buildings, and its construction material.

The study confirms that choosing the site of the city Om Dorman related with security needs (reasons) and their buildings performed its function efficiently.

Key words: Forts ( Al-Tawabi) / Wall / Dome / House. 
المبحث الأول: التعريف بمحمد أحمد المهدي، وتأسيس مدينة أم درمان.

ا-محمد أحمد بن عبدالله: الأه

وُلِّد محمد أحمد بن عبد عبداله بن فحل بن بن عبدالولي في جزيرة لبب من أعمال

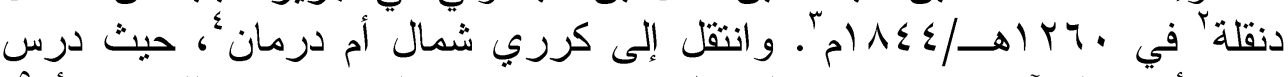

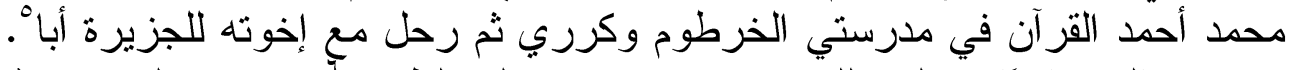

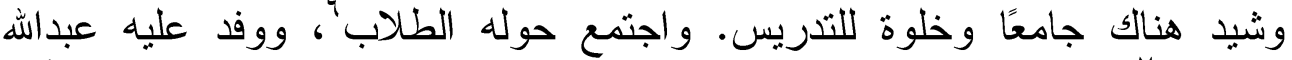

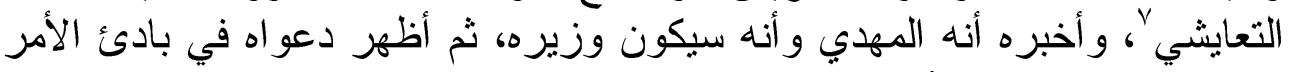

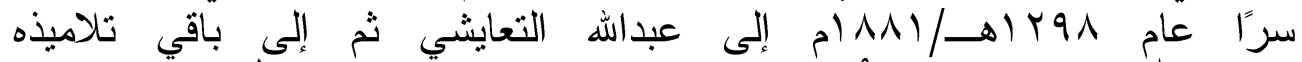

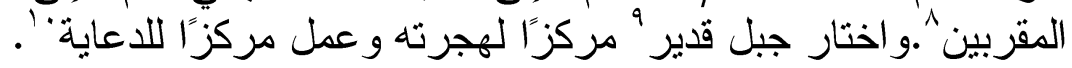

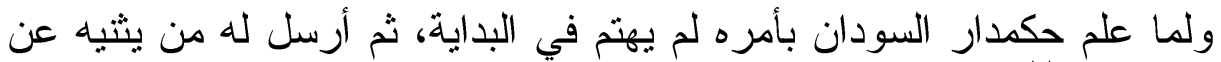

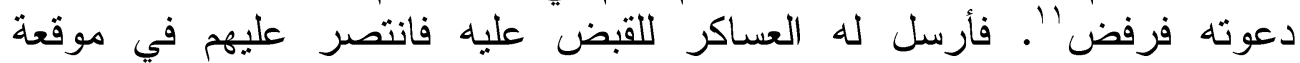

r لأن موطنه الأ صلي دنقلة عُرف بالدنقلاوي . Thomas Archer, the war in Egypt and the Sudan , an episode in the history of the British empire, vol,2.London 1886,p.211

r عبدالمحود أبو شامة، من أبا إلى تسلهاي حروب حياة الإمام المهدي، الخرطوم 9NV ام،

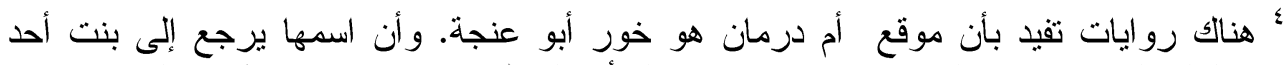

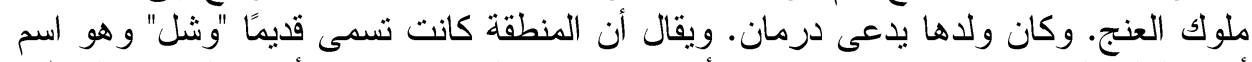

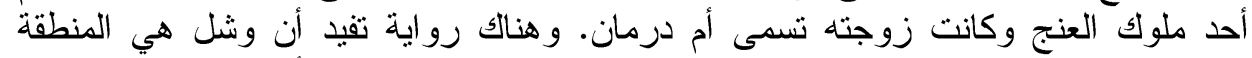

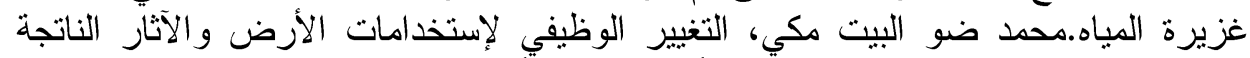

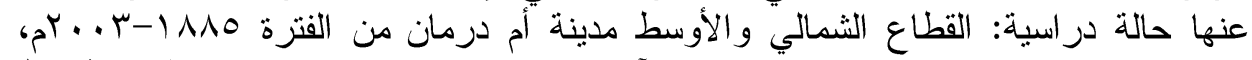

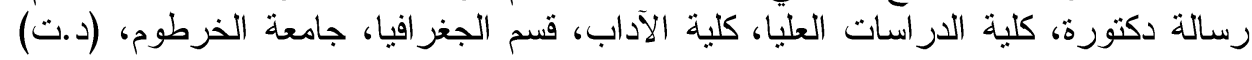
ص ر v

F. Rehfisch, a sketch of the early history of Omdurman, Sudan notes and recordes, no.45, vol, xlv,1964, P.35.

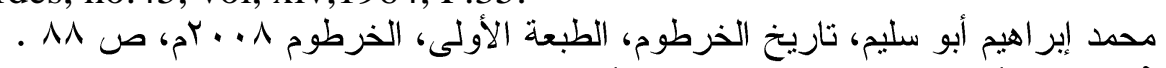

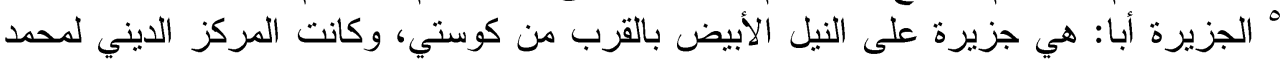

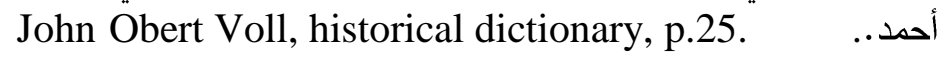

${ }^{6}$ J. Spencer .Trimingham ,Islam in the Sudan, London,1965, pp.93-94.

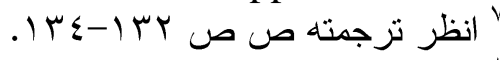

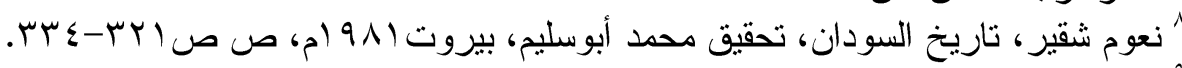

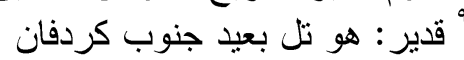

P.M.Holt,a modern history of the Sudan from the Funj sultanate to the

${ }^{10}$ P.M.Holt,a modern history, p.79. present day,London, 1963 , p.80.

11 R.A.Bermann,the Mahdi of Allah a drama of the Sudan,New York,1932,pp.118 -121. 


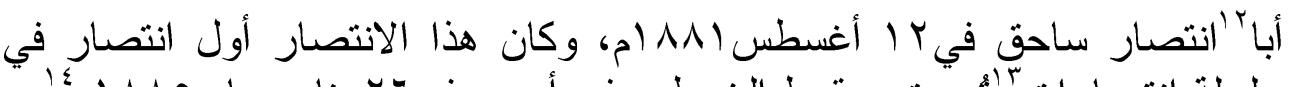

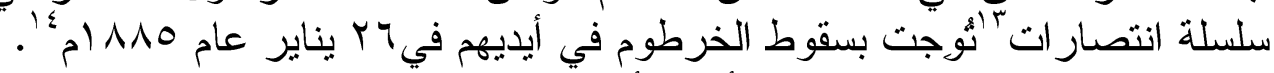

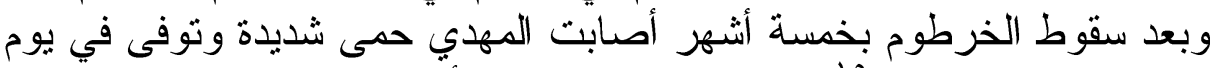

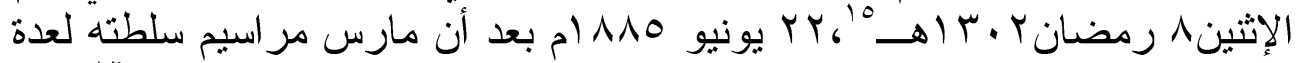

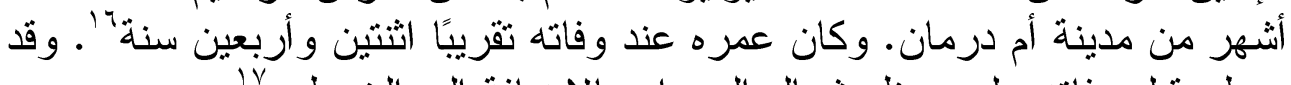

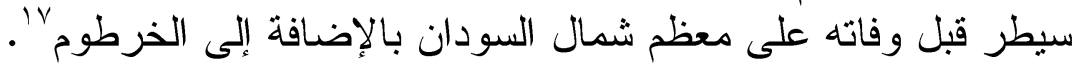

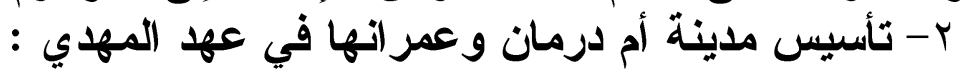

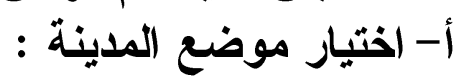

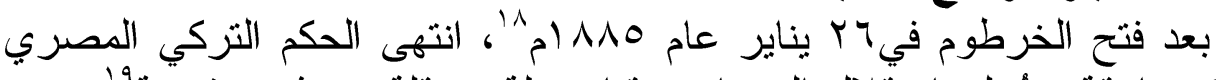

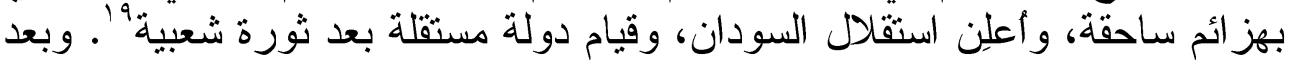

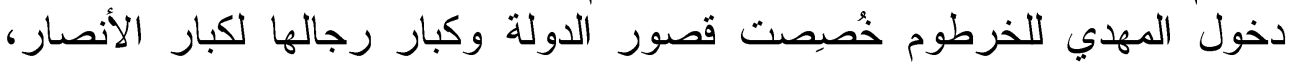

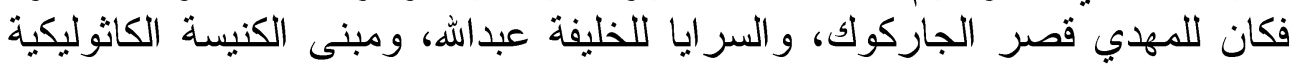
للخليفة شريف، ومبنى المديرية للقائد أبوقرجة. واستمر الوضع كذلك لفترة وجيزة،

12 J. Spencer .Trimingham ,Islam in the Sudan, p.94.

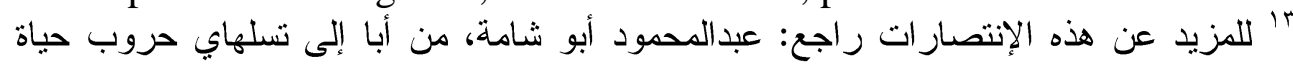

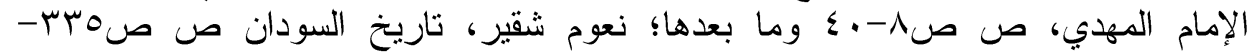

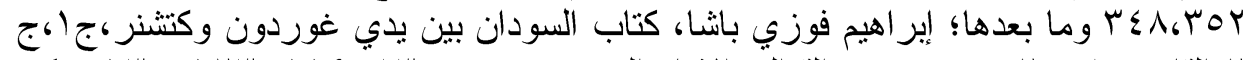

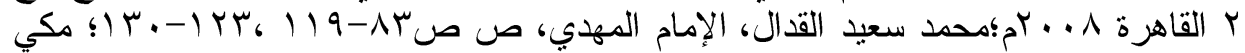

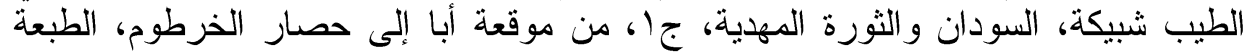

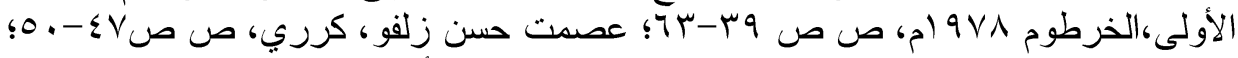

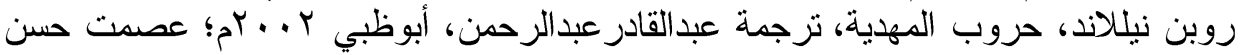

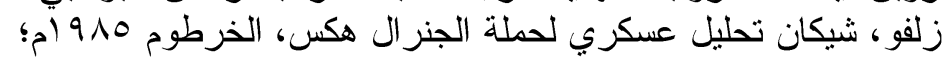

F.R.Wingate, Mahdiism and the Egyptian Sudan,second edition ,London and Edinburgh,1968, p92, etc, Thomas Archer, the war in Egypt and the Sudan,pp.283-250

Major F.R Wingate, Ten years captivity in the Mahdi's camp 1882-1892 from the original manuscripts of father Joseph Ohrawalder, London,1986,p. 76-90.

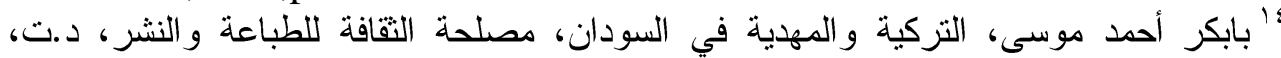

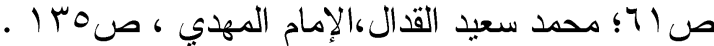

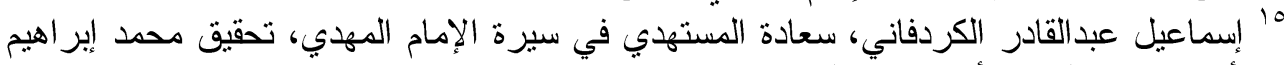

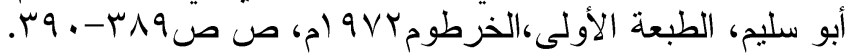

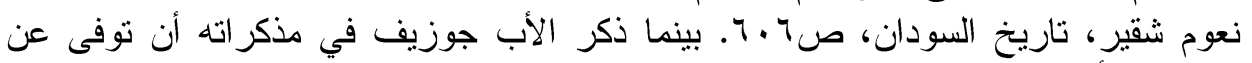

Major F.R Wingate, Ten years captivity, p.12. 0

${ }^{17}$ John Obert Voll,historical dictionary,p.p. 64 -65.

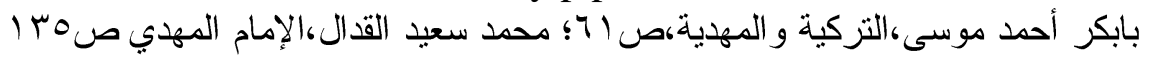

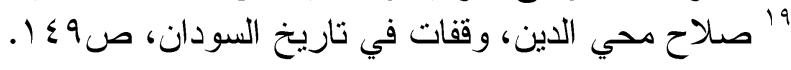




\section{الماملامح العمرانية والمعمارية لمدينة أم درمان الأثرية}

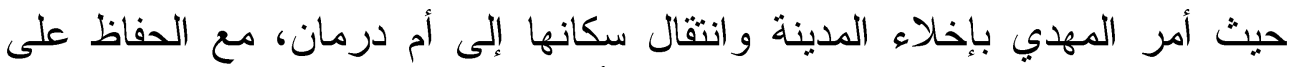

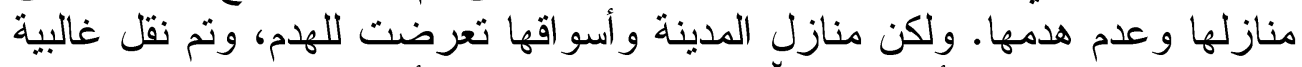

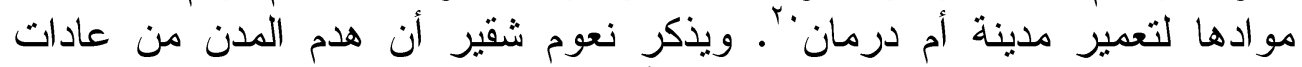

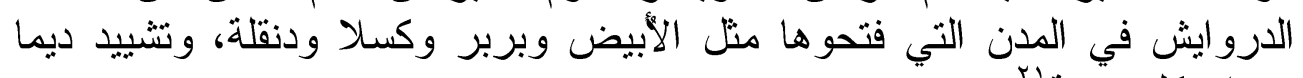

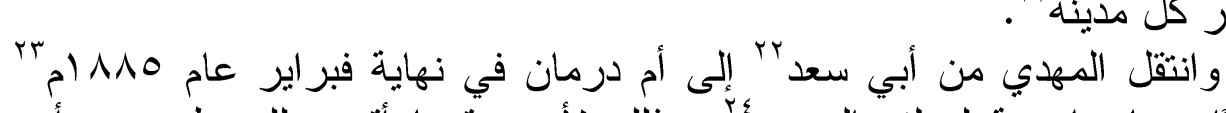

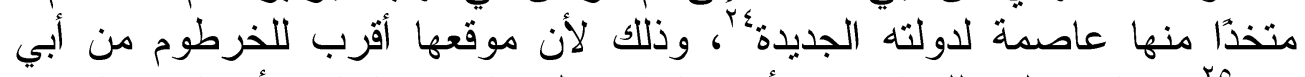

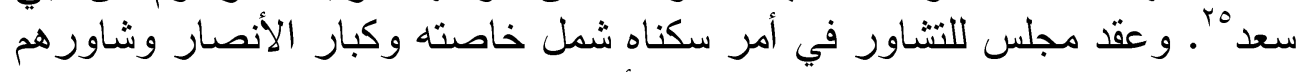

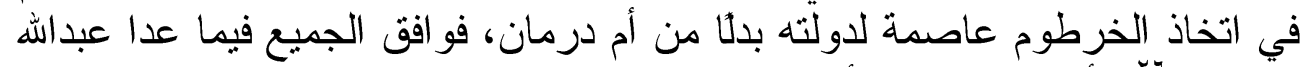

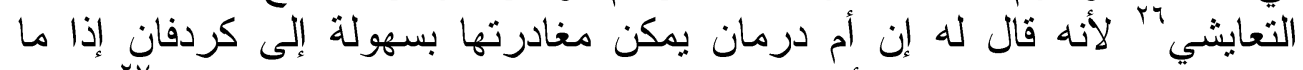

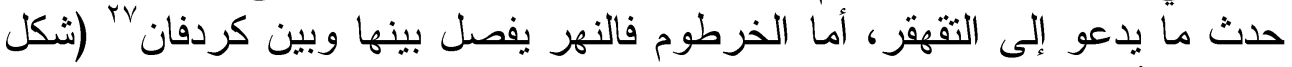

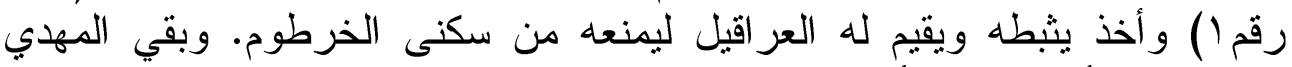

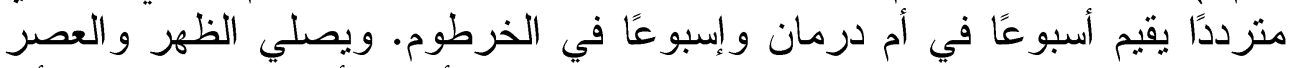

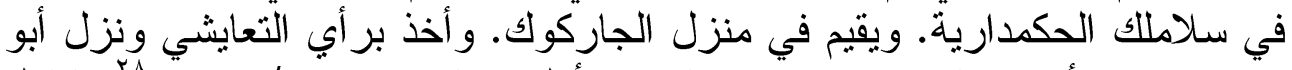

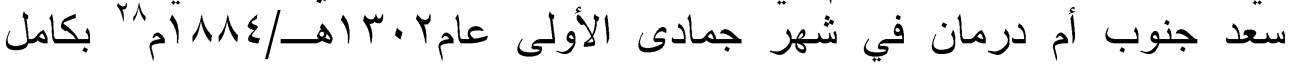

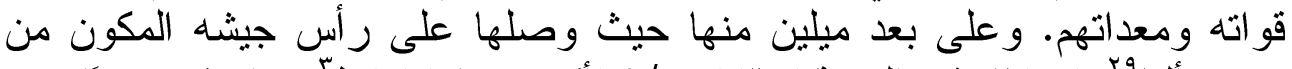

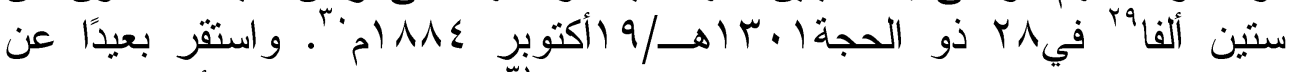

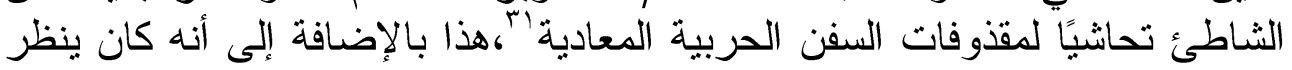

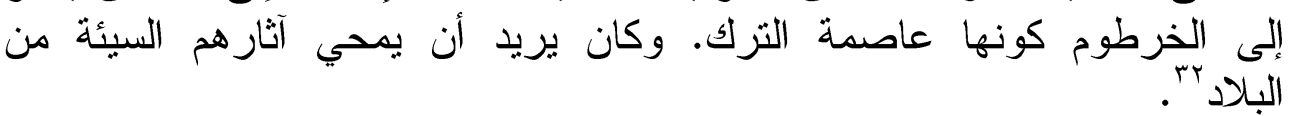

\section{ب- تخطيط أم درمان في عصر المهدي:}

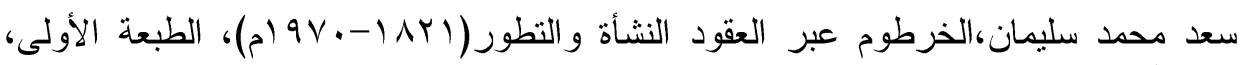

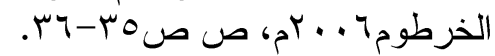

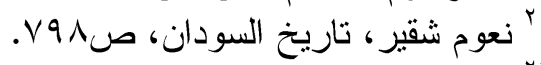

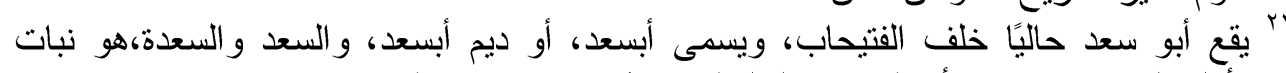

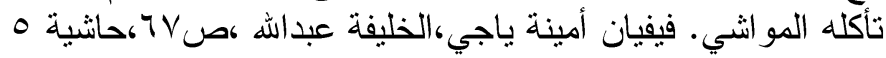

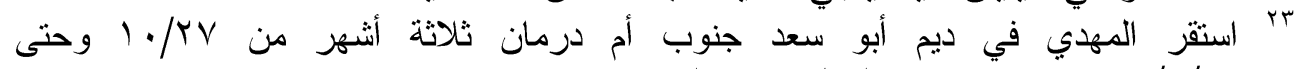

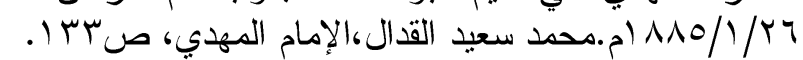

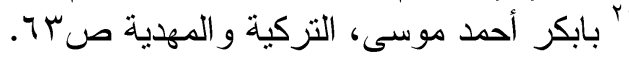

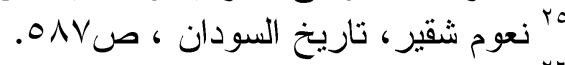

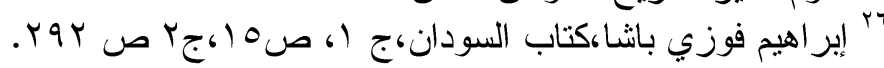

27 F.Rehfisch, a sketch of the early history of Omdurman,p.41.

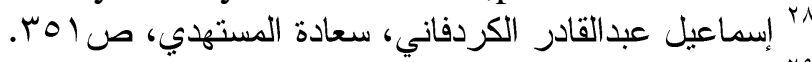

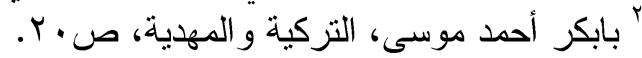

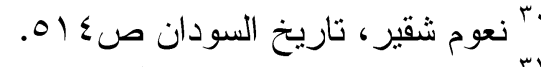

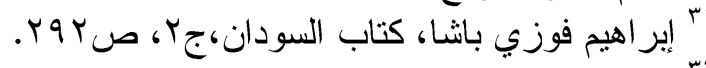

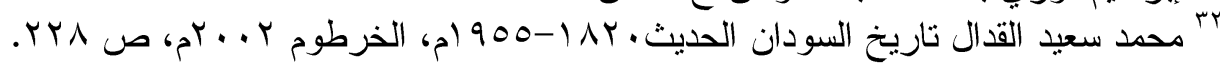




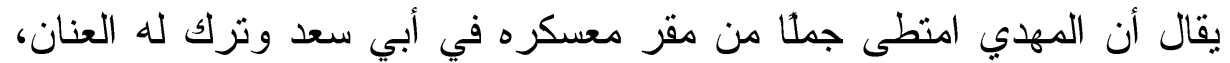

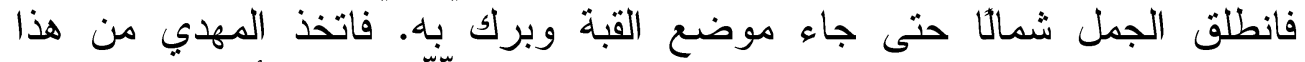

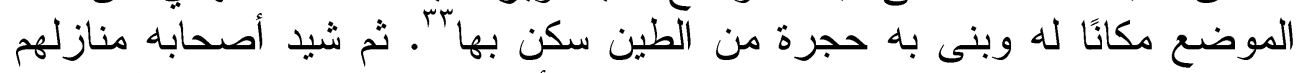

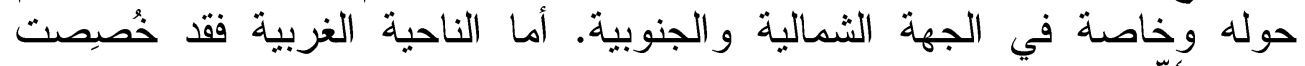

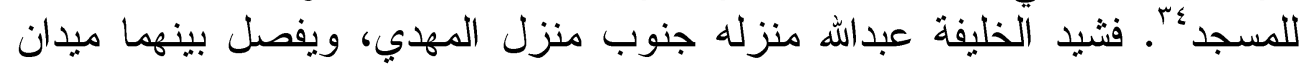

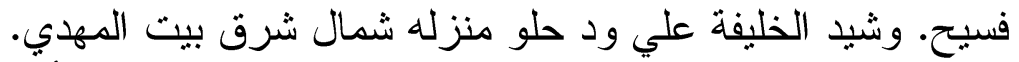

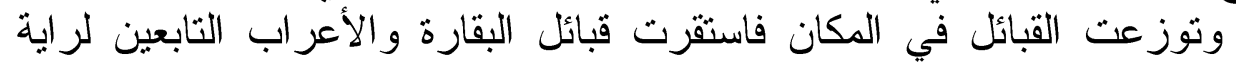

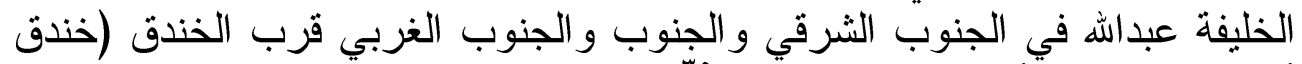

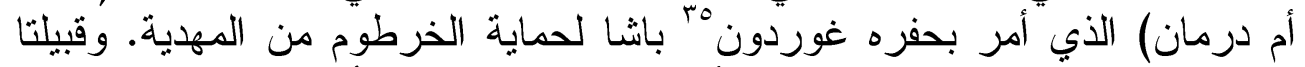

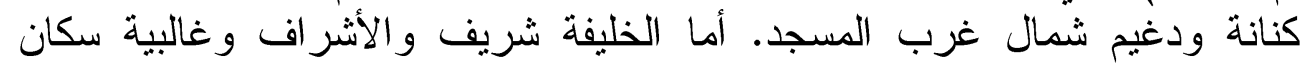
السودان الأوسط فقد استقروا شرق بيت المهدي وشماله حتى شاطئ النيل. كما

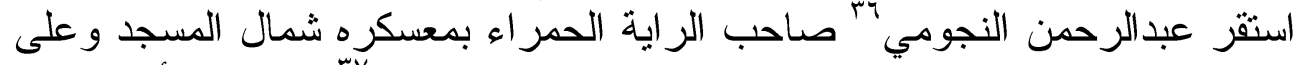

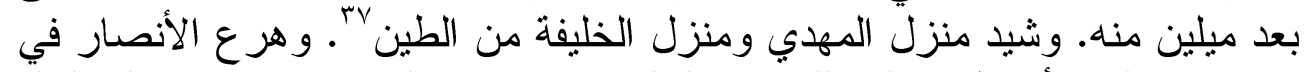

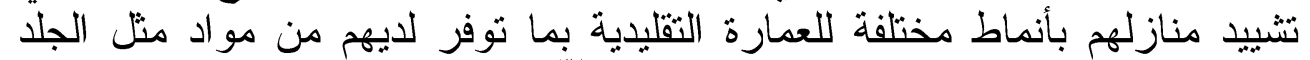

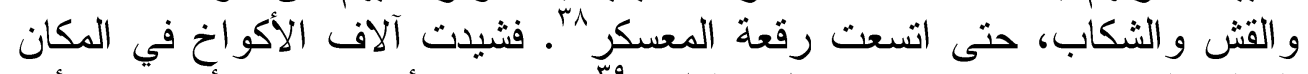

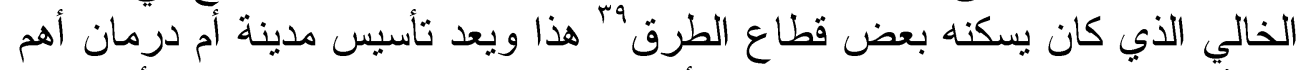

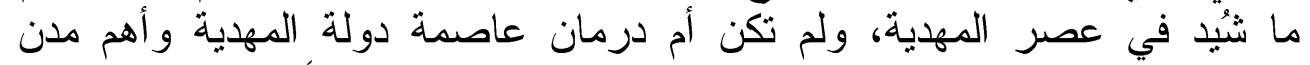

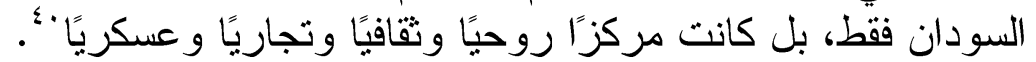

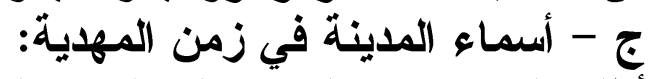

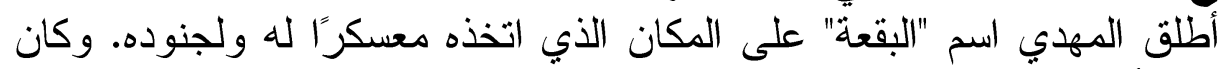

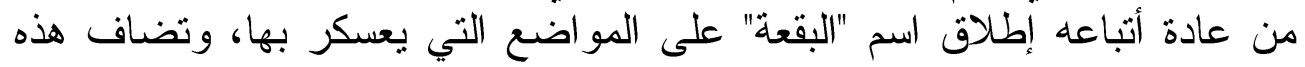

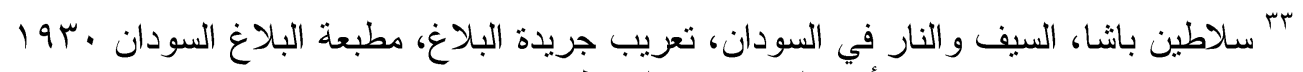

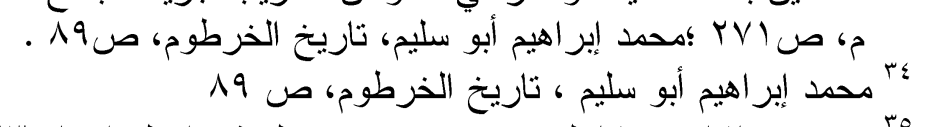

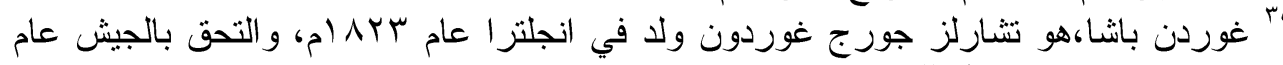

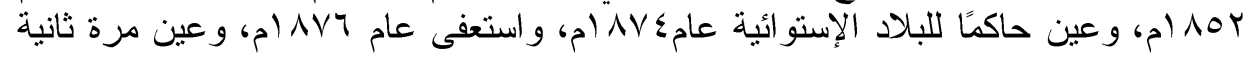

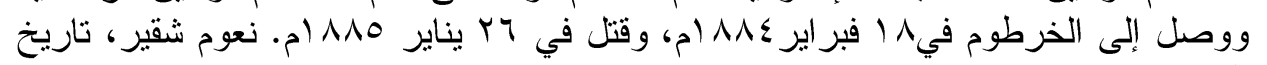
السودان، ص ص الفى الخرم في

Piers Compton, the last days of General Gordon, London, 1974, pp.180183.

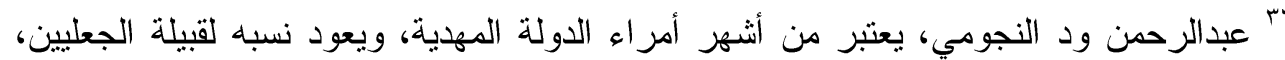

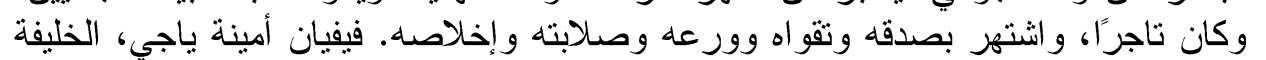

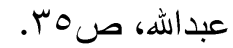

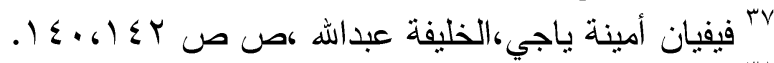

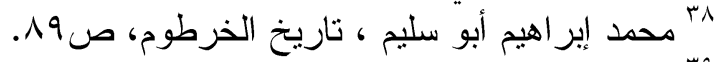
ra

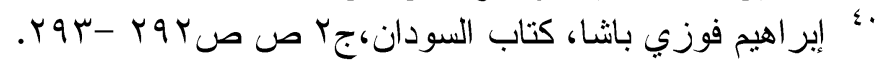




\section{الماملامح العمرانية والمعمارية لمدينة أم درمان الأثرية}

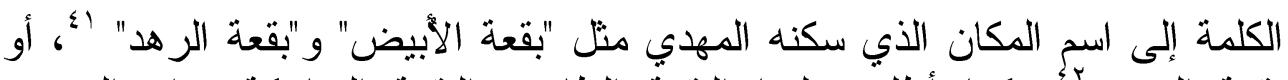

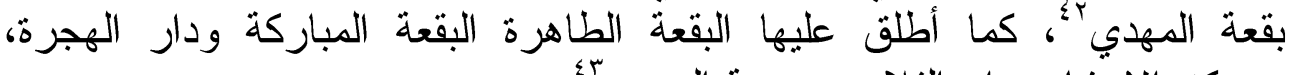

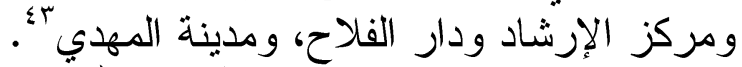

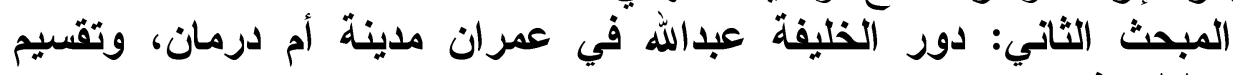

\section{خططها في عهده.}

ا - الخليفة عبدالهي عهده:

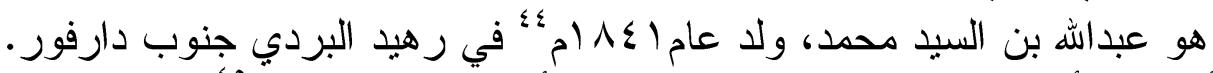

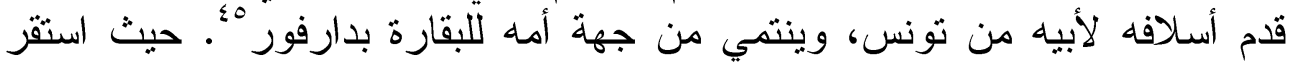

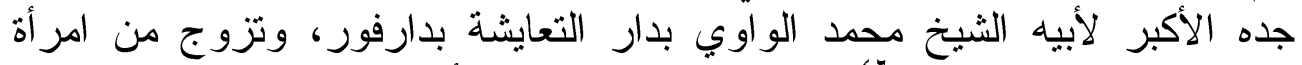

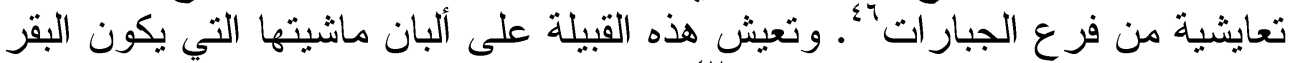

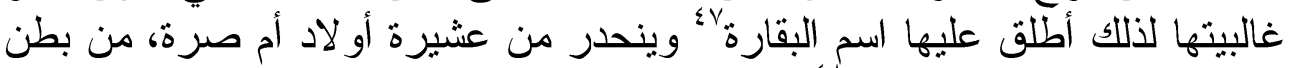

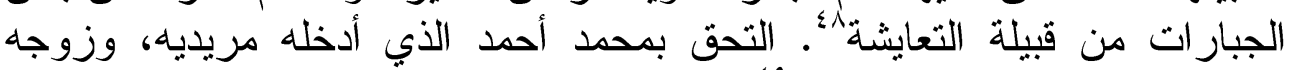

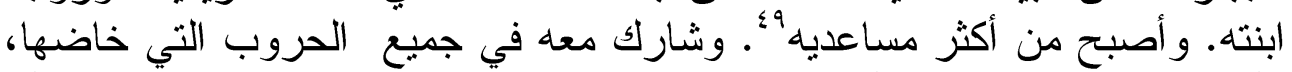

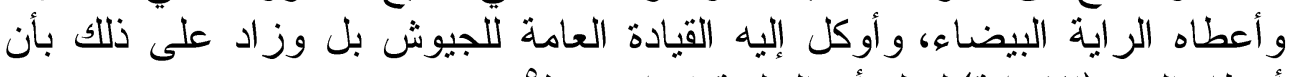

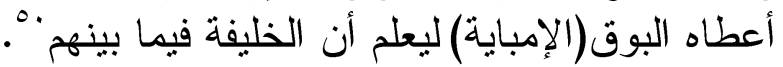

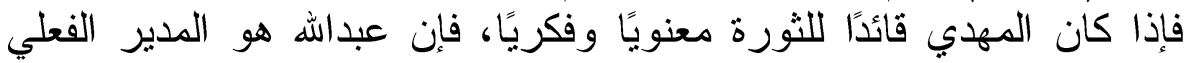

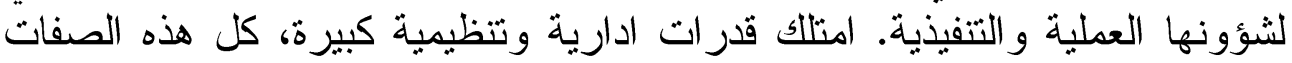

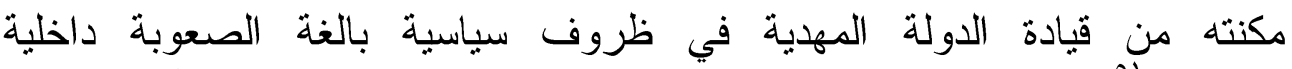

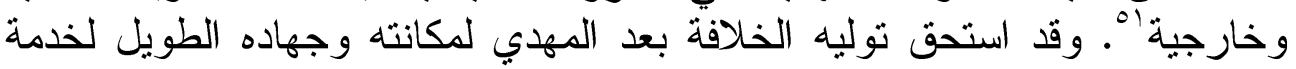

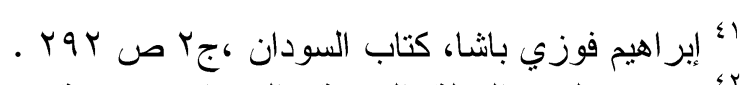

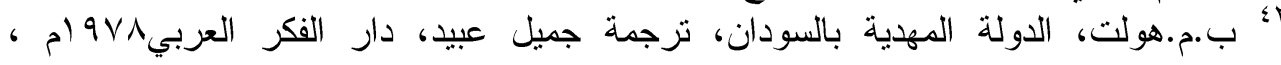

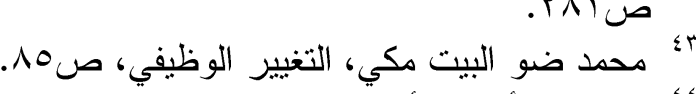

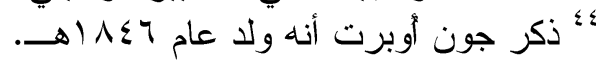

John Obert Voll, historical dictionary,p.28.

0؛ فيفيان أمينة ياجي،الخليفة عبداله، ص آ ب. ${ }^{46}$ J.A.Reid,some notes on the Khalifa Abdullahi from contemporary Sudanese sources, Sudan notes and recordes, no.21, vol, xxi,1938, p.207. Y؛ ريتشارد هلِ، معجم تزاجم أهل السودان، ترجمة سيف الدين عبدالحميد النعيم، الخرطوم 14 17

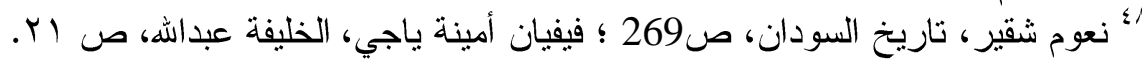
49 John Obert Voll, historical dictionary p.28.

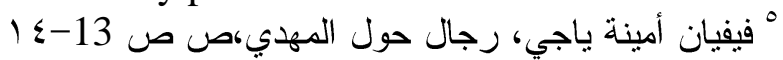

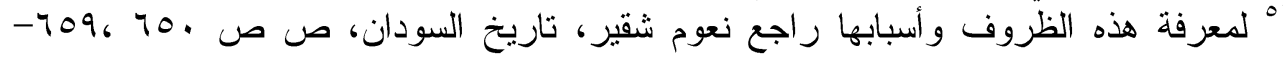
. ATY-VOV.VT.-TVT.VI. 


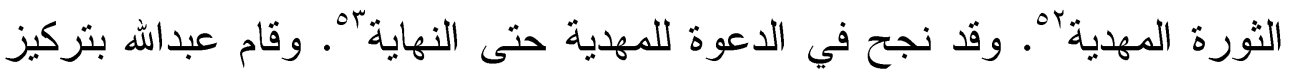

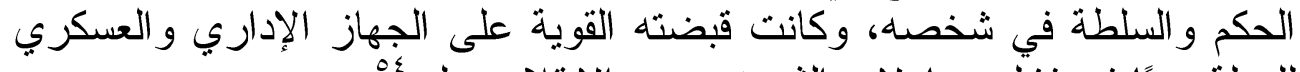

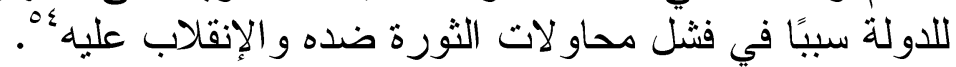

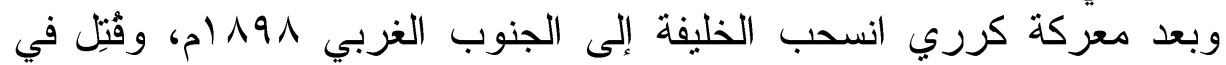

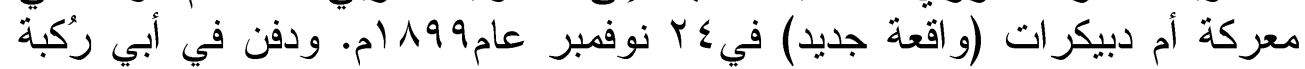

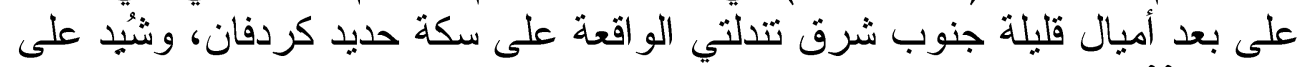
قبره قباة

r-أم درمان في عصر الخليفة عبدالله :

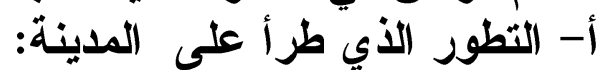

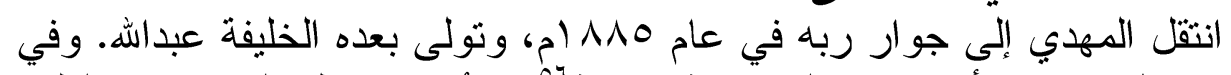

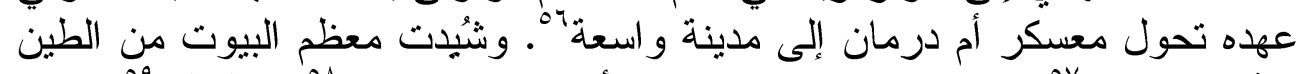

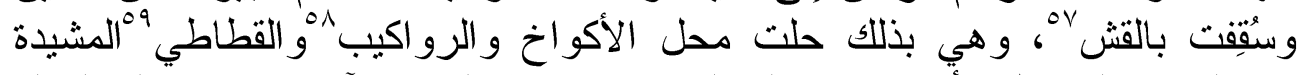

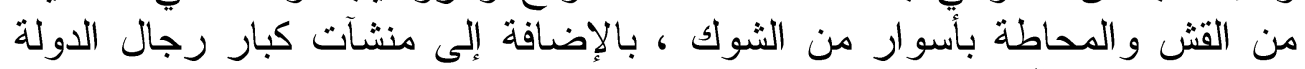

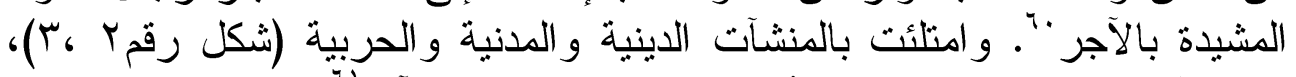

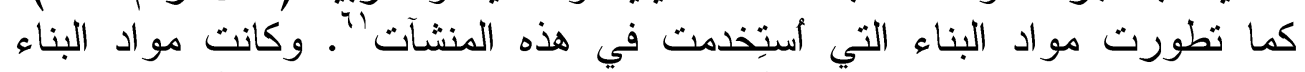

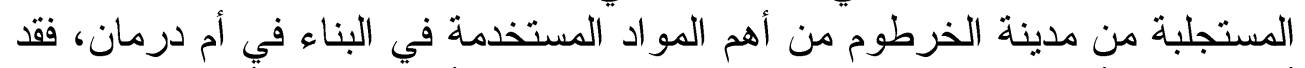

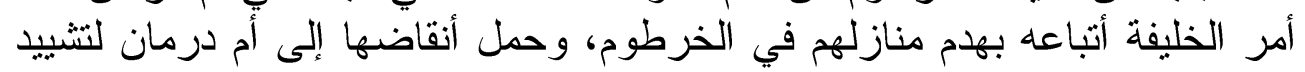

ro عبدالعزيز حسن الصاوي ومحمد علي جادين، الثورة المهدية مشروع رؤية جديدة، الطبعة

${ }^{53}$ J. Spencer .Trimingham ,Islam in the Sudan, p95.

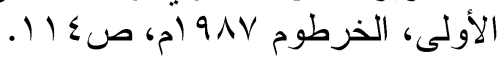

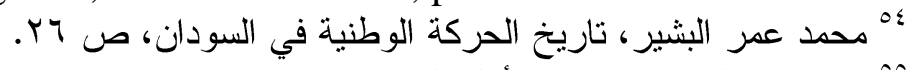

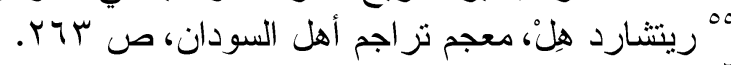

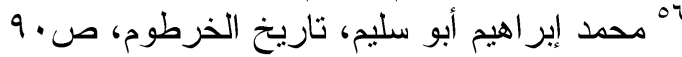

${ }^{57}$ F. Rehfisch, Omdurman during the Mahdiya, Sudan notes and recordes, no.48,vol, xlv111, 1967,P.34.

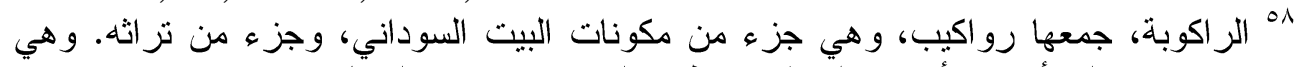

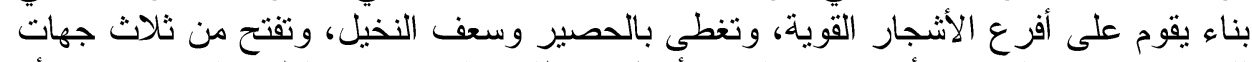

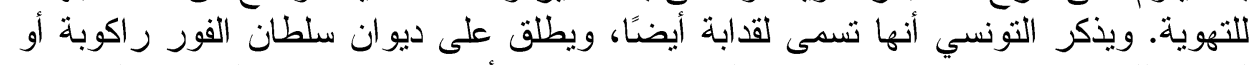

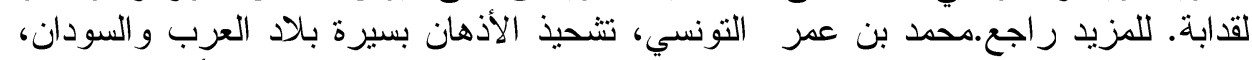

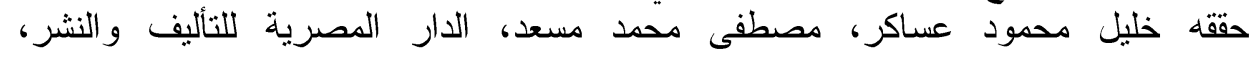

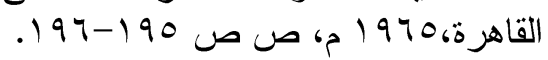

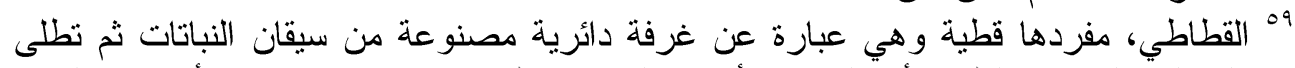

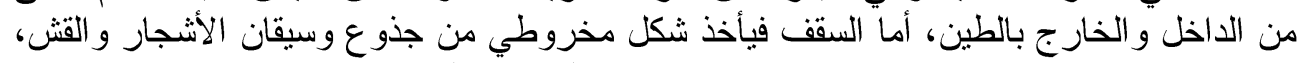

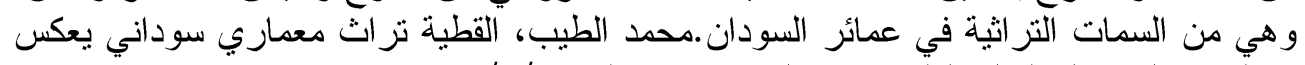

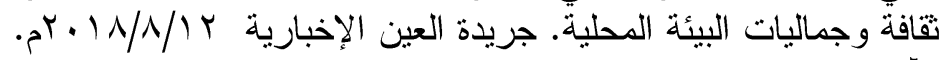

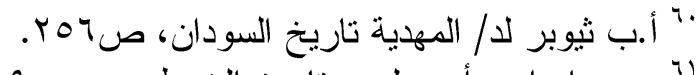

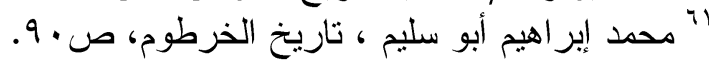




\section{الماملامح العمرانية والمعمارية لمدينة أم درمان الأثرية}

منازلها. ب" و أصبحت المدينة تعج بالسكان، وتزداد مساحتها ويزداد عدد سكانها بمرور الوقت، وساعد على ذلك سياسة تهجير القبائل التي اتبعها الخليفة عبدالهانها.

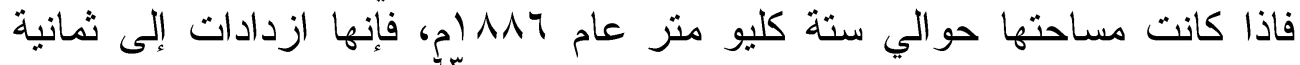

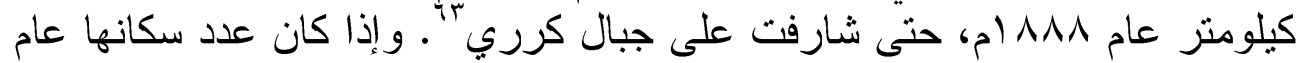

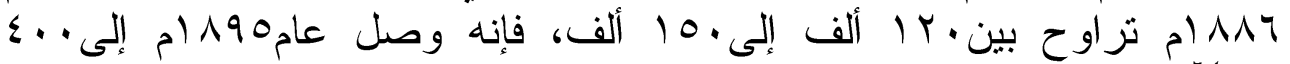

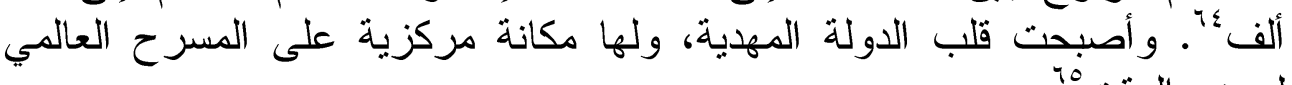
لبعض الوقت

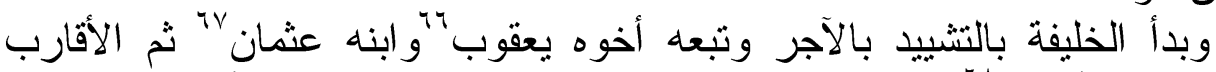

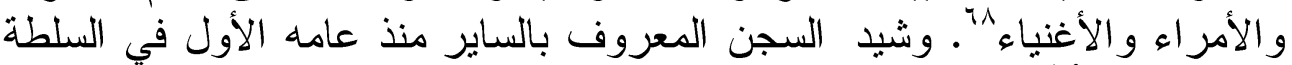

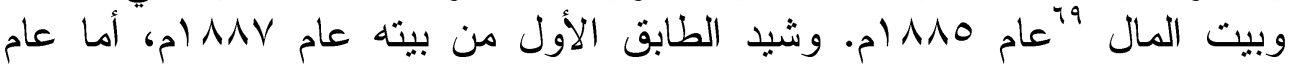
1/11 ام فقد حفل بالعديد من المنشآت فشيد فيه قبة المهدي، وبيت الأمانة، كما بدأ

$$
\text { rآ إبر اهيم فوزي، كتاب السودان، جr، ص } 107 .
$$

${ }^{63}$ F. Rehfisch,Omdurman during the Mahdiya, P.34 . "عثمان محمد عثمان، سياسة التهجير عند الخليفة عبدالله، مقال بمجلة الدراسات السودانية،

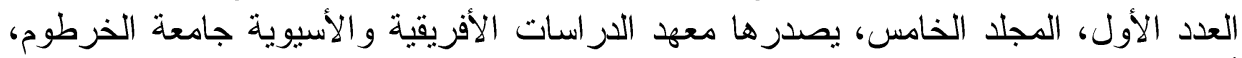
${ }^{65}$ F.Rehfisch, a sketch of the early history of Omdurman, p.41.

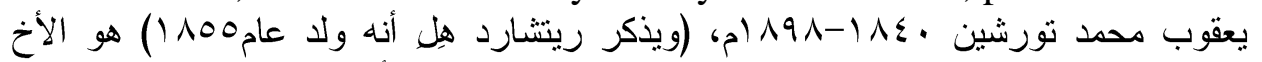

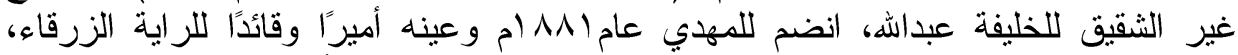

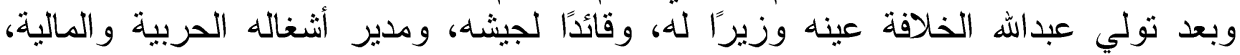

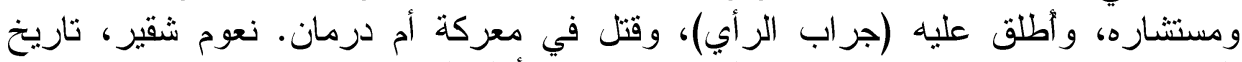

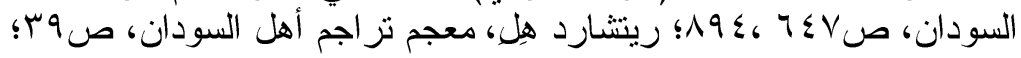
Major F.R Wingate, Ten years captivity in the Mahdi's camp 18821892,pp.313,324. , .

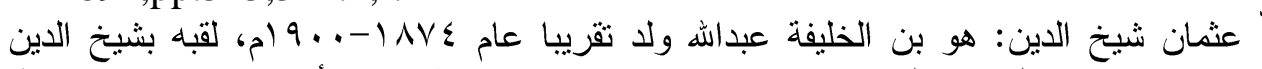

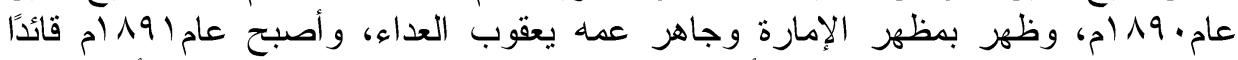

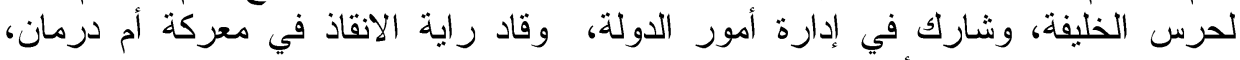

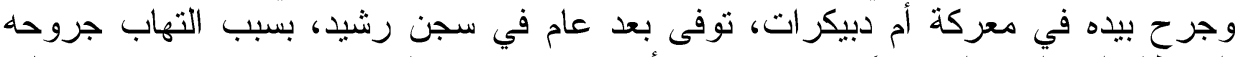

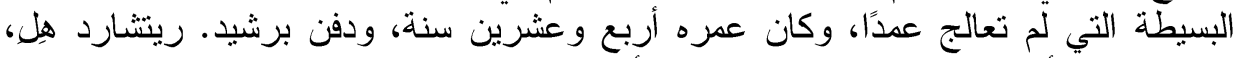

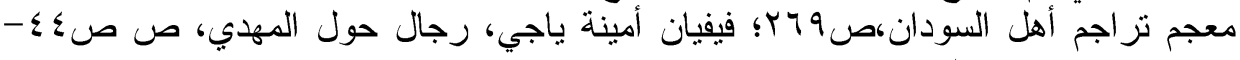

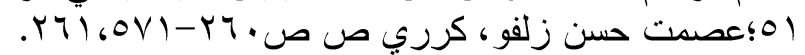

${ }^{68}$ F.Rehfisch, a sketch of the early history of Omdurman,p. 41.

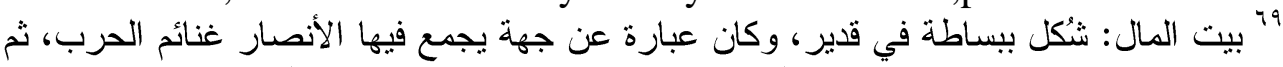

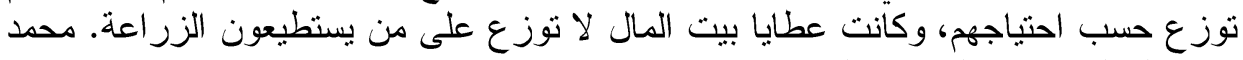

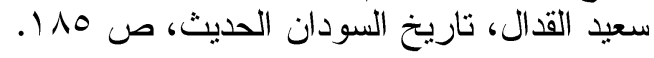




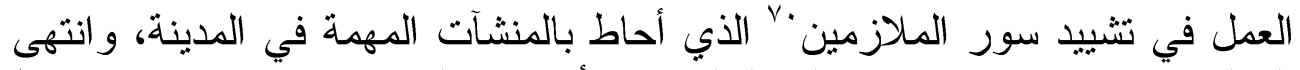

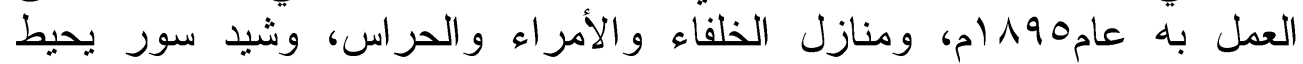

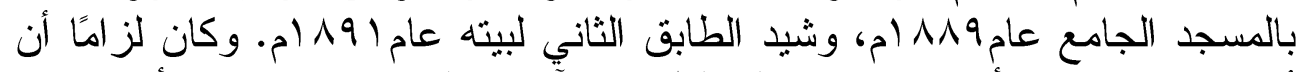

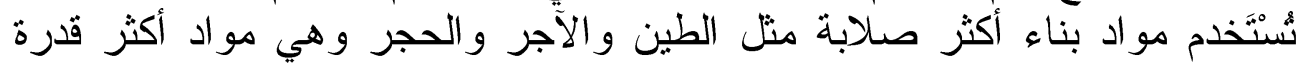

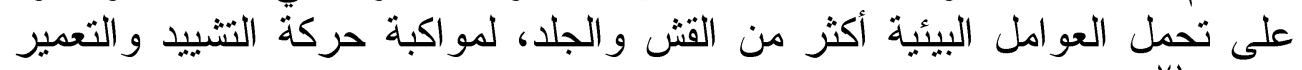

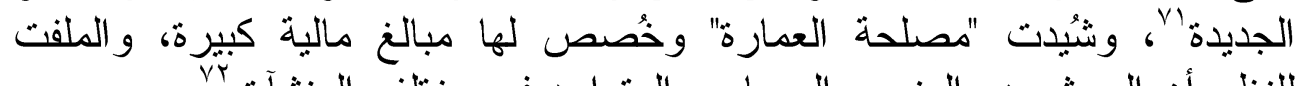

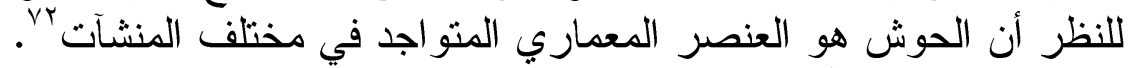

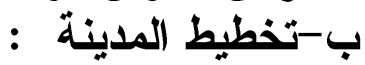

شُيدت المدينة بسر عة وبدون تخطيط بسبب تسار ع الناس للسكن فيها. وشيدوا

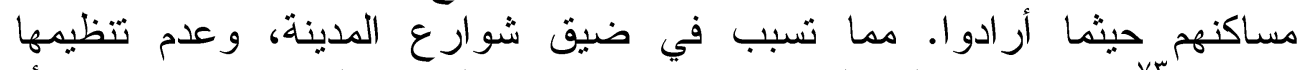

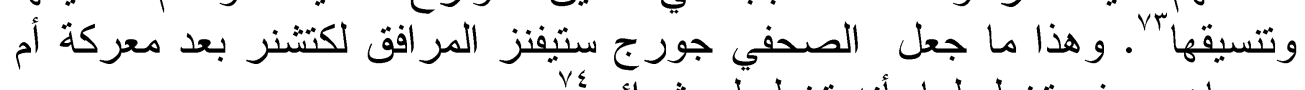

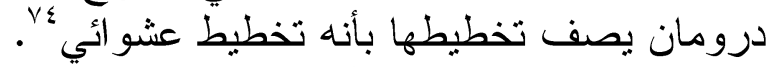

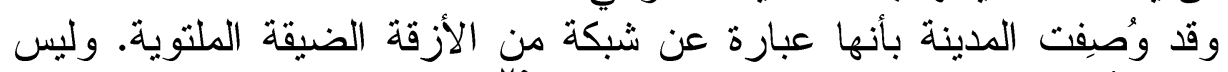

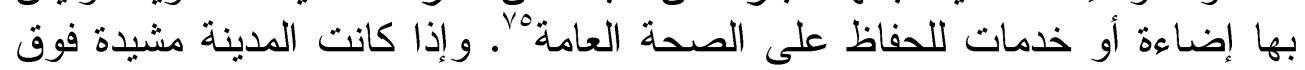
أرض مستوية إلا أنه في بعض الأحيان كانت هناك تلكان الكل صغيرة مما جعل المدينة

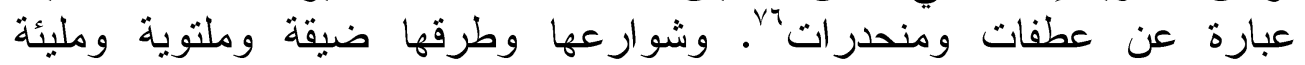

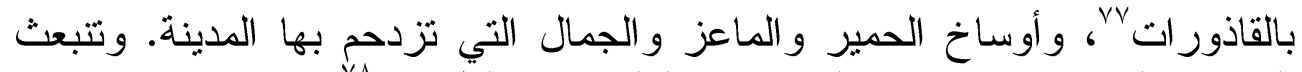

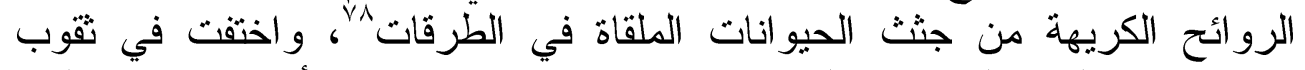

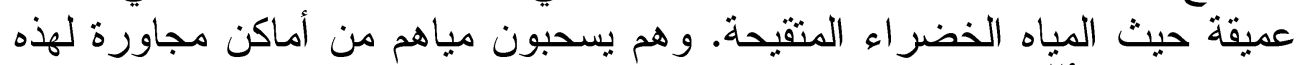

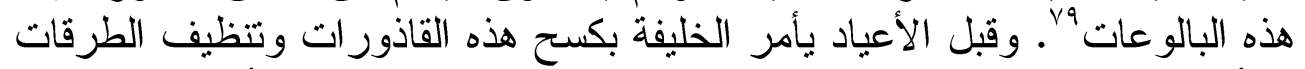

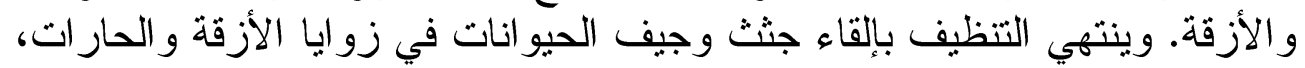

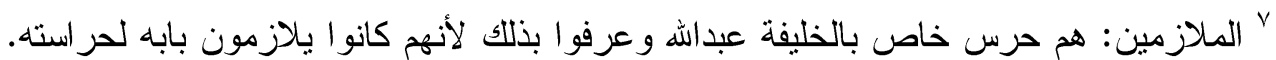

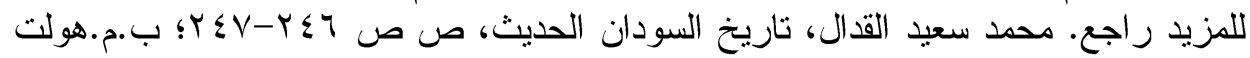

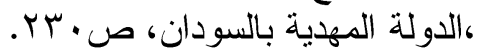

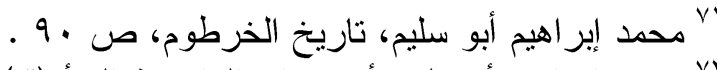

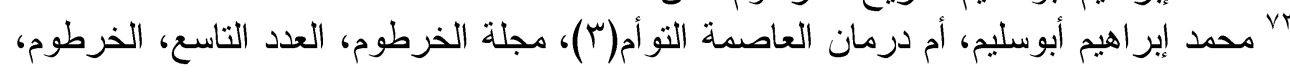

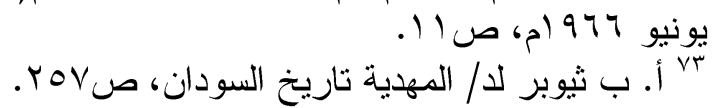

74 G.W.Steevens, with Kitchener to Khartum, twenty-second edition,New York,1898 .pp.300,309.

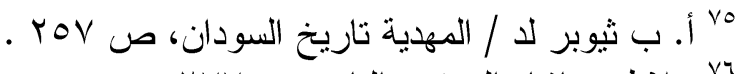

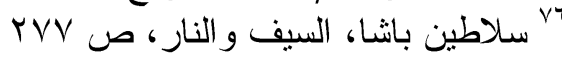

${ }^{77}$ F. Rehfisch,Omdurman during the Mahdiya, P.34.

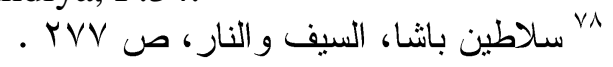

${ }^{79}$ G.W.Steevens, with Kitchener to Khartum. pp.300,309. 


\section{الماملامح العمرانية والمعمارية لمدينة أم درمان الأثرية}

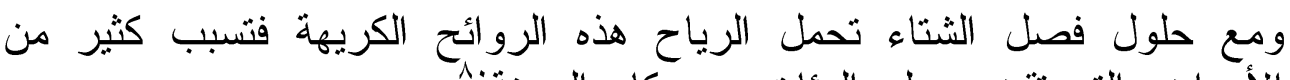

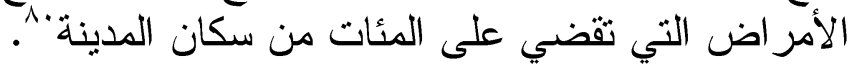

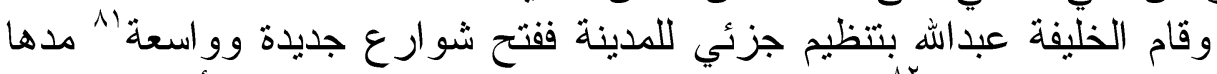

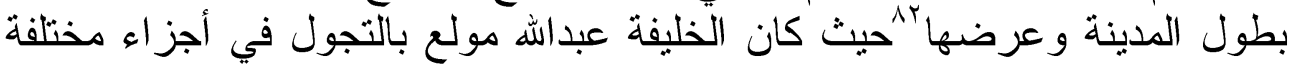

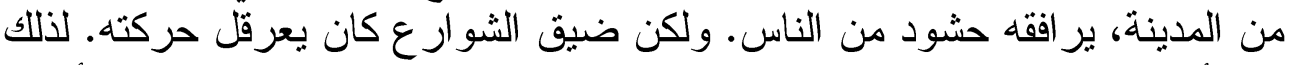

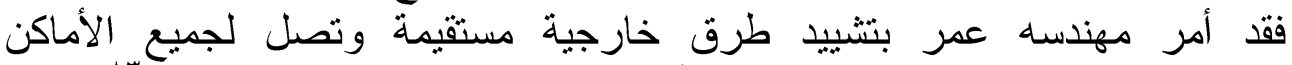

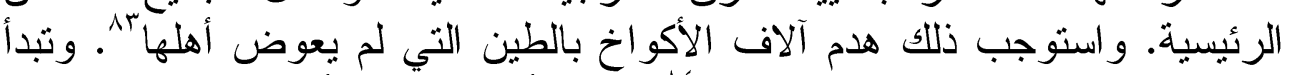

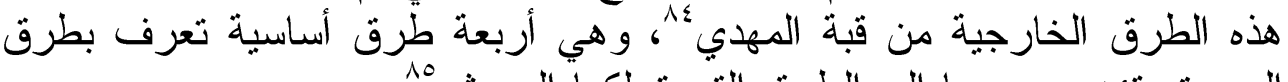

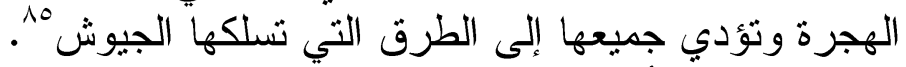

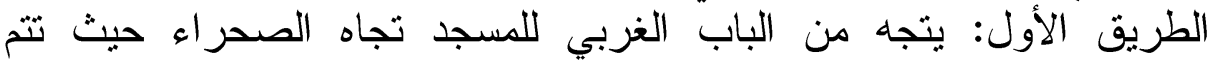

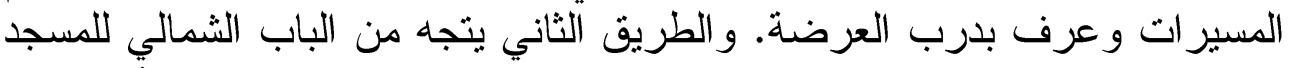

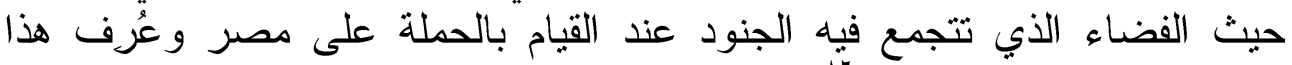

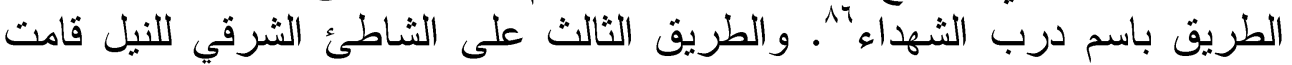

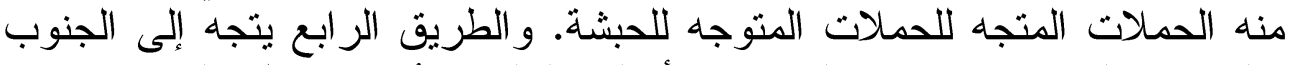

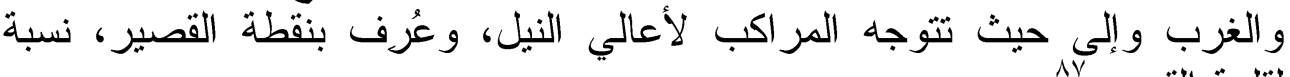

وبالرغم من أن فتح هذه الشوارع كان عملا جيدًا، إلا أنه لم يشمل كل المدينة

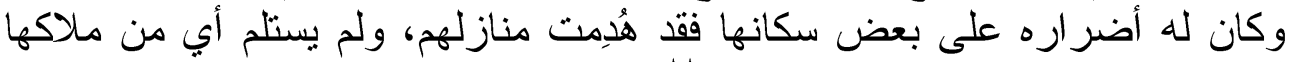

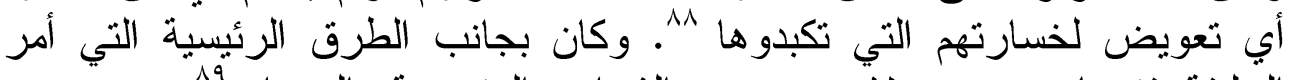

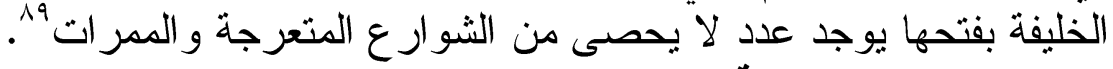

ج- امتداد المدينة:

تمتذ مدينة أم درمان بمحاذاة نهر النيل شمالّا وجنوبًا. لأن الناس كانوا يفضلون القرب من النهر لسهولة الحصول على الماء. وهذا ما يفسر امتداد المدينة من الني

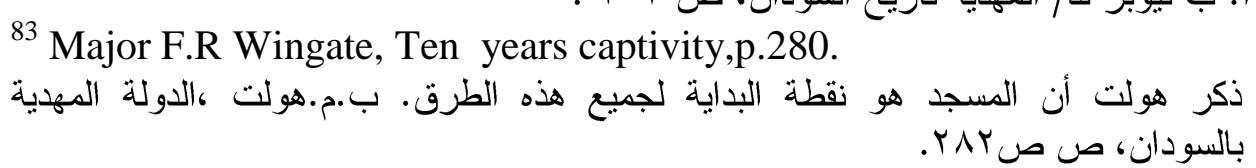

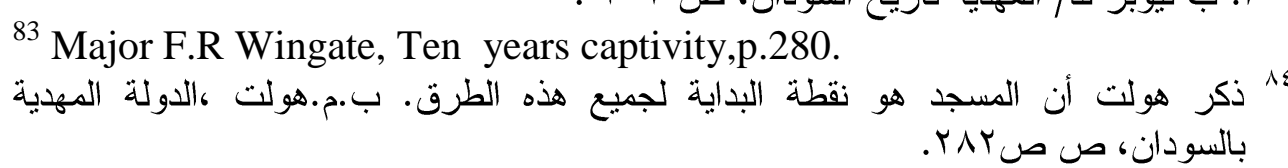

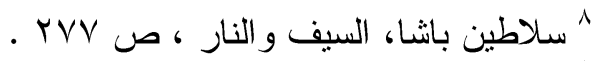

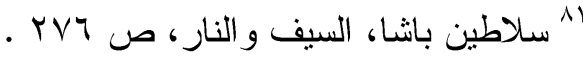

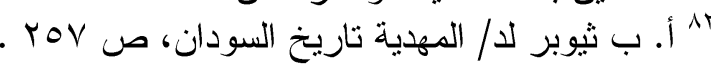

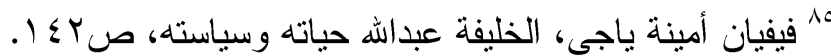

${ }^{86}$ Major F.R Wingate, Ten years captivity,p.280.

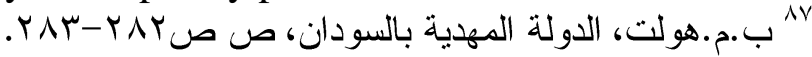

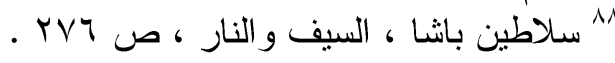

${ }^{89}$ Major F.R Wingate, Ten years captivity,pp.280-281. 


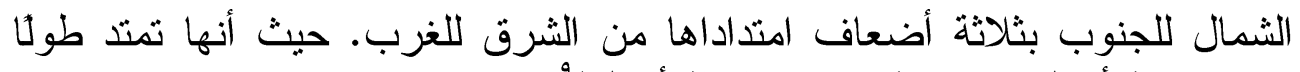

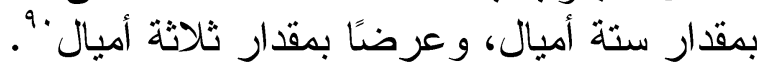
د - أقسام المدينة:

يمكن تقسيم المدينة إلى أربعة أقسام شمالي وجنوبي، وشمالي غربي و أوسط :

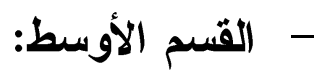

يعد القسم الأوسط (شكل رقمء) أهمها لأنه قلب المدينة ومركز الخلافة ومن الهن

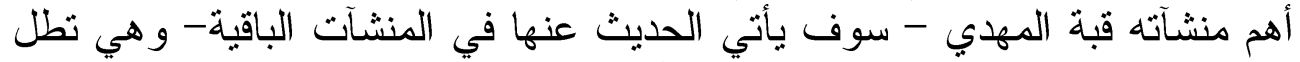

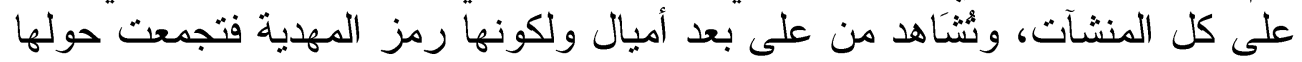

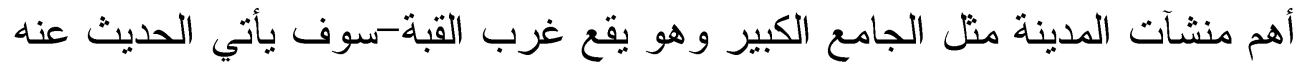

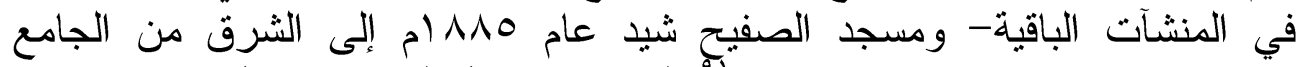

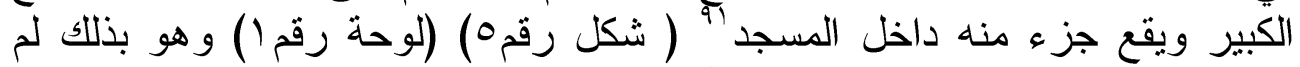

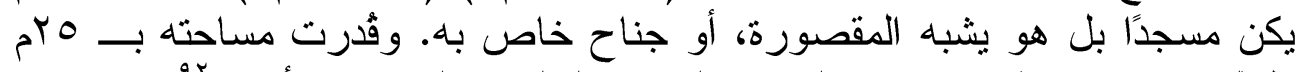

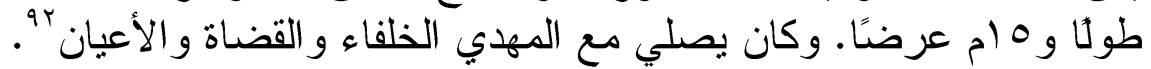

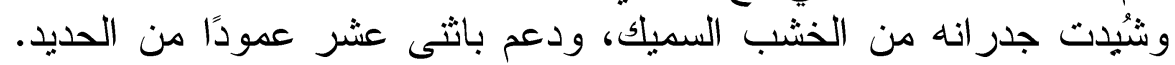

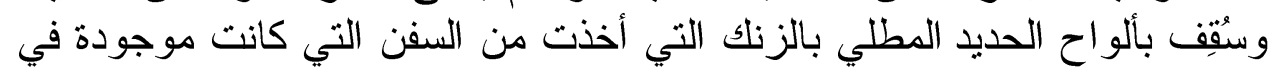

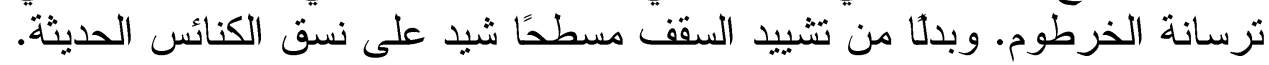

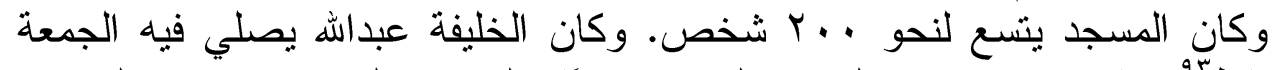

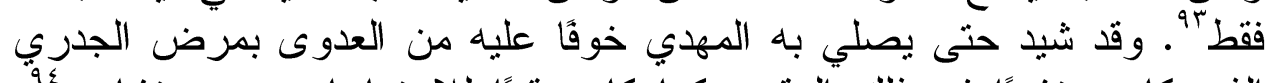

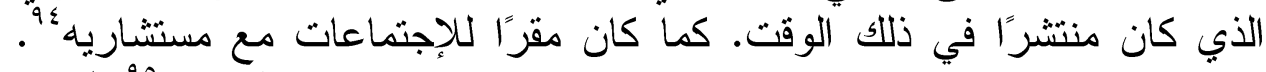

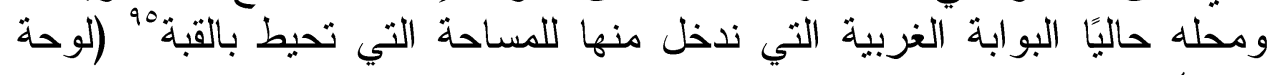

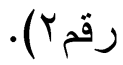

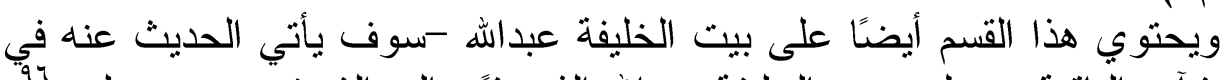

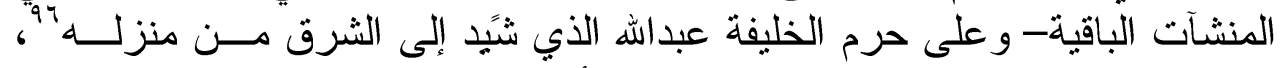

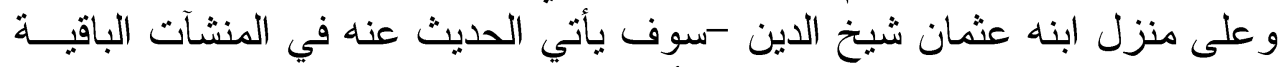

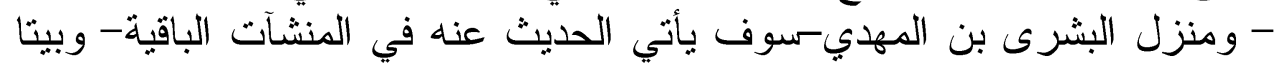
الأمير يعقوب؛ حيث شيد بيتًا في القطاع الأوسط كان يقع جنوب مساكن القضاة،

${ }^{90}$ F.Rehfisch,a sketch of the early history of Omdurman,p.42.

${ }^{91}$ F.R.Wingate,Mahdiism and the Egyptian Sudan,p.484.

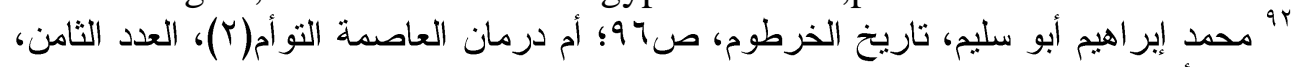

${ }^{93}$ F.R.Wingate,Mahdiism and the Egyptian Sudan,p.484.

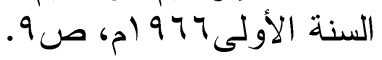

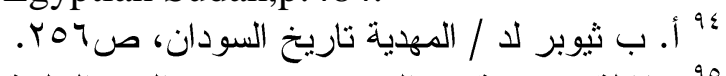

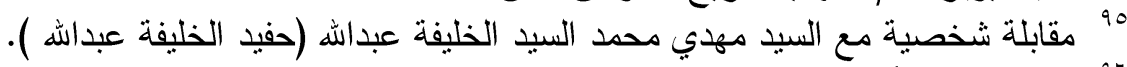

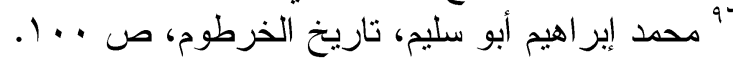




\section{الماملامح العمرانية والمعمارية لمدينة أم درمان الأثرية}

وكتبة الخليفة التي توجد جنوب المسجد، وهذا البيت هو بيته القـــيم. وتحـلـل دار

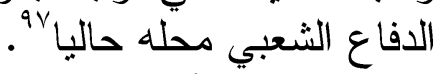

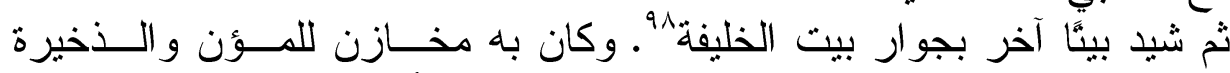

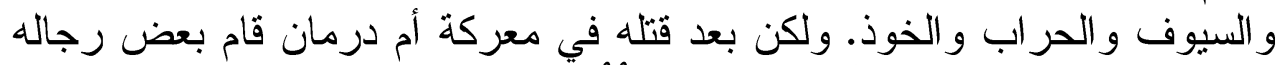

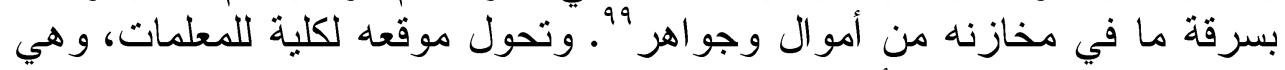

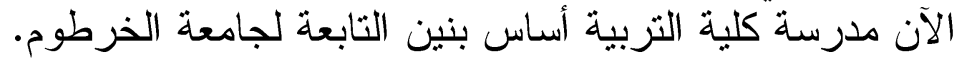

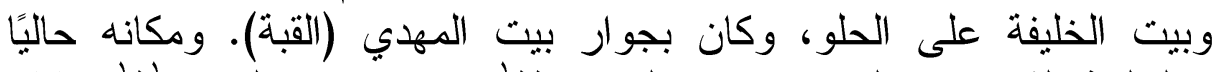

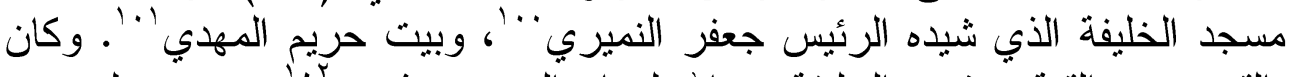

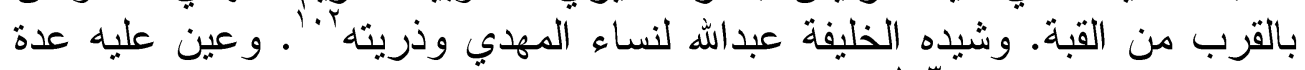

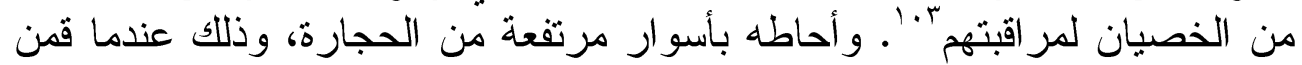

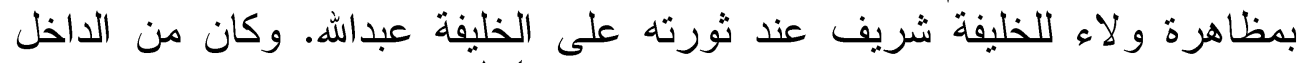

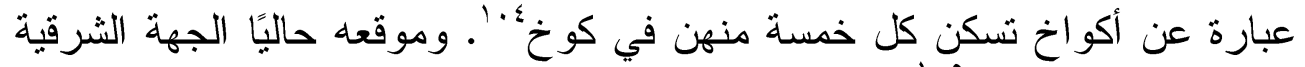

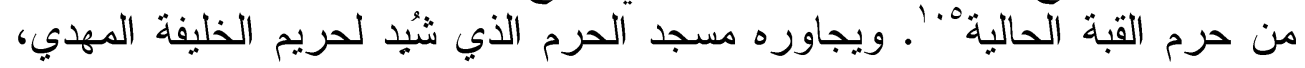

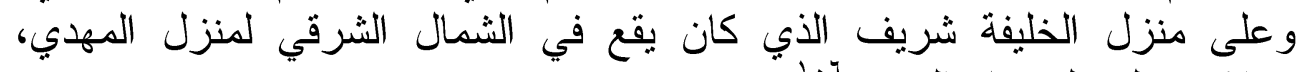

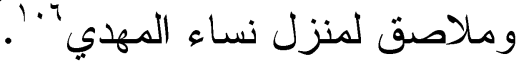

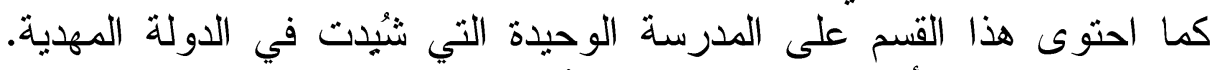

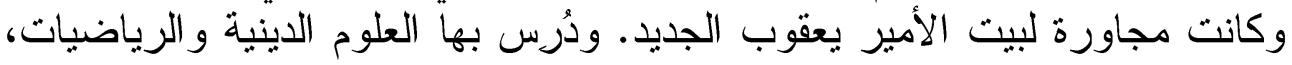

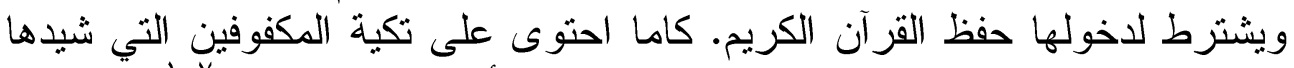

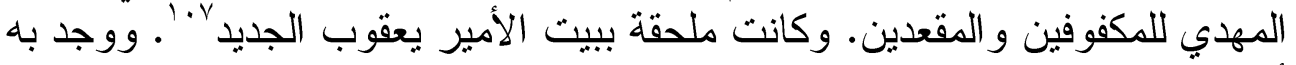

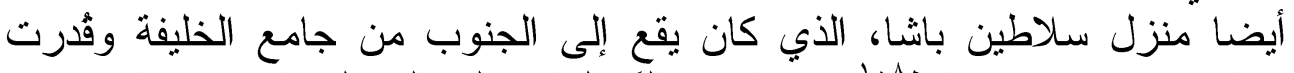

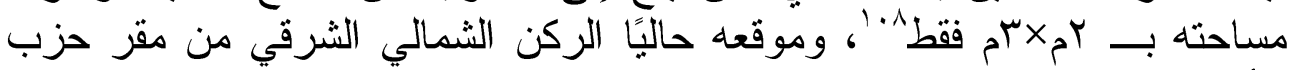
الأمة.

"9قابلة شخصية مع السيد/مهدي السيد أحمد خليفة عبداله، وبرفيسور فيصل محمد موسى أستاذ التاريخ، كلية الآداب، جامعة النيلين.

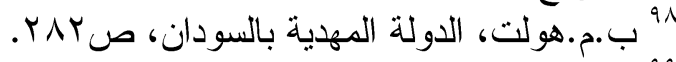

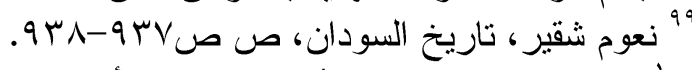

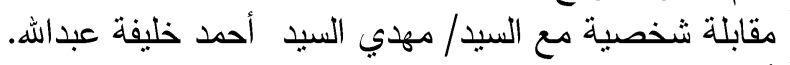

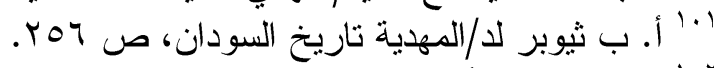

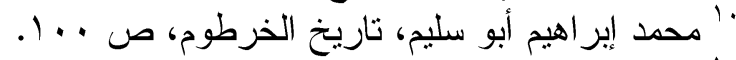

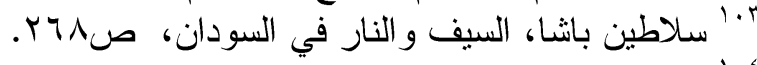

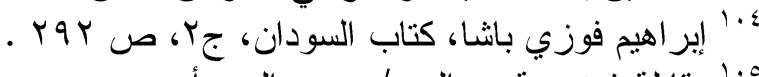

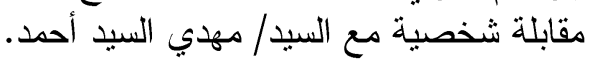

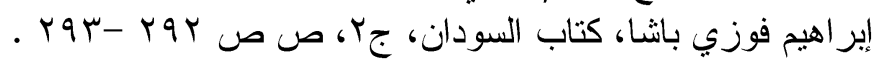

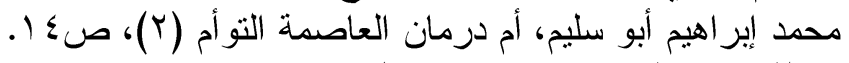

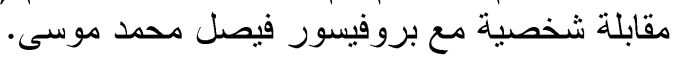




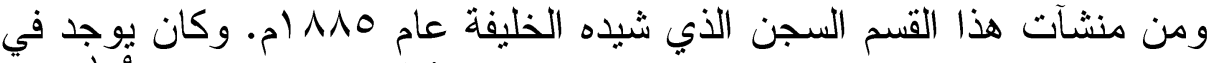

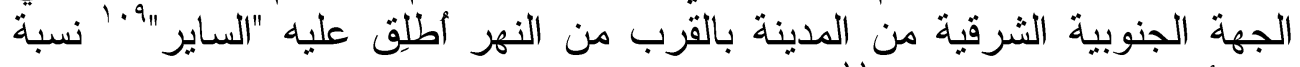

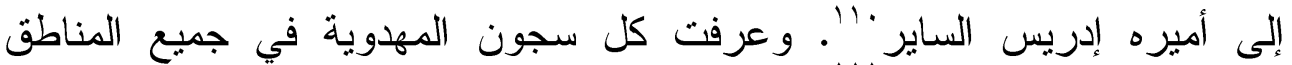

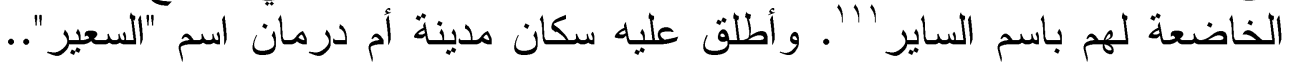

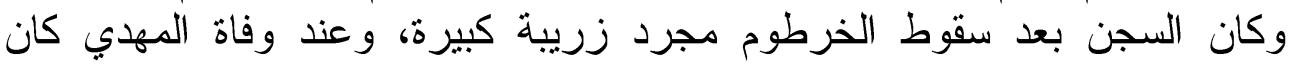

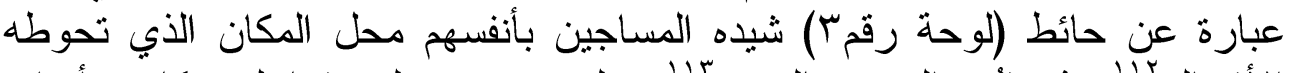

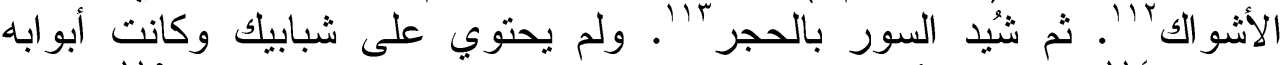

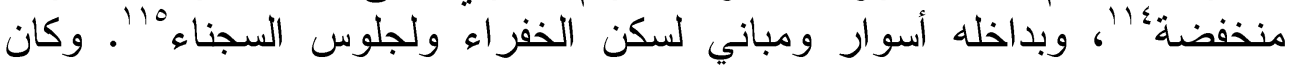

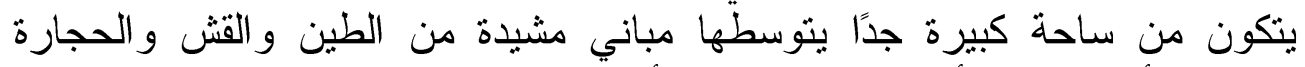

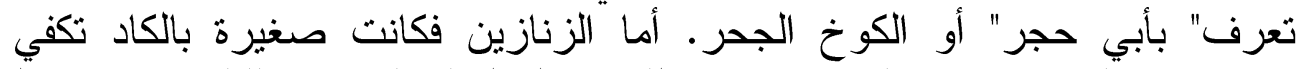

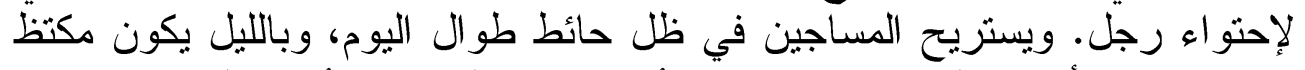

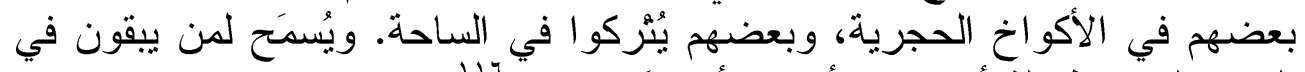

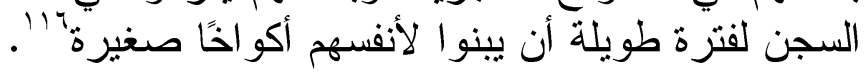

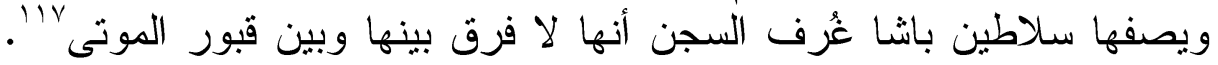

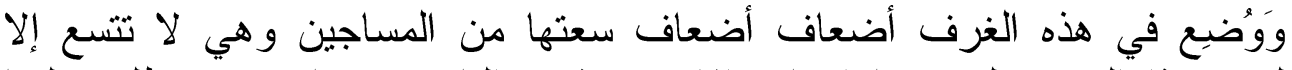
لربع هذا العدد. وليس بها إضاءة إلا من شقوق الباب. ومنها غرف فئن يطلق عليها

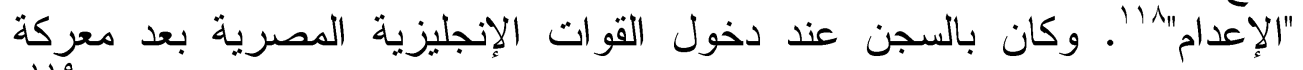

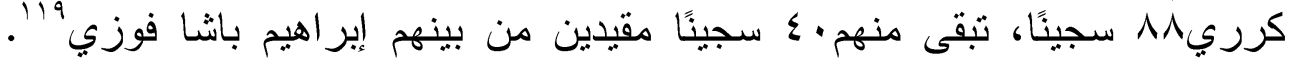

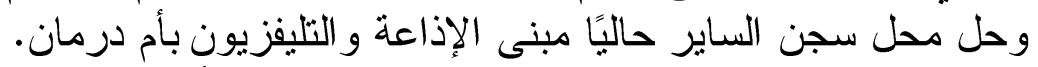

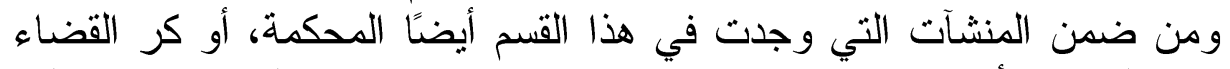

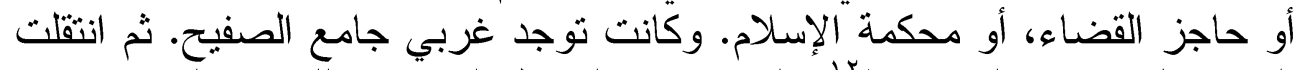

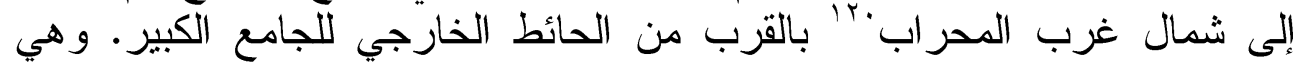

هو أدريس الساير من قبيلة" الجمع" شرقي كردفان، ولحق بالمهدي في جبل قدير فقلده وظيفة

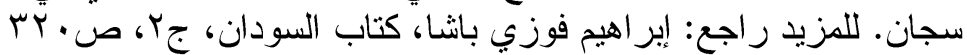
Major F.R Wingate, Ten years captivity,p.344,

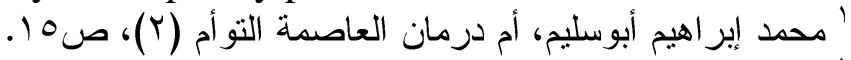

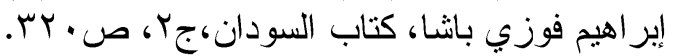

${ }^{112}$ Major F.R Wingate, Ten years captivity, pp.344-345.

${ }^{114}$ F. Rehfisch,Omdurman during the Mahdiya, P.41.

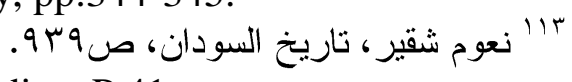

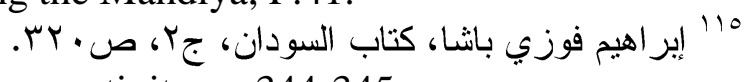

${ }^{116}$ Major F.R Wingate, Ten years captivity,pp 344-345.

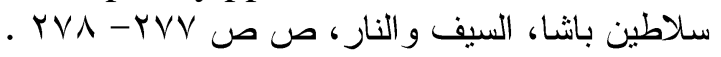

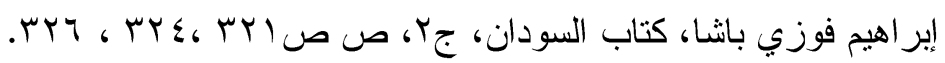

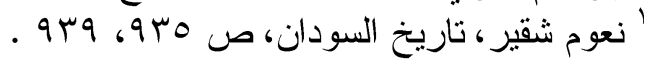

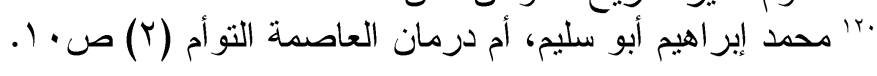




\section{الماملامح العمرانية والمعمارية لمدينة أم درمان الأثرية}

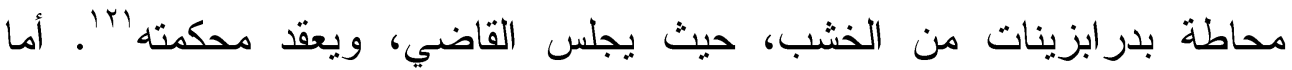
الإسطبل فكان بجوار بيت الخليفة وسُقف بالقش. كما حفرت الآبار الصالحة للشرب إنقاب

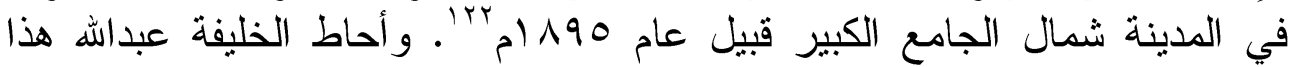

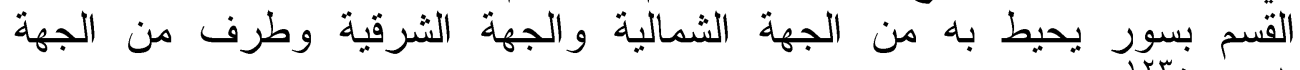

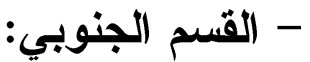

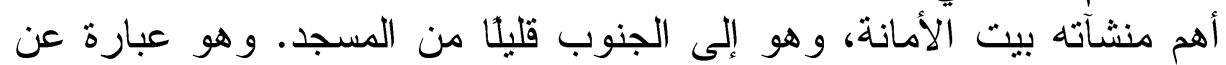

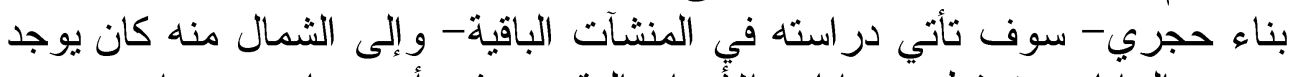

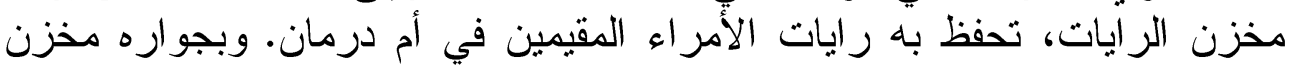

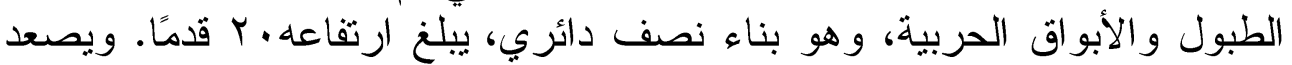

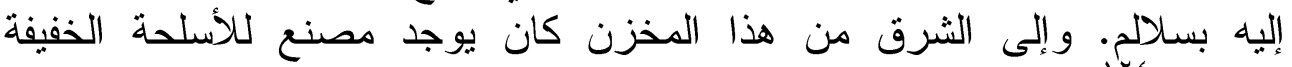

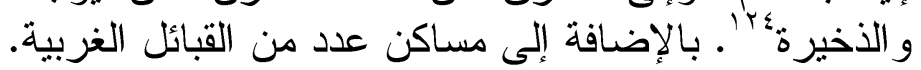

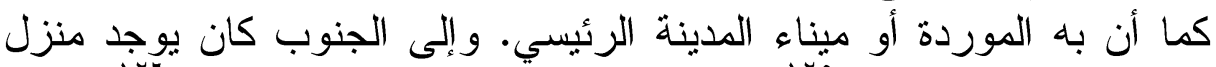

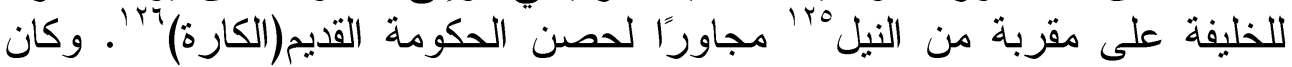

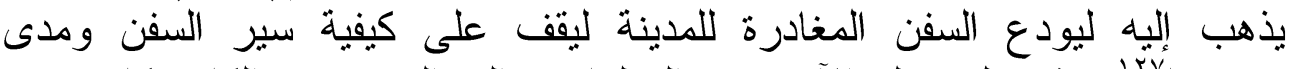

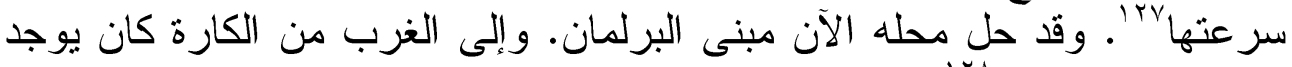

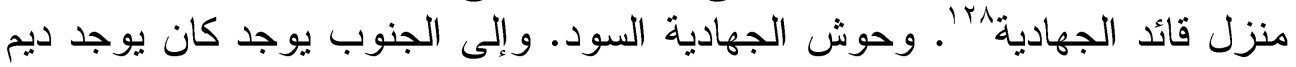
يونس. وفي هذا الحي يوجد منزل آخر للخليفة عبدالله. وفي جنوب الديم فضاء واسع الفاء

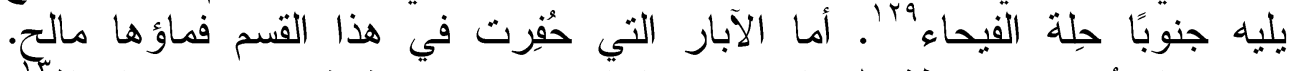

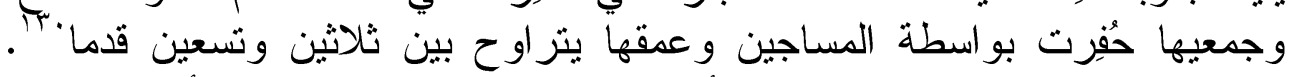

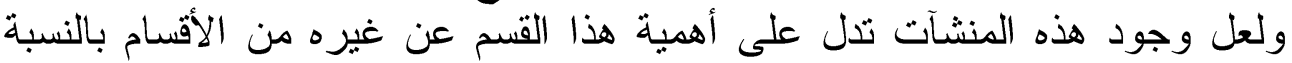

${ }^{121}$ Major F.R Wingate, Ten years captivity,p.280.

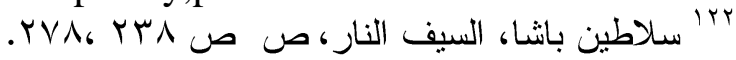

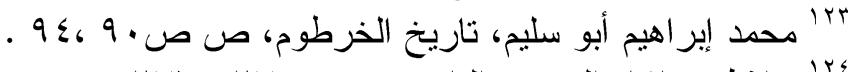

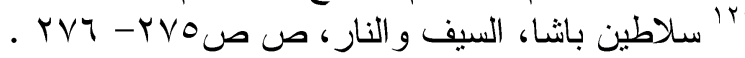

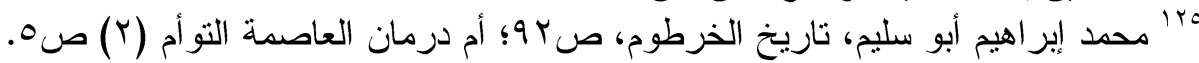
126 Major F.R Wingate, Ten years captivity,p.281.

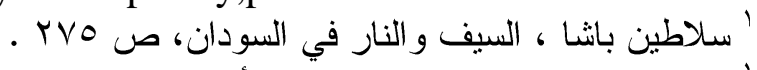

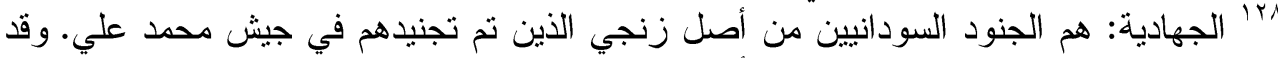

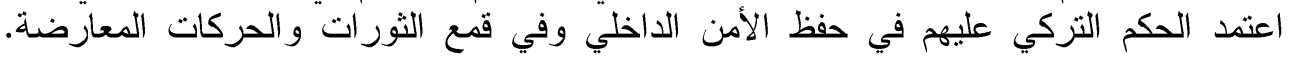

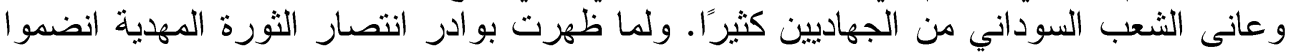

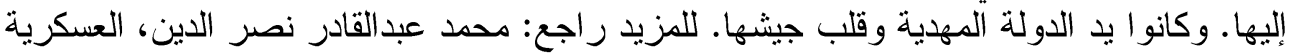

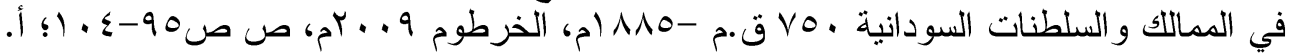

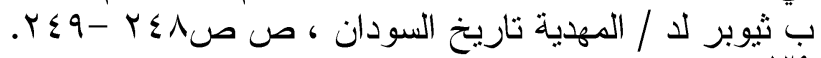

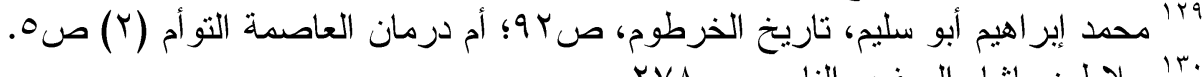

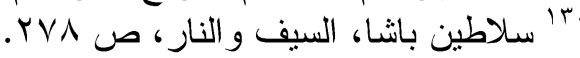




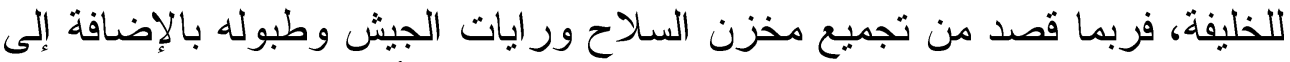

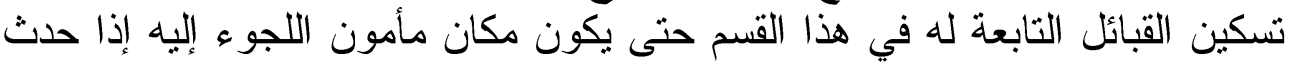

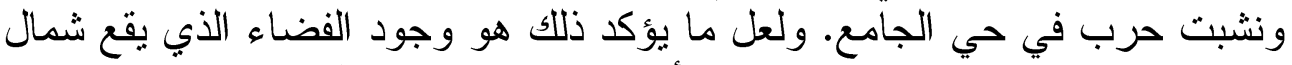

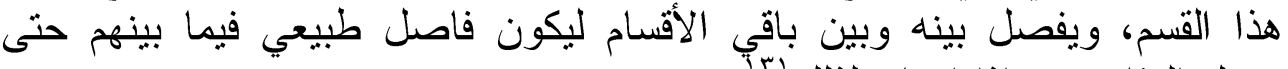

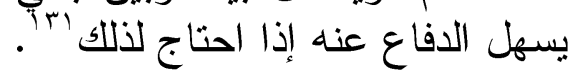

\section{- القسم الثمالي الغربي:}

أهم منشآته السوق الكبير السوق الكبير: الكبير أسبس سوق أم درمان قبل المهدية ولم

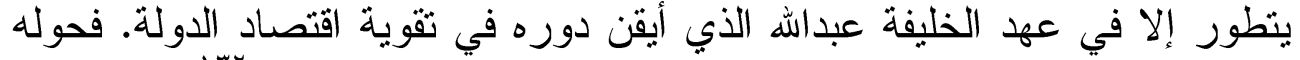

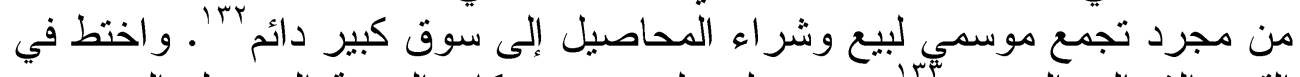

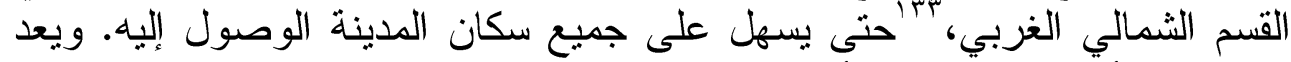

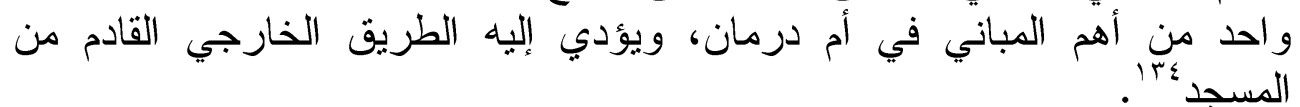

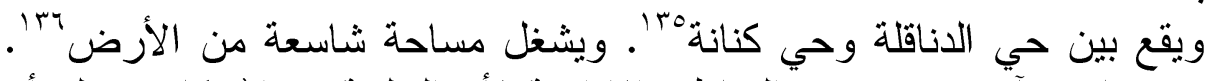

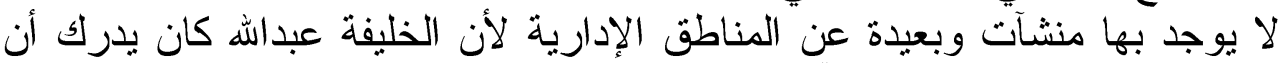

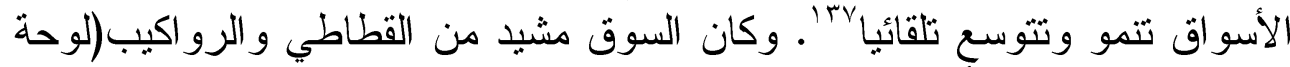
رقمع) ويفصل بينها أزقة ضيقة ضيقة وملتوية.

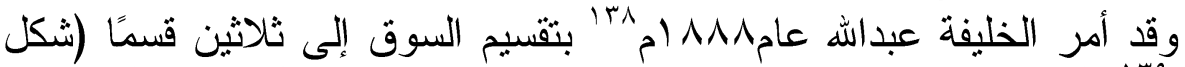

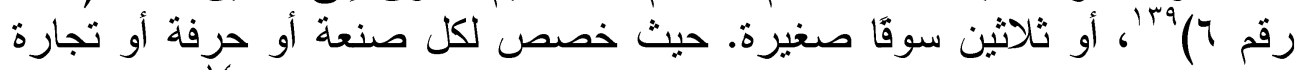

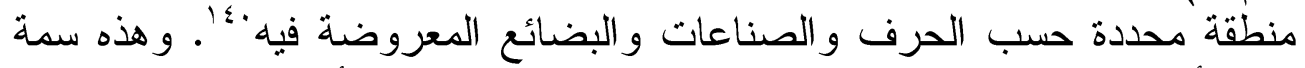

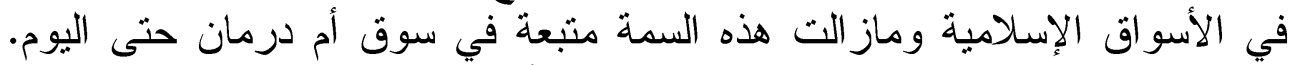

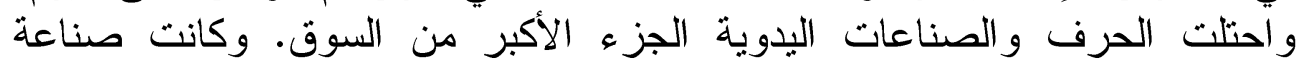

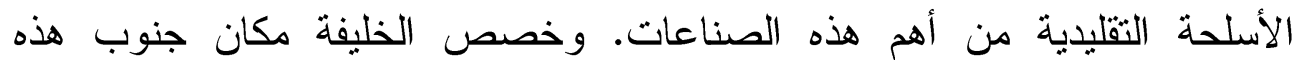
الأسواق لصناع وبائعي الحراب، حيث كانت أهم أنواع الصناعات في مدينة أم

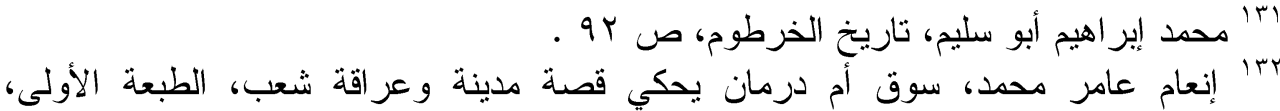
${ }^{133}$ F.R.Wingate,Mahdiism and the Egyptian Sudan,p.483.

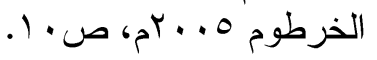

${ }^{134}$ Major F.R Wingate, Ten years captivity,p.282.

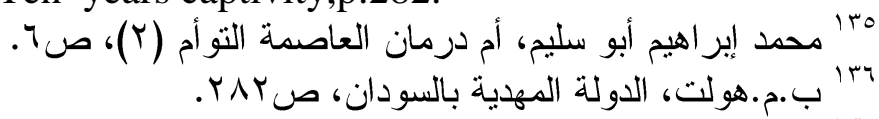

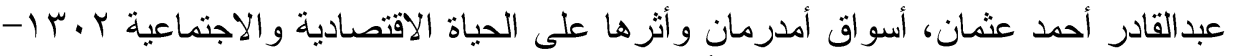

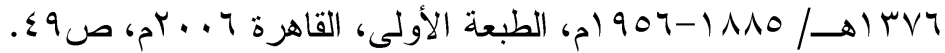

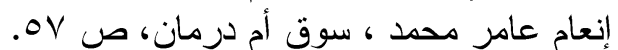

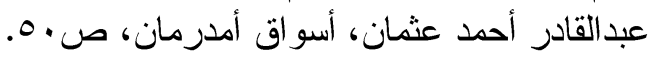

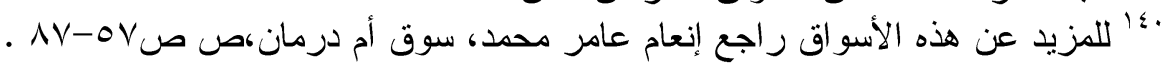




\section{الماملامح العمرانية والمعمارية لمدينة أم درمان الأثرية}

درمان كلها. وكانت صناعة الذخيرة و المتفجرات و السكة نُصنْعَ بإشر اف مباشر من

وكانت المنطقة التي تضم الجزارين هي أكبر مناطق أو أجزاء السوق.

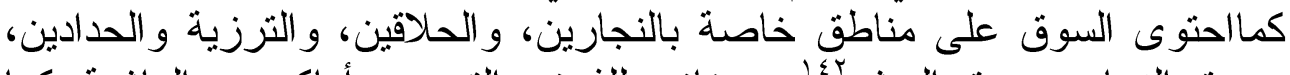

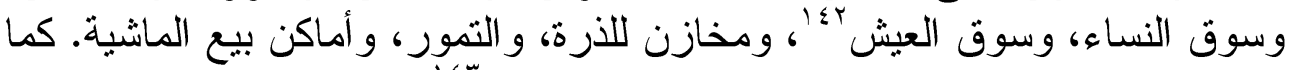

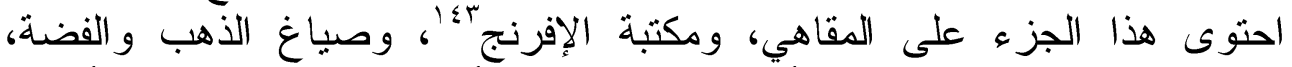

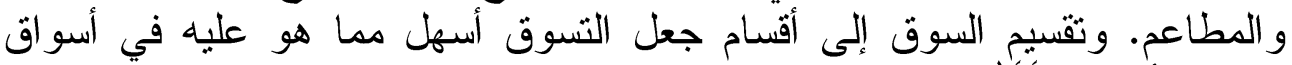

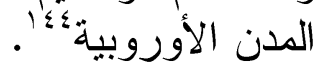

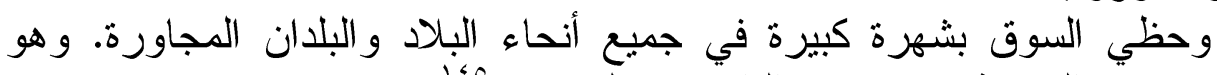

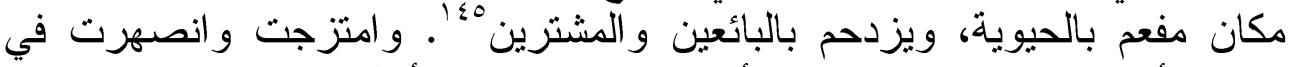

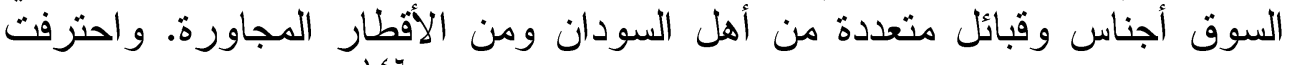

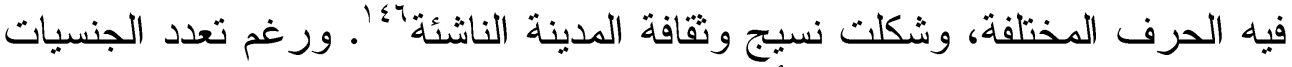
و الملل الني كانت بالسوق إلا أنه يعد نموذجًا للنسامح و التعايش الثقافي وحسن التعامل.

اهتم الخليفة عبدالله بحفظ النظام داخل السوق عن طريق المحتسبين كما كان

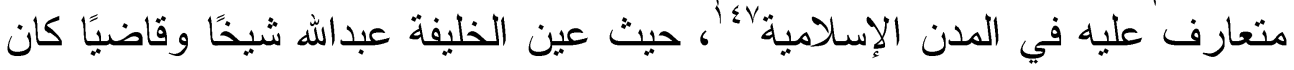

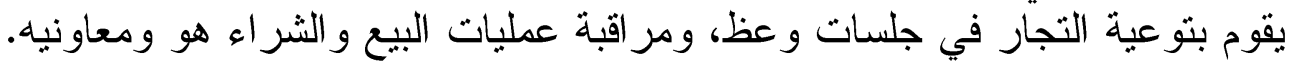

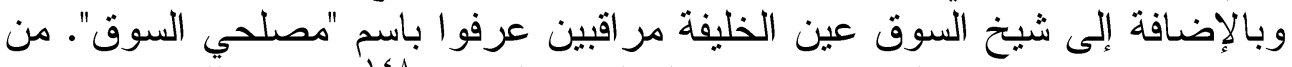

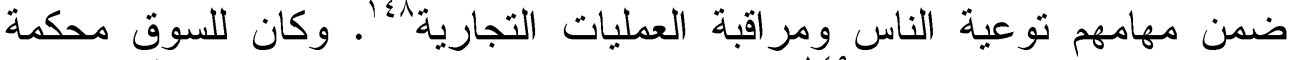

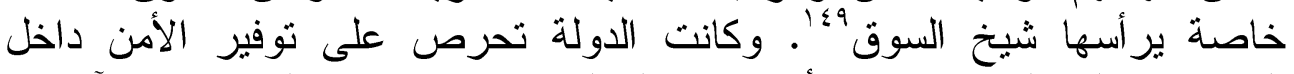

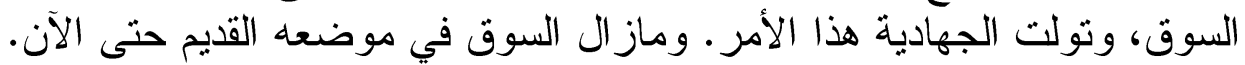

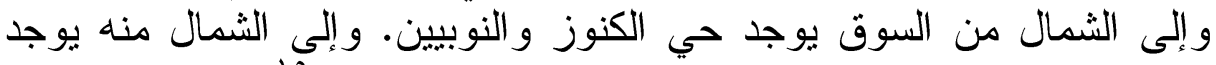

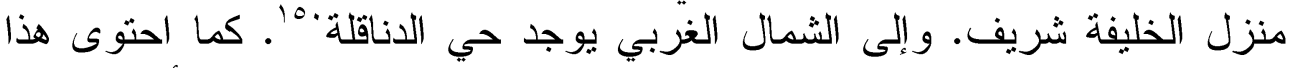

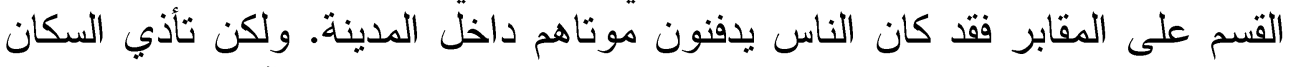

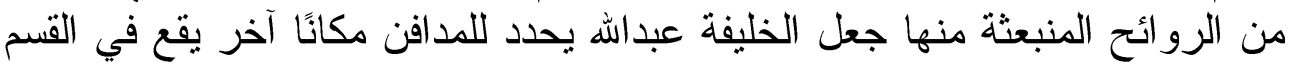

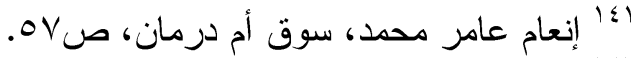

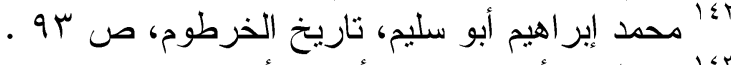

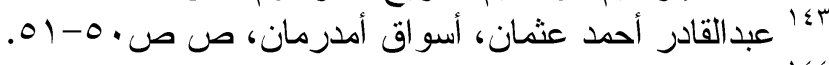

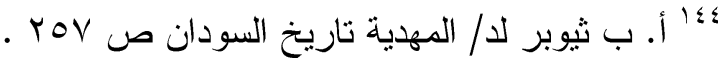

145 Major F.R Wingate, Ten years captivity,p.282.

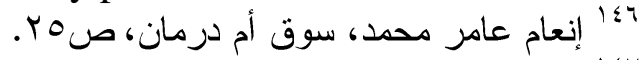

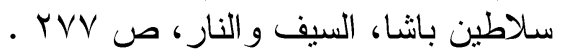

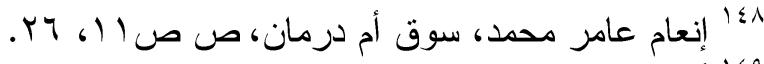

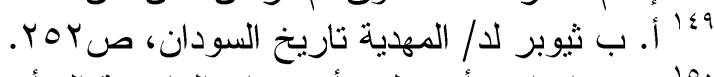

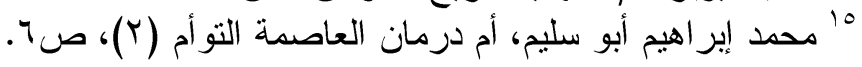




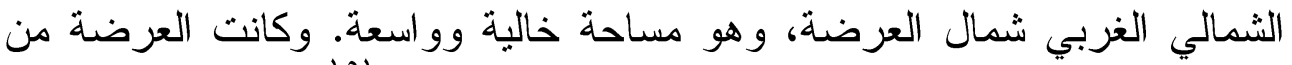

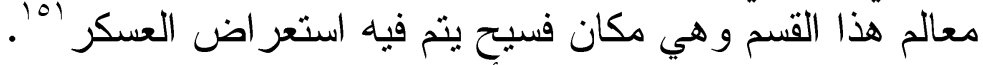

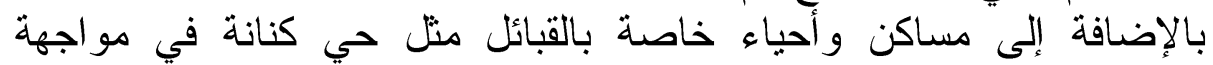

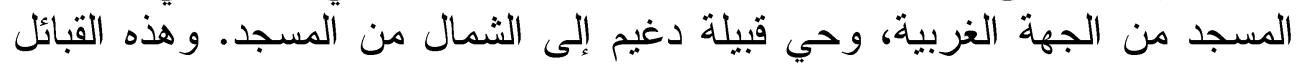

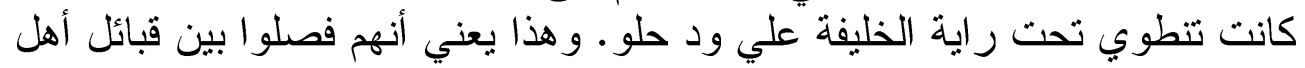

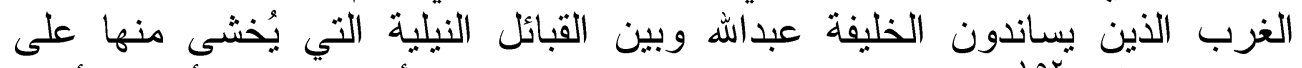

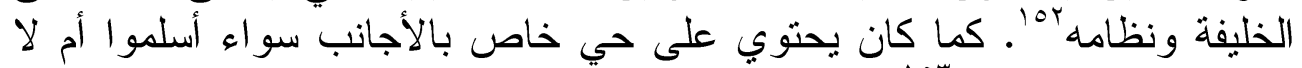

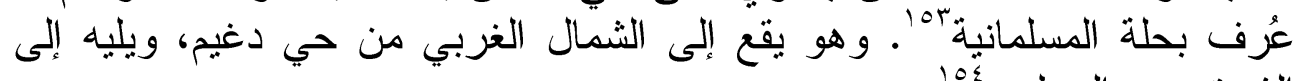

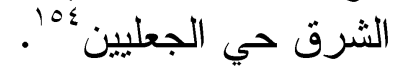

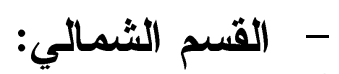

أهم منشآته بيت الهجرة وهو مسجد وبيت للخليفة عبداله. وكان الخليفة ينزل بهــا

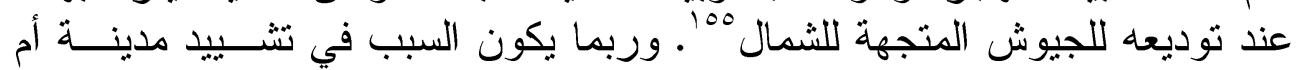

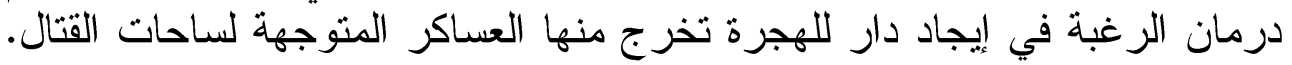

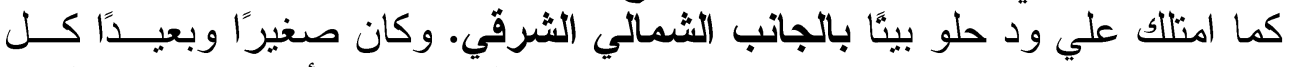

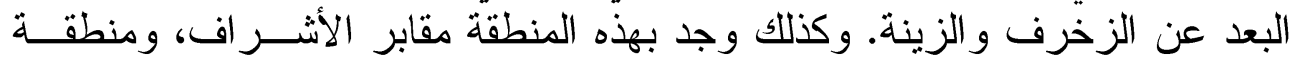

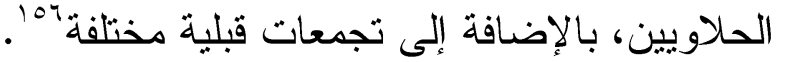

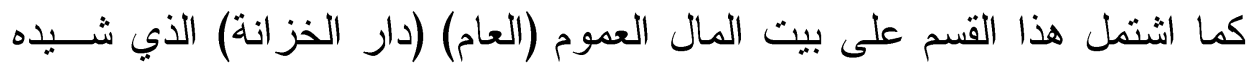

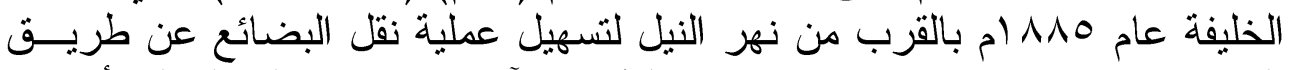

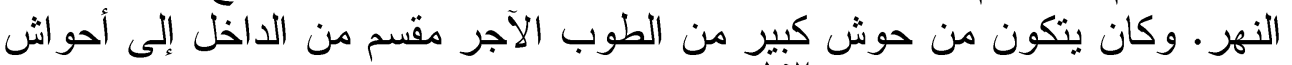

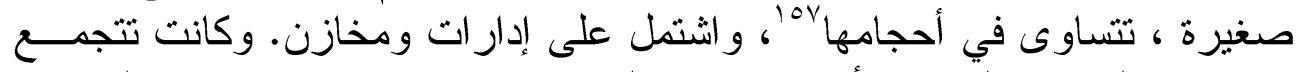

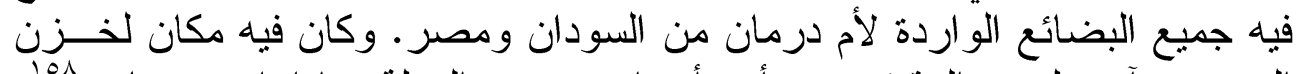

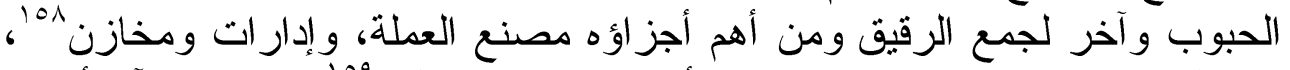

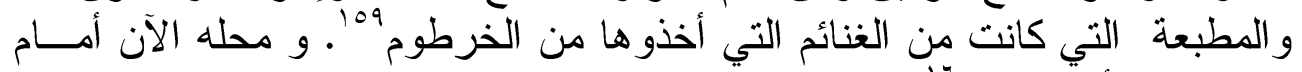

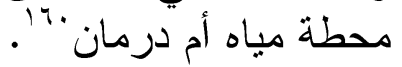
واحتوى هذا القسم على سوق الرقيق (سوق النبيذ): كان يقع إلى الجنوب

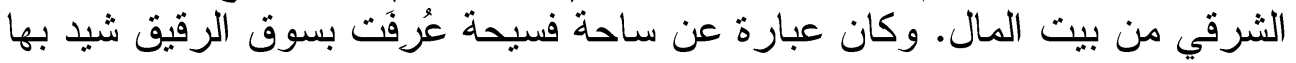

155 Major F.R Wingate, Ten years captivity,p.281.

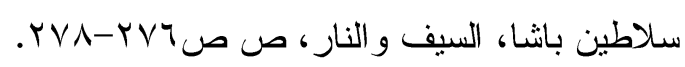

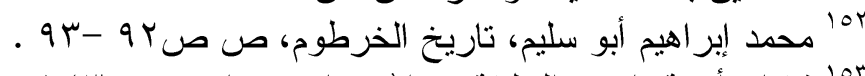

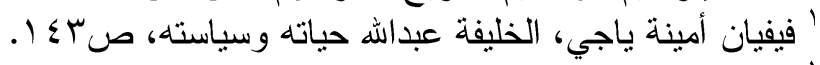

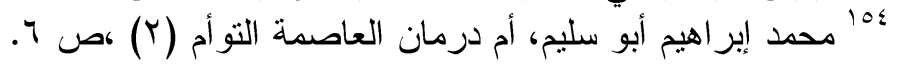

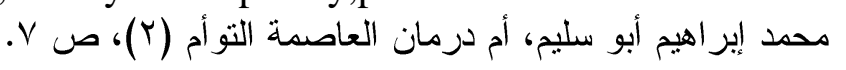

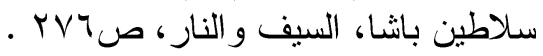

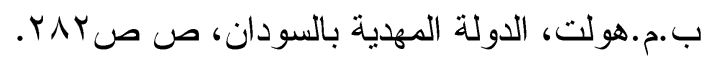

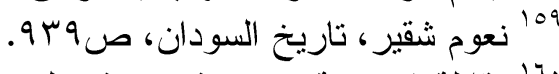

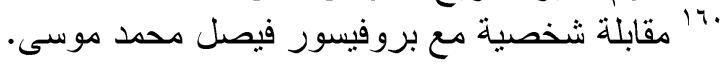




\section{الماملامح العمرانية والمعمارية لمدينة أم درمان الأثرية}

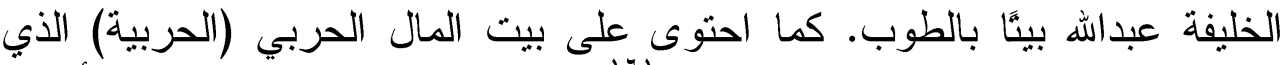

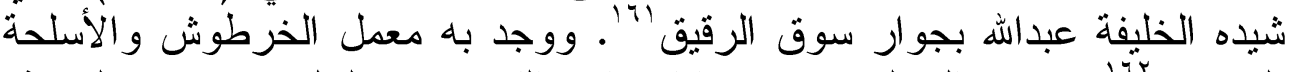

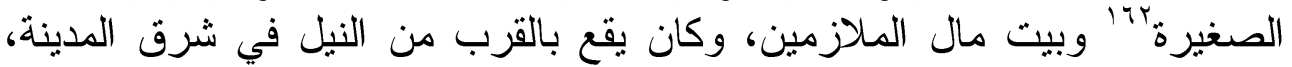

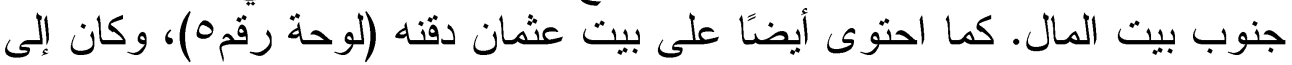

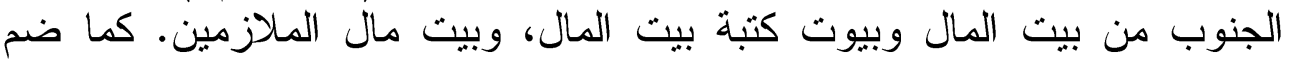

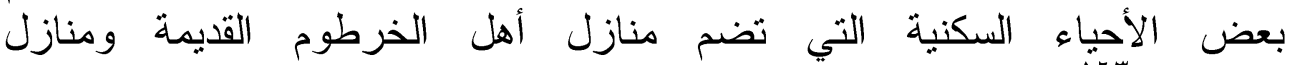

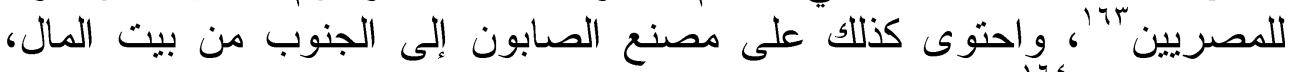

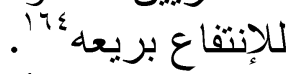
وقد علا شأن مدينة أم درمان في عهد الخليفة عبداله. وتناقص شأن مدينة الخرطوم التي تحولت إلى خرائب وأنقاض، ولم ألم ييق فيها من المنشآت الظاهرة

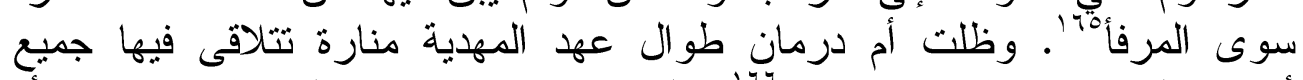

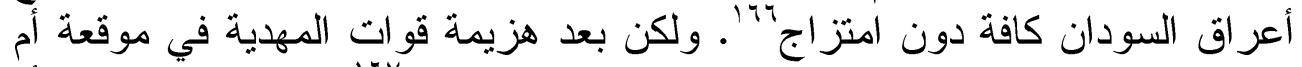

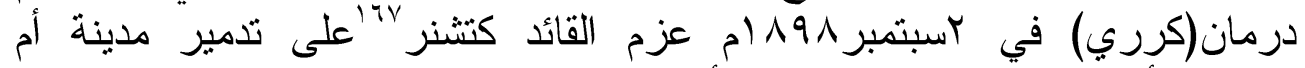

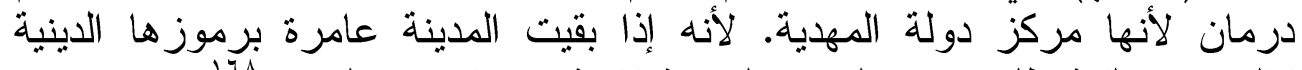

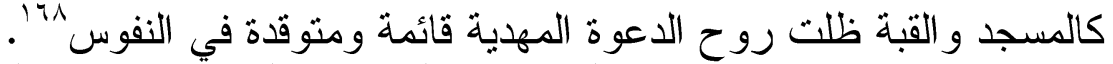

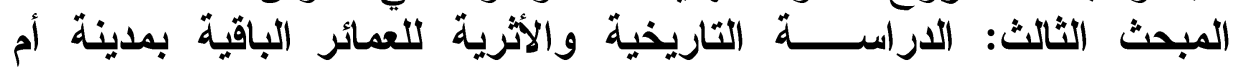

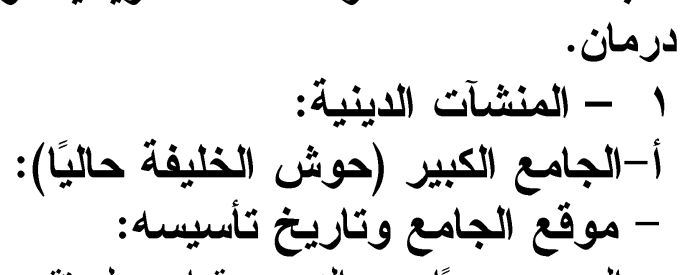

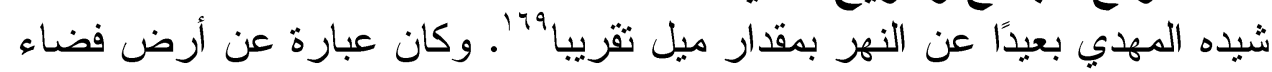

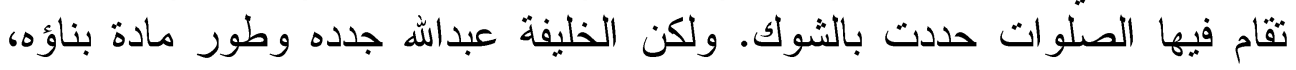

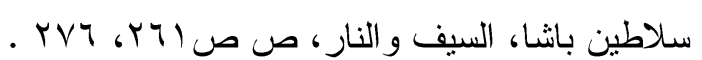

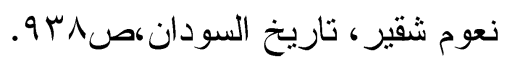

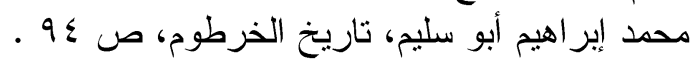

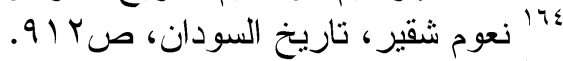

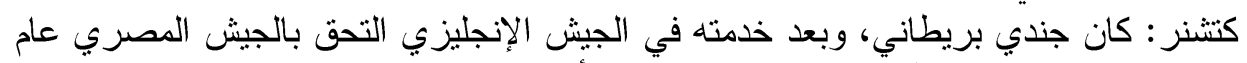

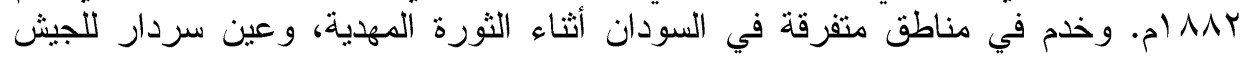

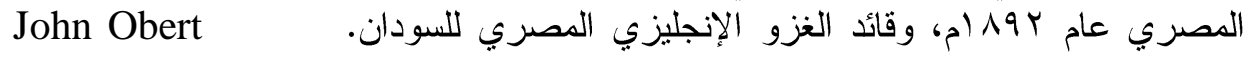

Voll,historical dictionary,pp, 60-61 .

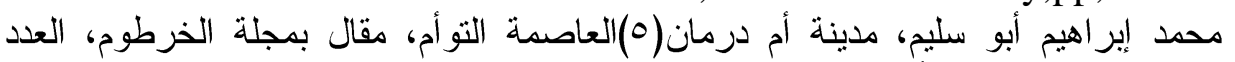

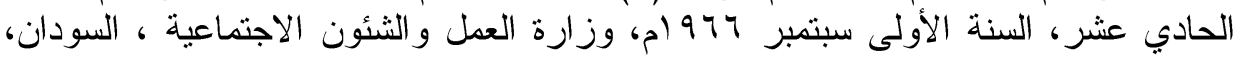
ص V. 179 إبر اهيم فوزي باشا، كتاب السودان، جr، ص ra r. 


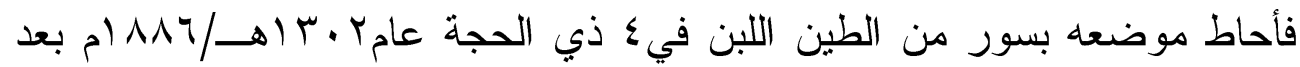

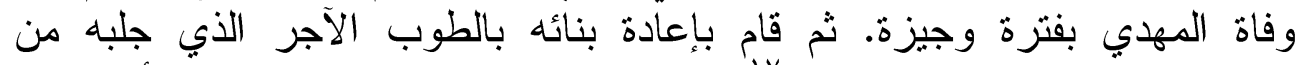

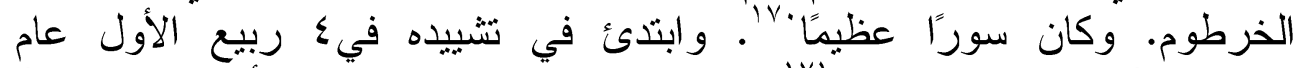

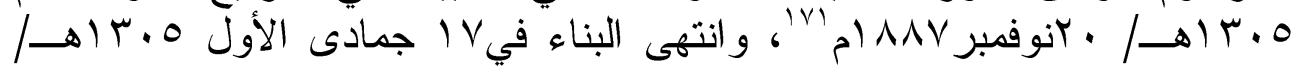

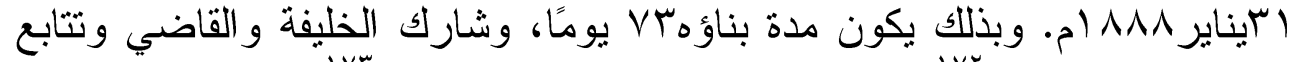

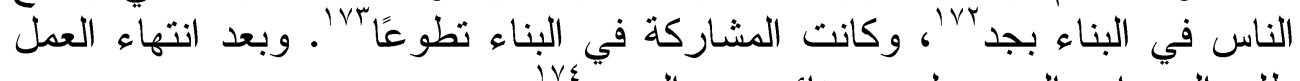

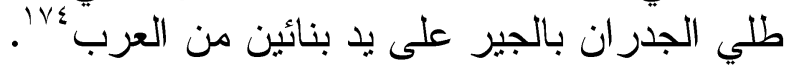

وردت عدة آراء في مساحة الجامع ومنها ما ذكره ونجت في تقرير أعده عام

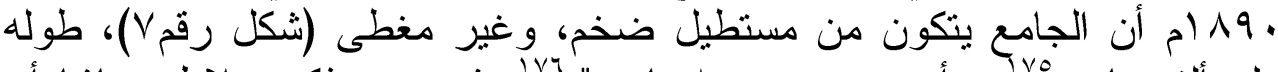

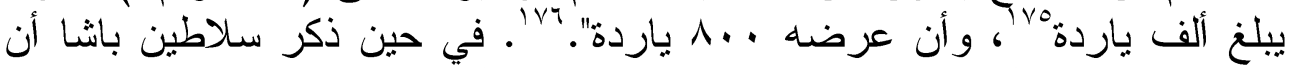

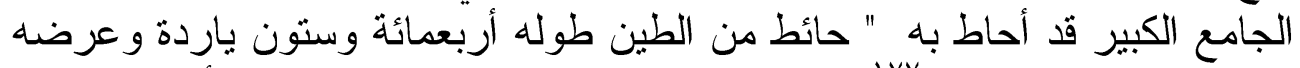

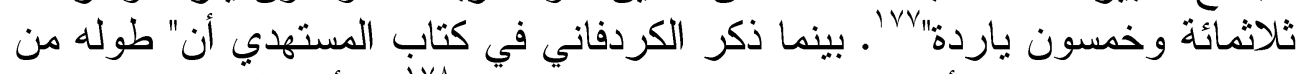

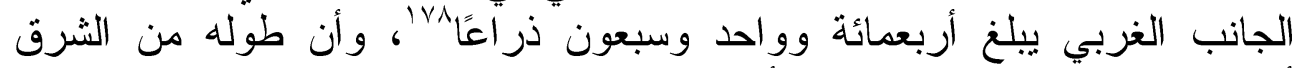

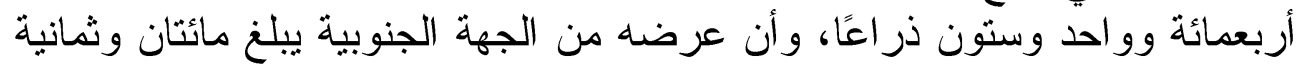

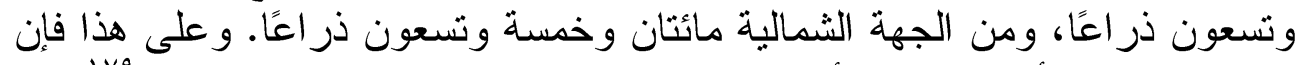

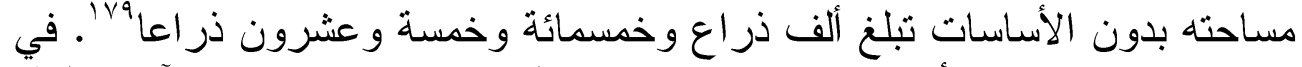

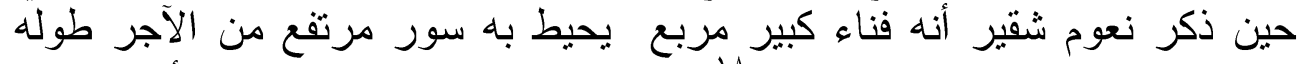

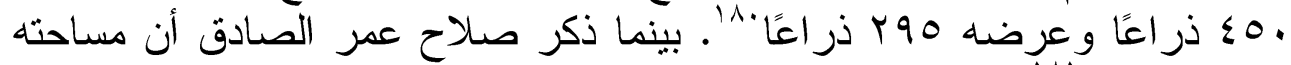

$$
.^{|\lambda|} \text { a) } \leqslant \Lambda x^{2} r q T
$$

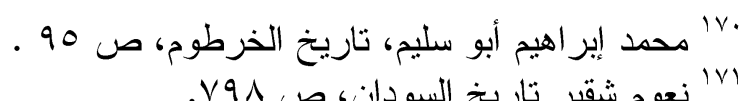

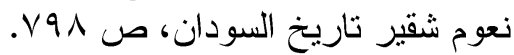

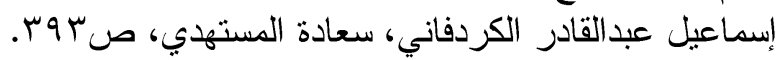

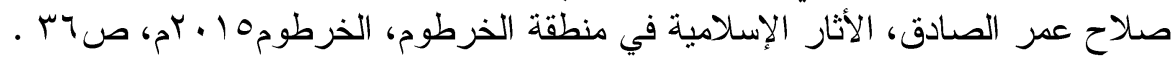

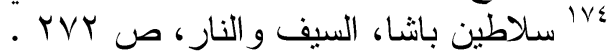

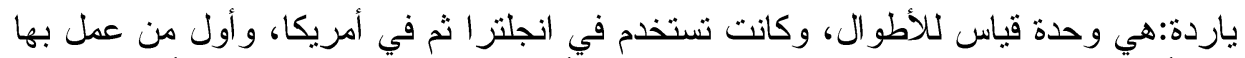
هنري الأول الملك الإنجليزي وقدرها بالمسافة بين أنفه ونهاية طرف إنبان إصبعه الأوسط، وهي ${ }^{176}$ F.R.Wingate,Mahdiism and the Egyptian Sudan,p.484.

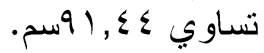

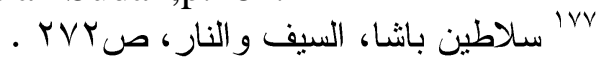

الإل الذراع: هو وحدة قياس للطول، وتعتمد على طول ساعد الإنسان من المرفق وحتى نهاية

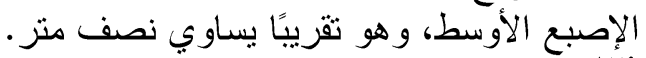

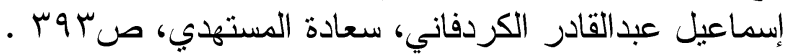

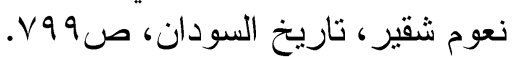

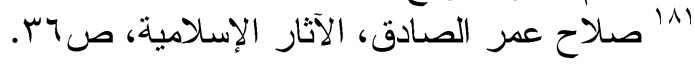




\section{الماملامج العمرانية والمعمارية لمدينة أم درمان الأثرية}

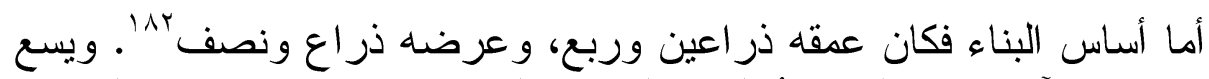

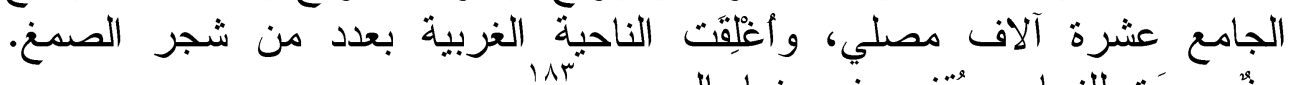

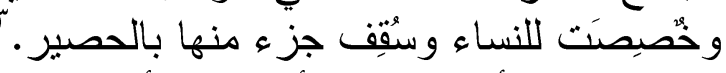

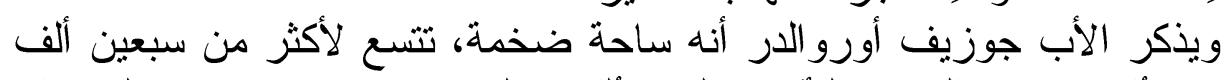

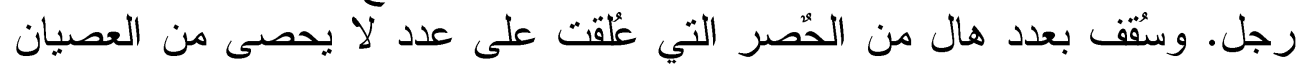

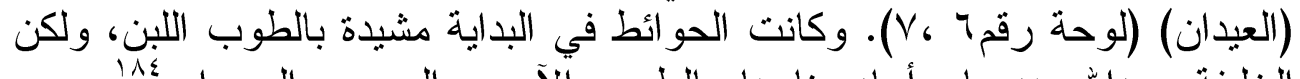

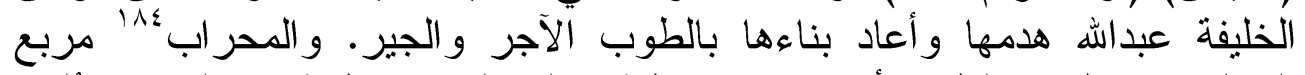

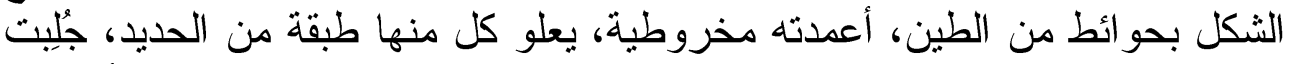

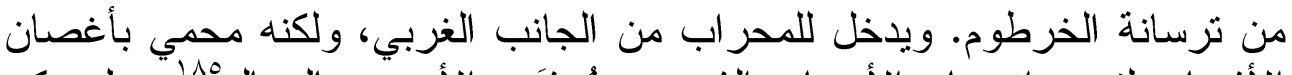

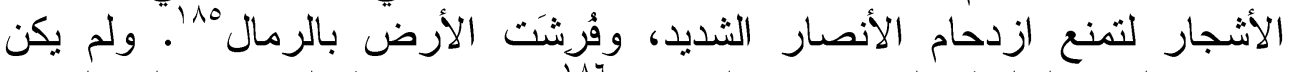

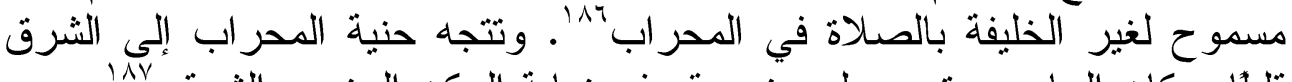

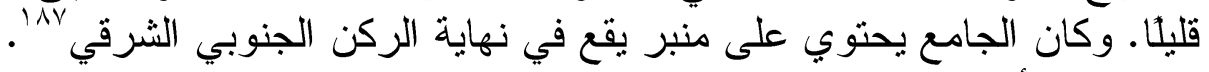

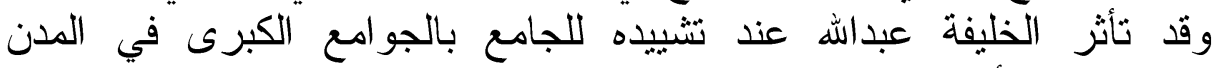

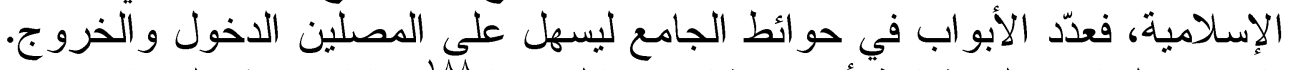

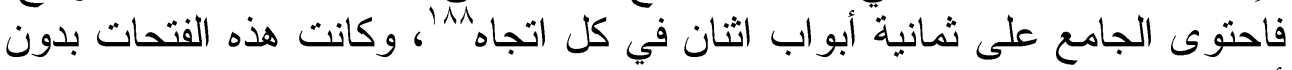

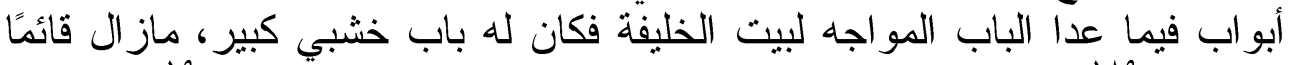

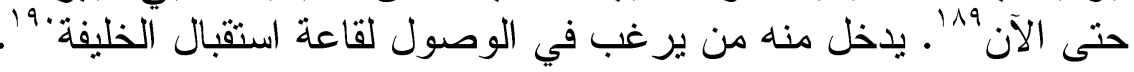

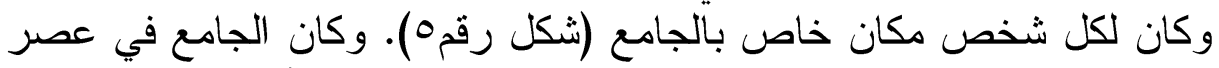

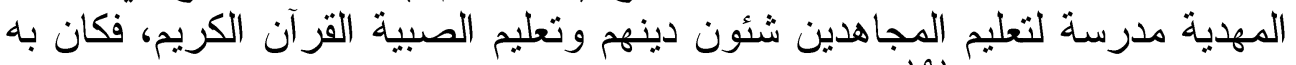

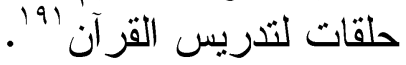

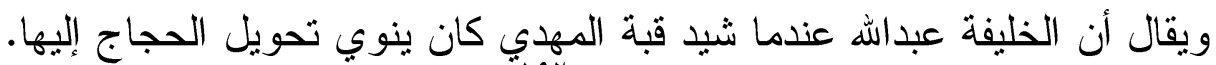

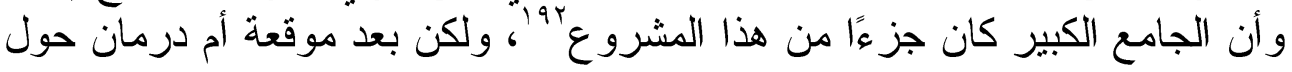

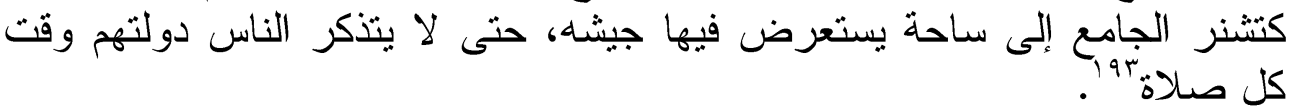

\section{(Ar}

${ }^{183}$ F.R.Wingate, Mahdiism and the Egyptian Sudan,p. 484.

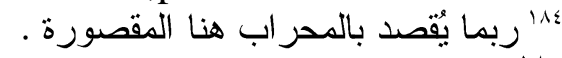

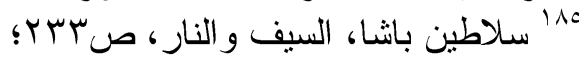

Major F.R Wingate, Ten years captivity,p.279.

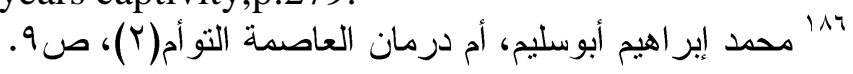

${ }^{187}$ F.R.Wingate,Mahdiism and the Egyptian Sudan,p. 484.

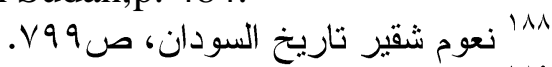

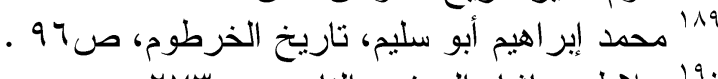

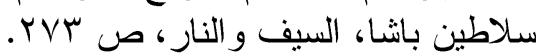

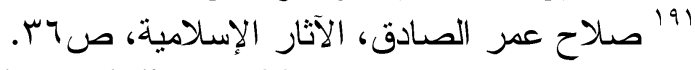

${ }^{192}$ F. Rehfisch,Omdurman during the Mahdiya, P.38.

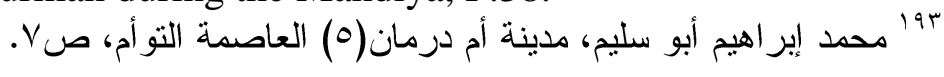




\section{- الجامع في العصر الحديث}

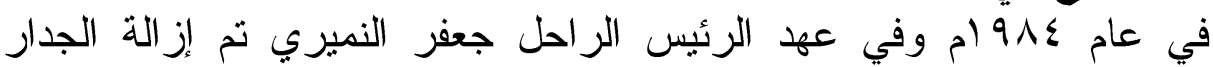

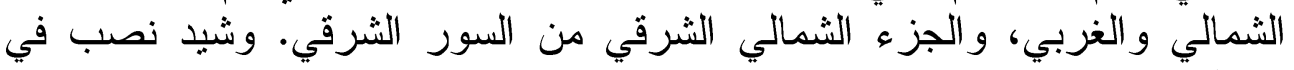

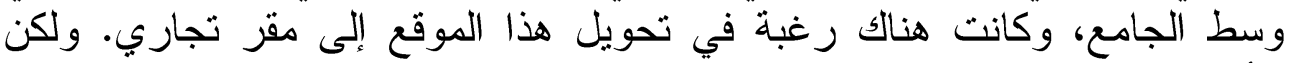

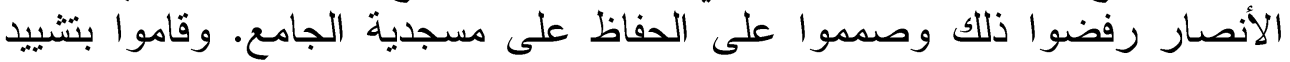

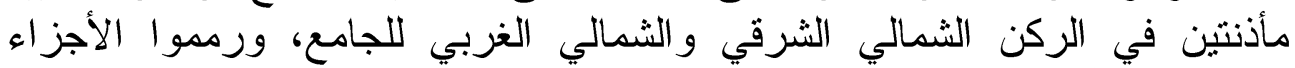

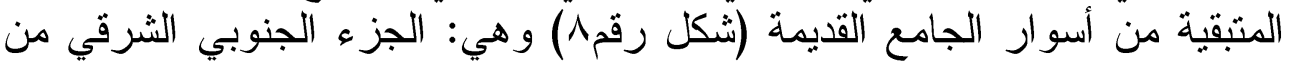

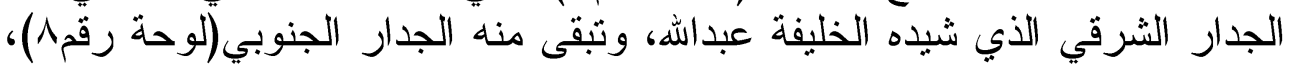

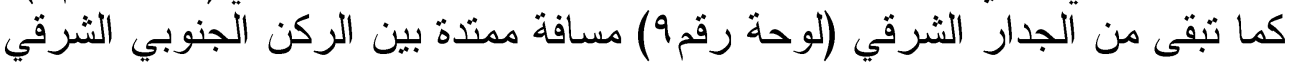
حيث يلتقي بالجدار الجنوبي وحتى الباب الكبير المؤدي لداخل البئ البيت.

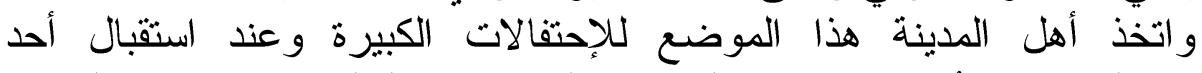

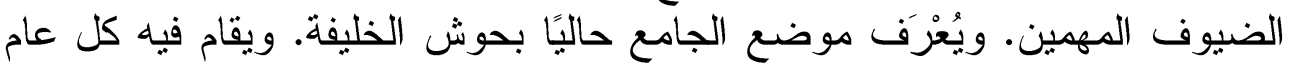

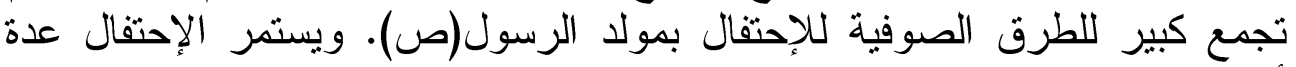

\section{: المنشآت الجنائزية

$$
\text { أ- القبة : }
$$

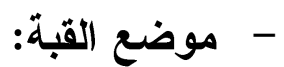

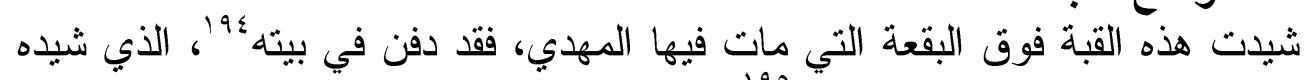

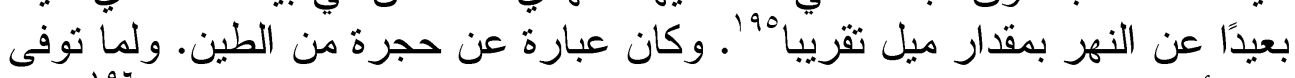

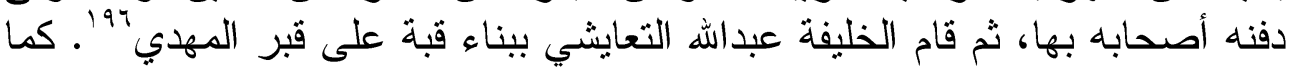

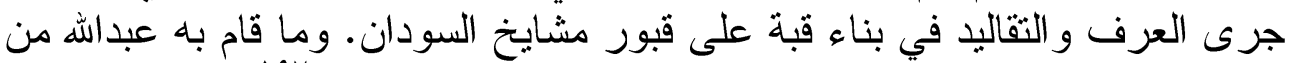

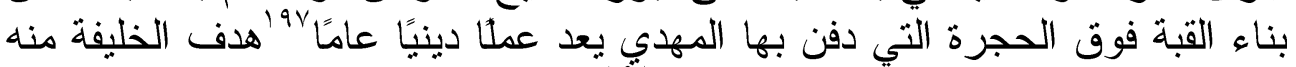

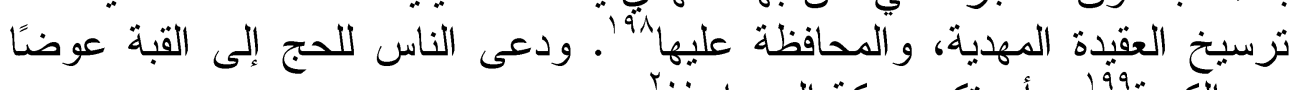

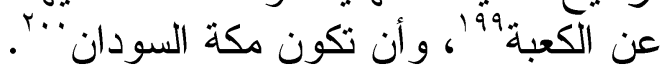

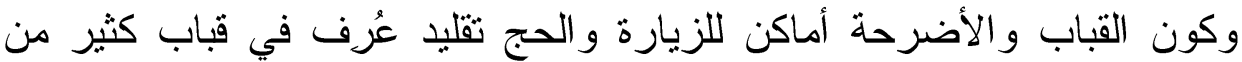

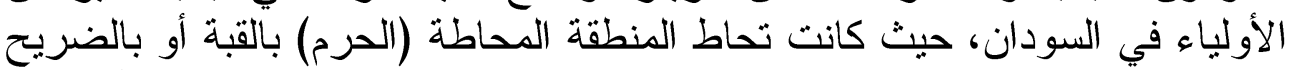

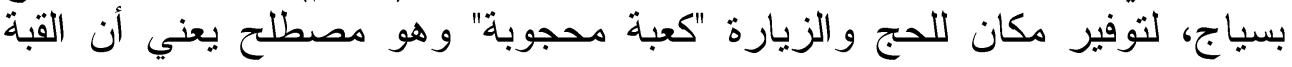

${ }^{194}$ F. Rehfisch, Omdurman during the Mahdiya, P.38.

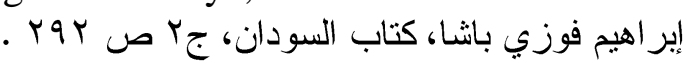

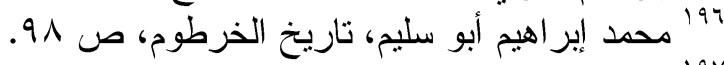

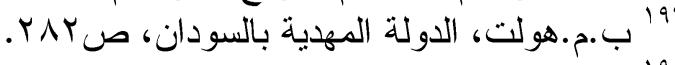

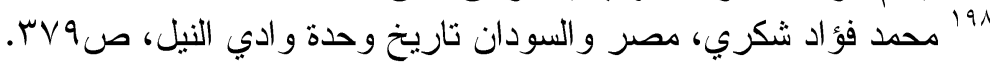

${ }^{199}$ F.R.Wingate,Mahdiism and the EgyptianSudan, p. 482.

${ }^{200}$ F. Rehfisch,Omdurman during the Mahdiya, p.38. 


\section{الماملامح العمرانية والمعمارية لمدينة أم درمان الأثرية}

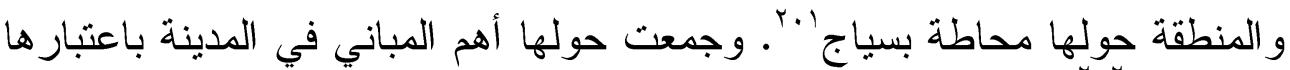

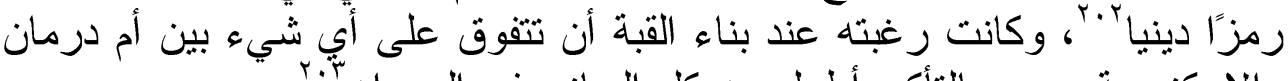

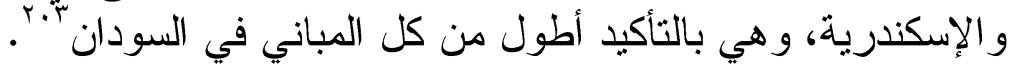

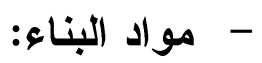

كُلف مهندس مصري اسمه إسماعيل أفندي بوضع رسم لهذه الهذه القبة وشيدها

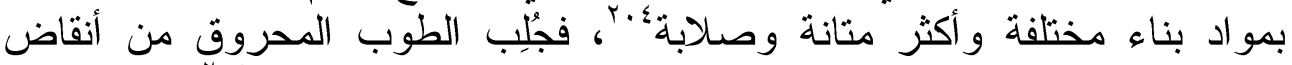

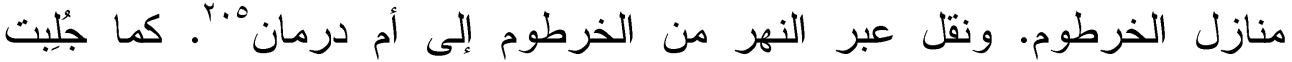

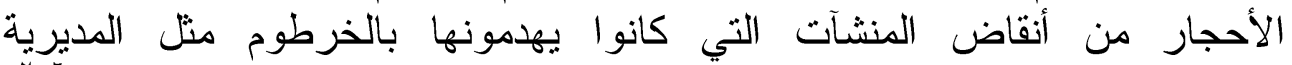

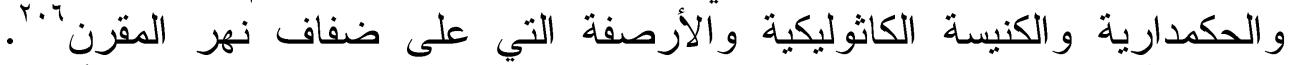

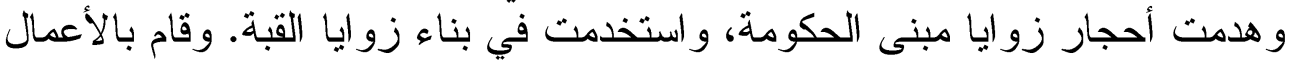

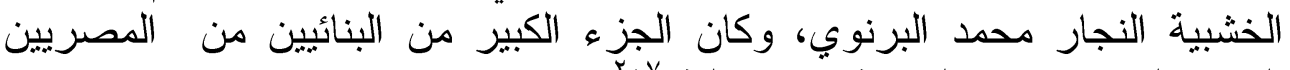

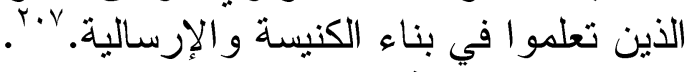
- العاملون في البناء:

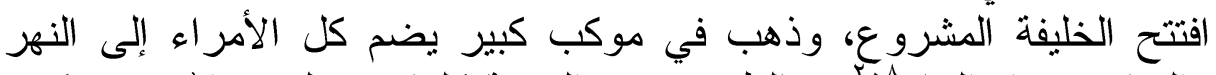

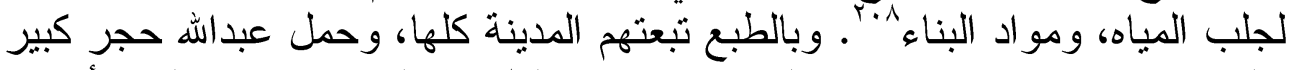

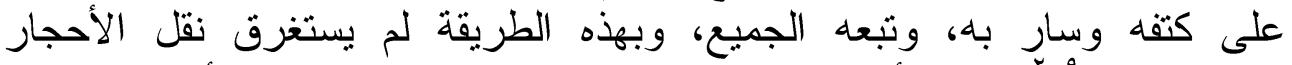

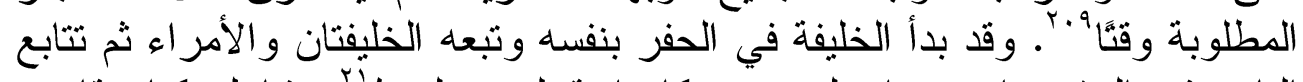

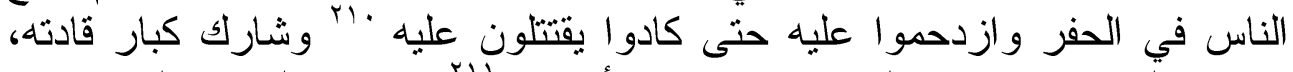

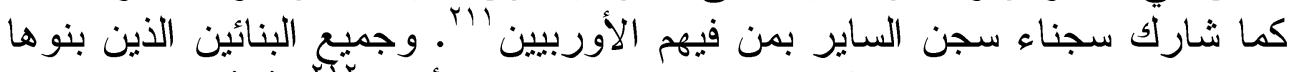

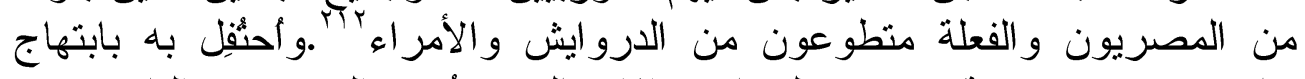

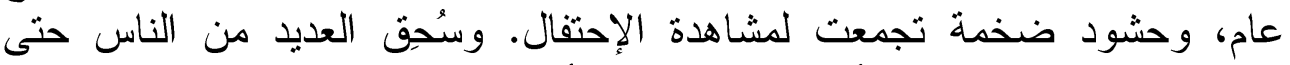

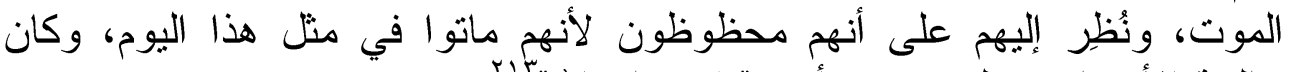

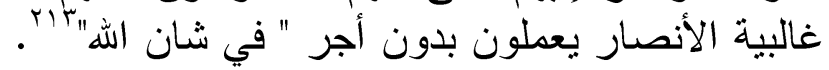

r.r. صلاح عمر الصادق، قباب شرق السودان"قيمها الوظيفية و النقافية النفسية"، الخرطوم

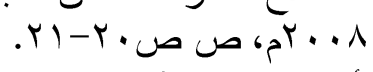

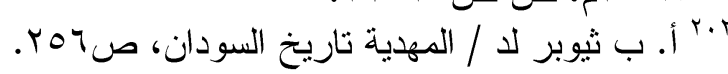

203 Major F.R Wingate, Ten years captivity,p.275.

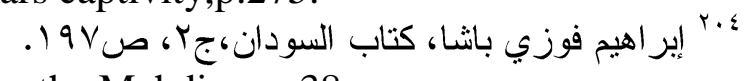

${ }^{205}$ F. Rehfisch,Omdurman during the Mahdiya, p.38.

${ }^{207}$ F.R Wingate, Ten years captivity,pp.275-276

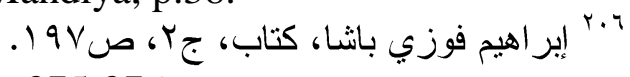

${ }^{208}$ F. Rehfisch,Omdurman during the Mahdiya, p.38.

${ }^{209}$ Major F.R Wingate, Ten years captivity,pp.276-277

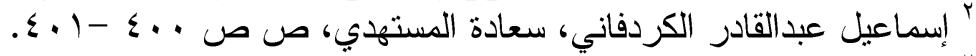

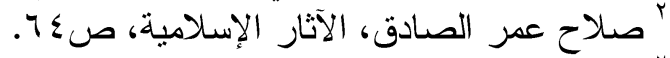

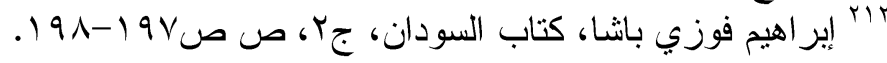

${ }^{213}$ Major F.R Wingate, Ten years captivity,pp.275-276 


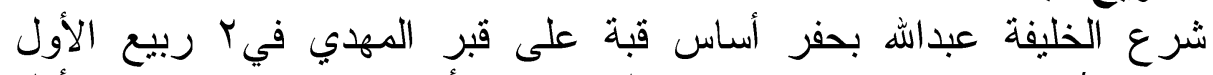

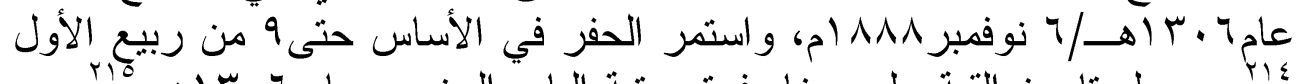

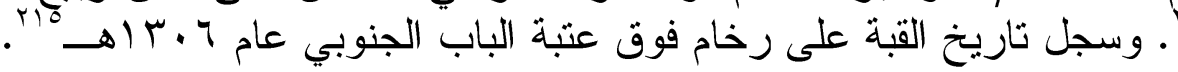

\section{- وصف البناء}

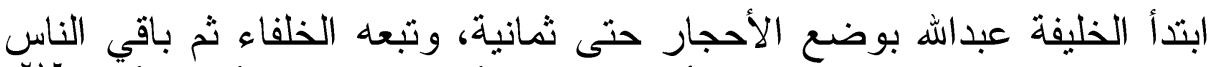

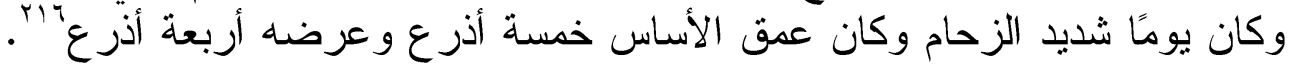

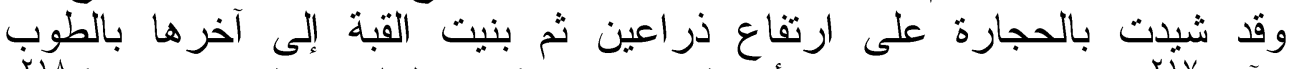

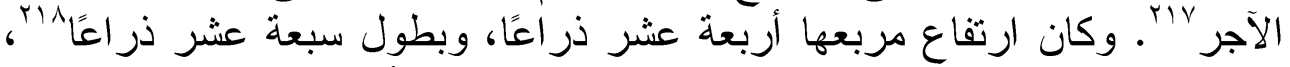

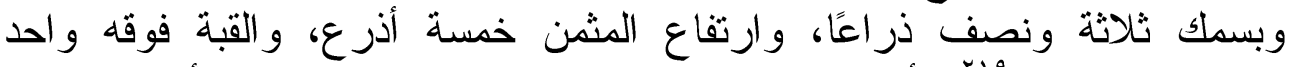

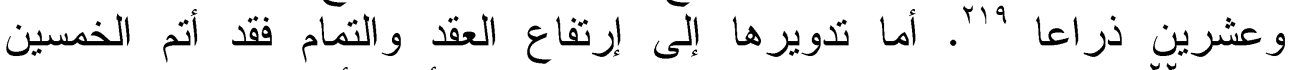

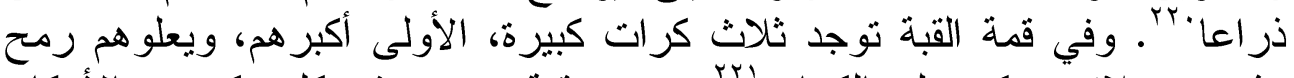

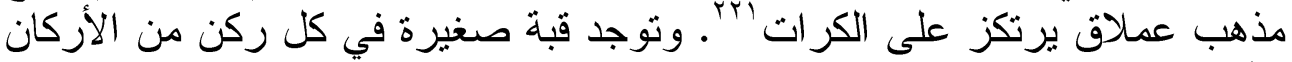

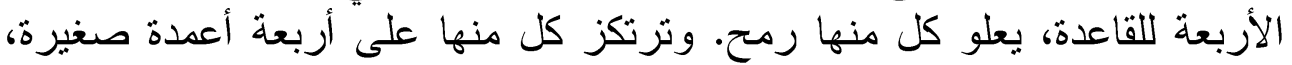

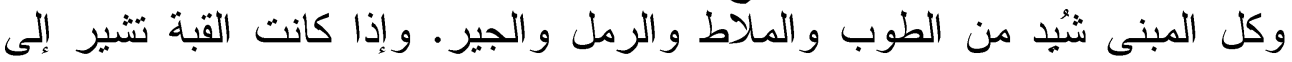

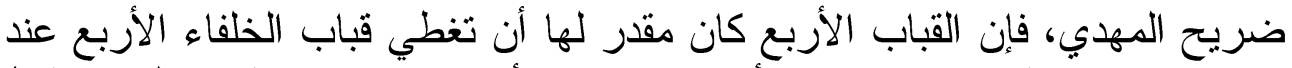
وفاتهم. وزواياً القاعدة مشيدة من أحجار مربعة مأخوذة من من مبنى الإنى البعثة (الإرسالية)

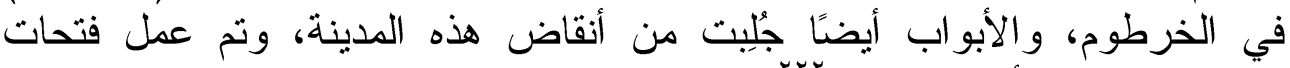

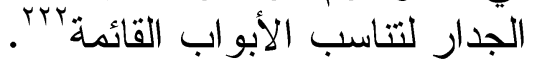

وللقبة بابان كبيران شيُدا بالحجر التبو المنحوت أحدهما يتجه شمالا والآخر

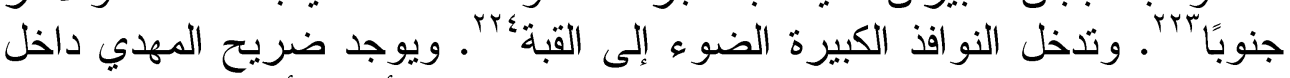

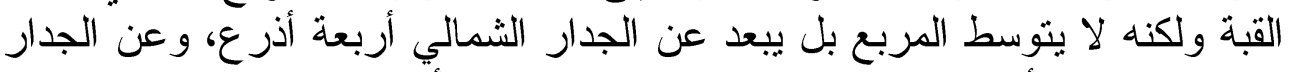

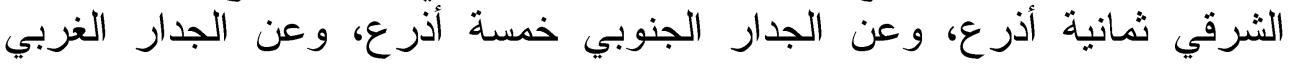

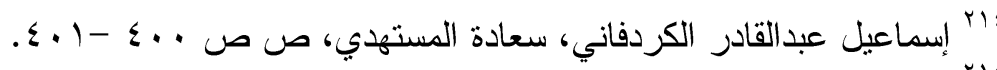

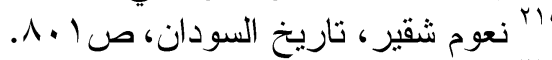

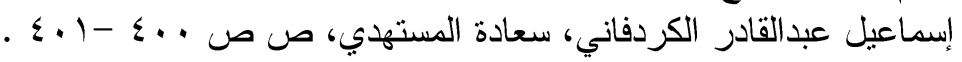

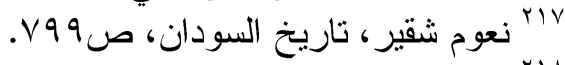

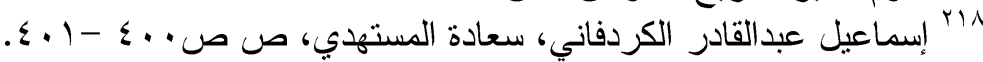

F. Rehfisch,Omdurman during the Mahdiya, PP.38-39.

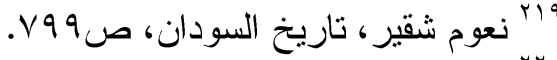

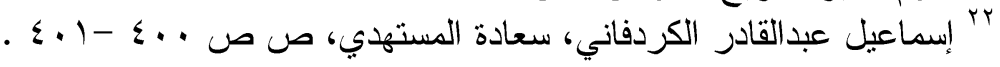

${ }^{221}$ Major F.R Wingate, Ten years captivity,pp.277-278

${ }^{222}$ F. Rehfisch,Omdurman during the Mahdiya, PP..38-39.

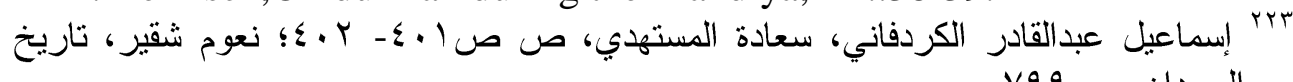

${ }^{224}$ Major F.R Wingate, Ten years captivity,pp.277-278

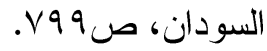




\section{الماملامح العمرانية والمعمارية لمدينة أم درمان الأثرية}

أربعة أذرع ع ror وبعد الانتهاء من تشبيد القبة أحيط القبر بمقصورة من النحاس،

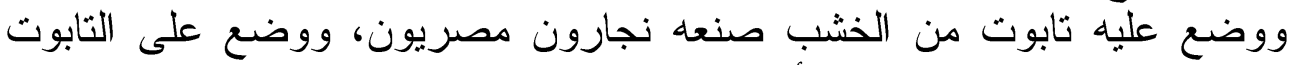

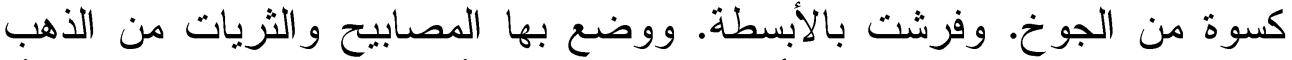

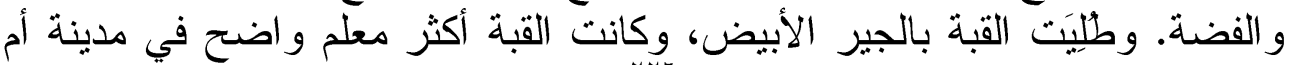

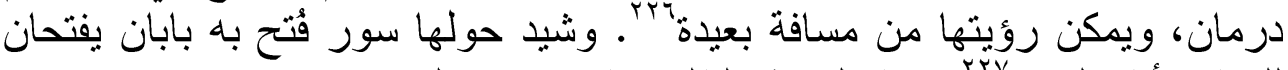

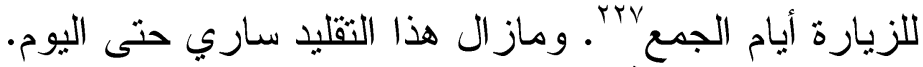
- قصف القبة:

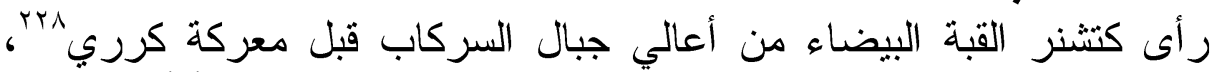

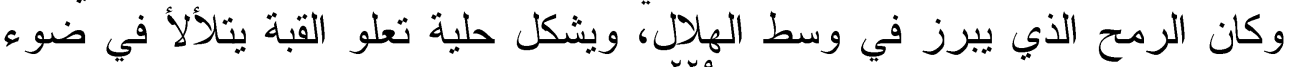

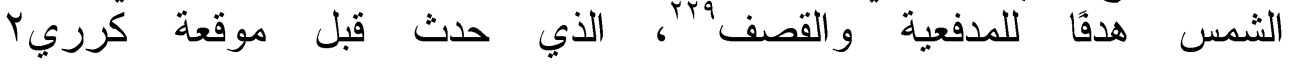

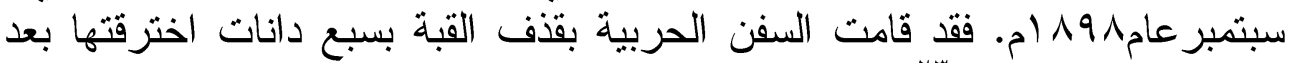

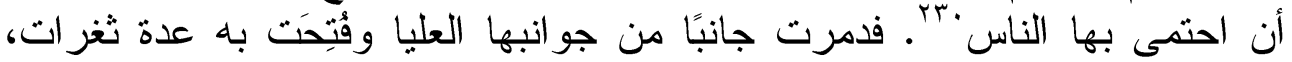

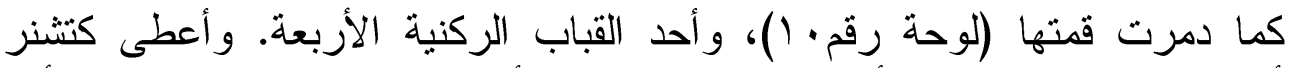

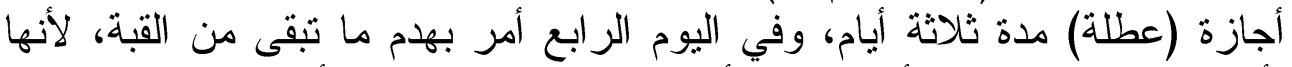

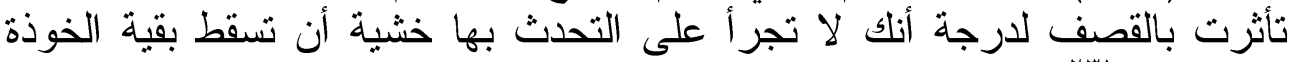

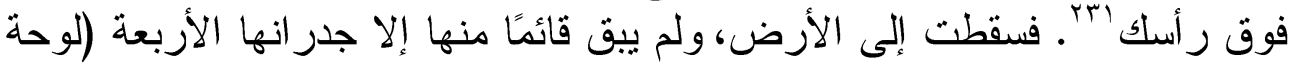

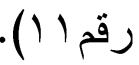

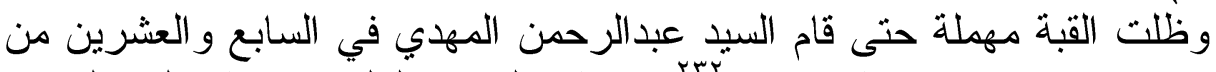

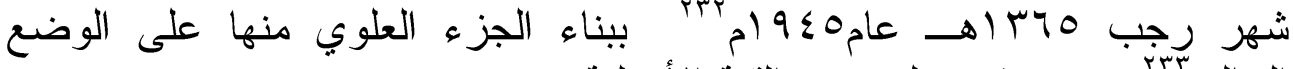

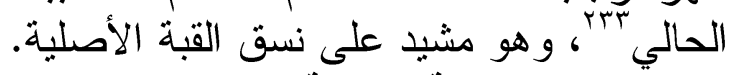
- وصف القبة القديمة من خلافل الصن الصور الإرشيفية:

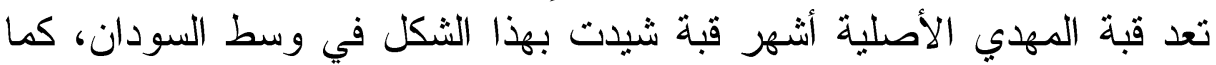

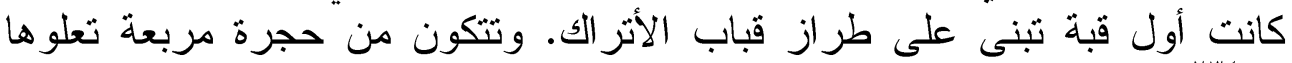

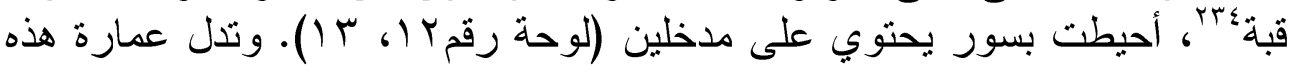

Pro إسماعيل عبدالقادر الكردفاني، سعادة المستهدي، ص r • ؛. ${ }^{226}$ F.R.Wingate,Mahdiism and the Egyptian Sudan,p. 485

${ }^{228}$ G.W.Steevens, with Kitchener to Khartum, p.295.

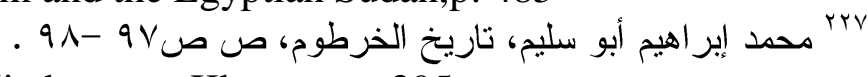

${ }^{229}$ R.A. Bermann,the Mahdi of Allah.1931,p.20.

.

231 G.W.Steevens,with Kitchener to Khartum,pp.308-309.

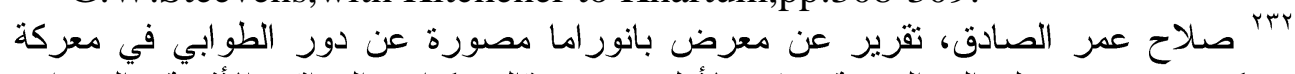

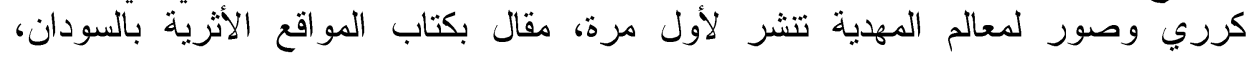
صـ •r.

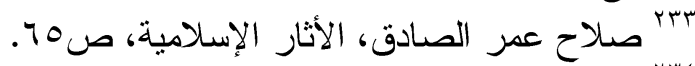

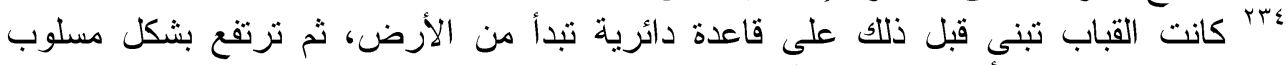

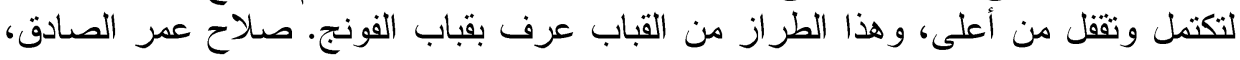




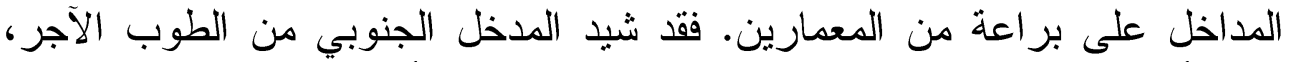

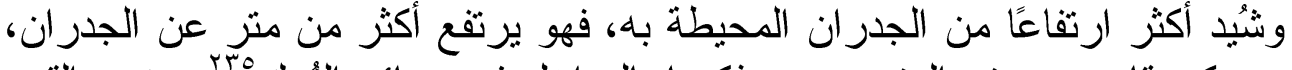

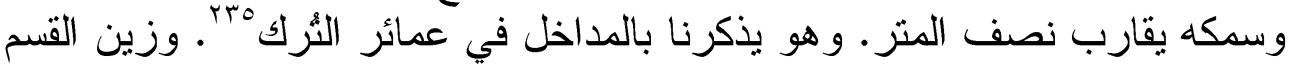

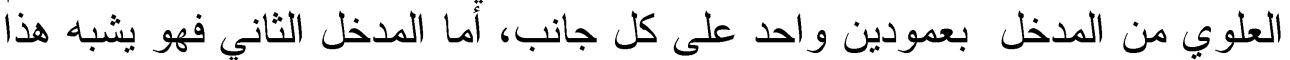

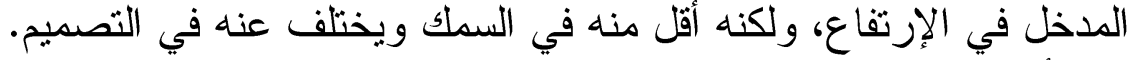

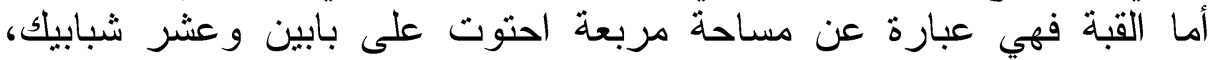

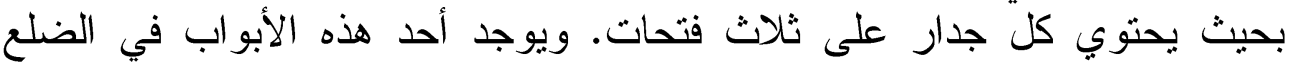

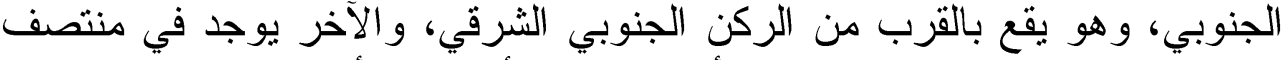

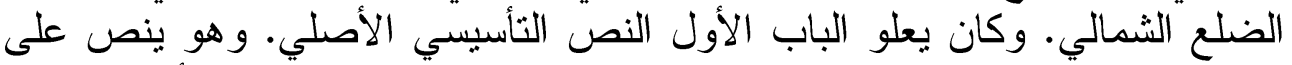

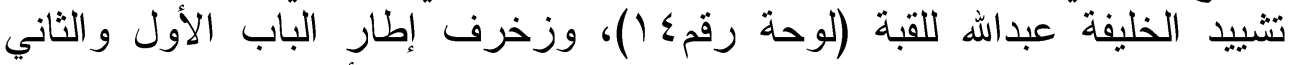

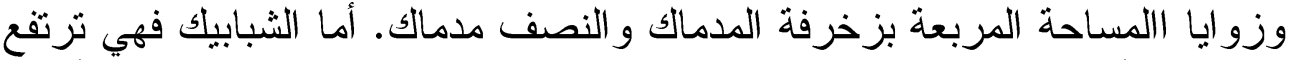

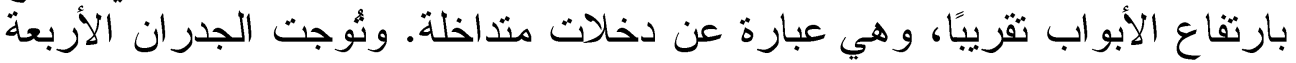

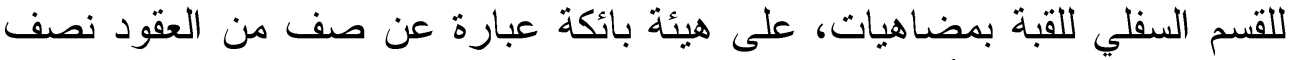

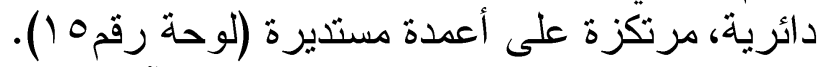

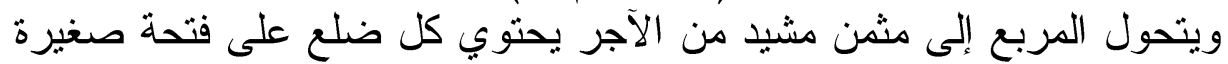

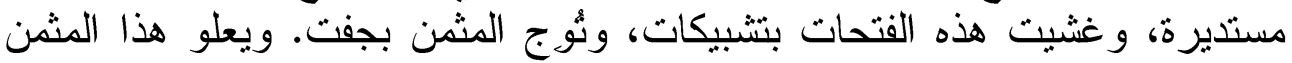

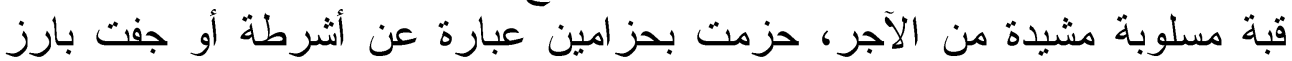

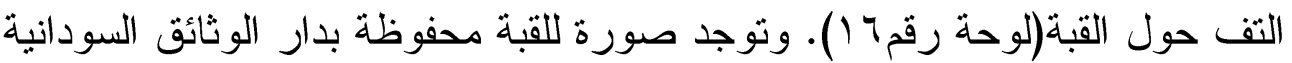

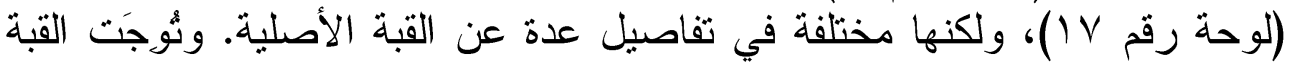

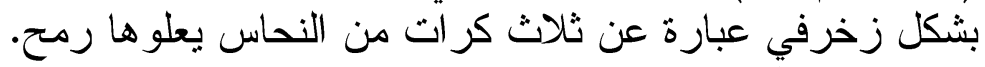

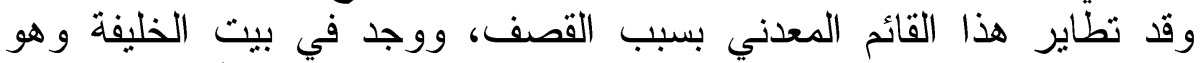

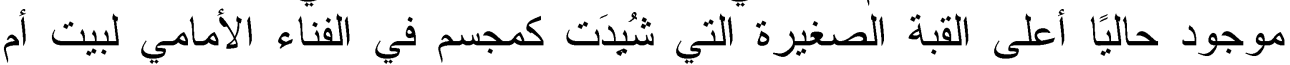

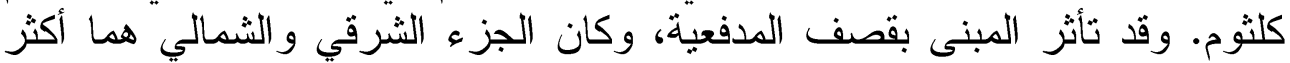

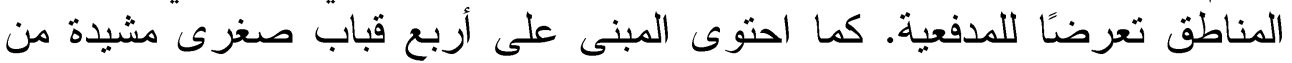

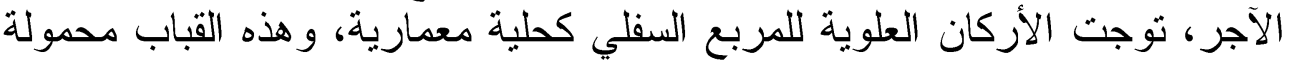

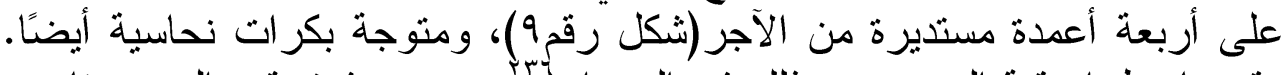

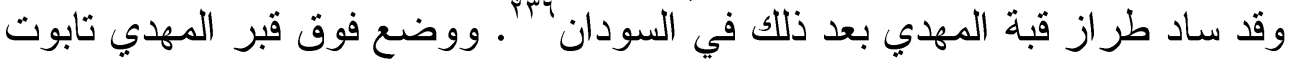

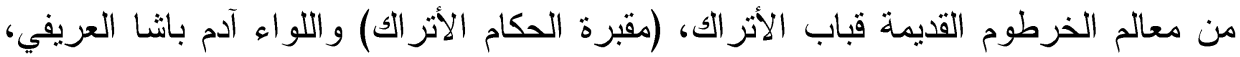

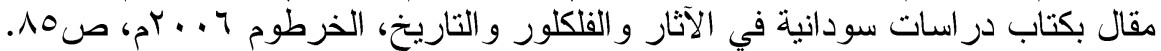

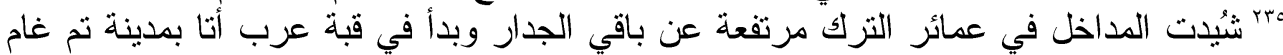

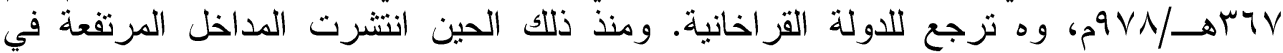

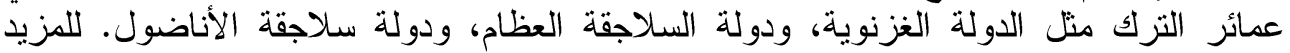

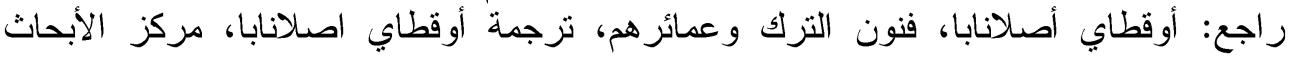

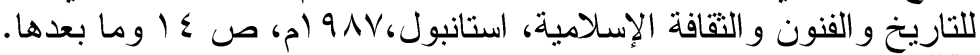

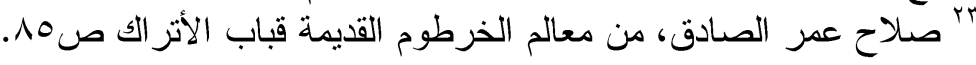




\section{هام الملامح العمرانية والمعمارية لمدينة أم درمان الأثرية}

تابوت من الخشب ثم أحيط بمقصورة من النحاس تأثرت هي الآخرى بقذف

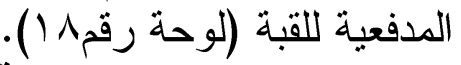
- وصف ومقاسات القبة الحة الحالية:

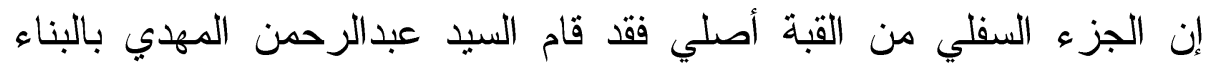

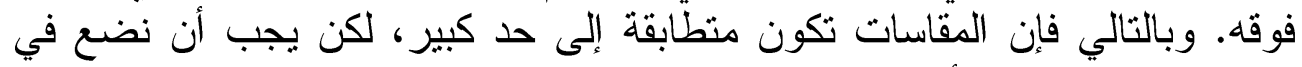
الإعتبار الملاط الذي أضيف عند ترميم الجزء السفلي مما يجعل هنالك فروق طفيفة

\section{وصف القبة من الخارج:}

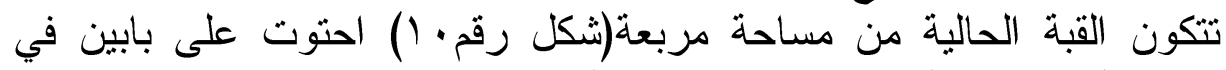

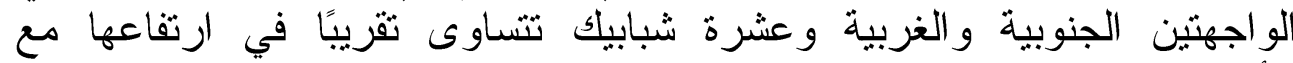

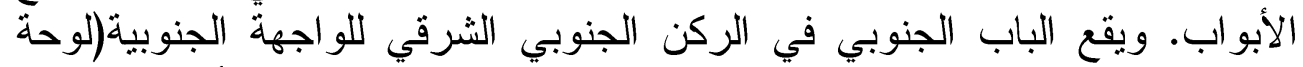

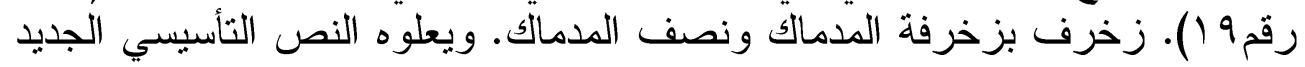

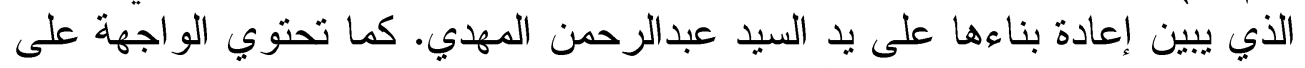

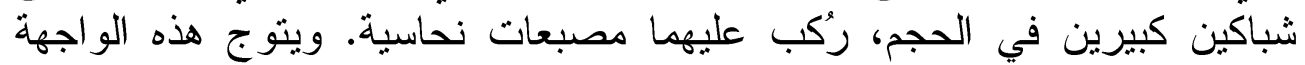

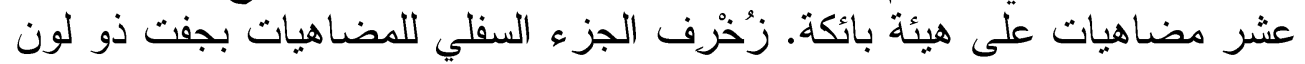

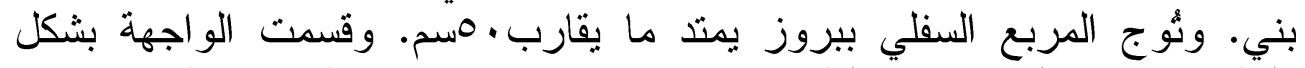

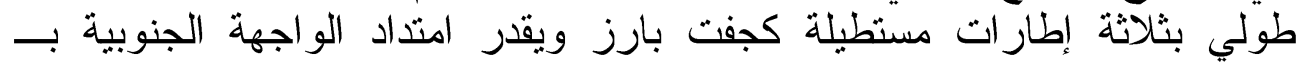

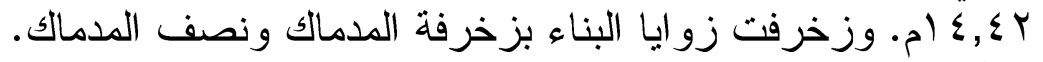

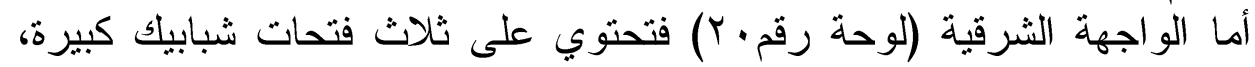

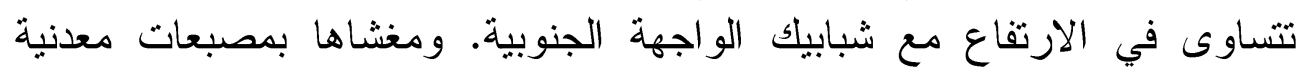
أيضًا، وتتشابه هذه الواجهة فيما تبقى مع الواجهة الجنوبية بما في ذلك الكيات المقاسات.

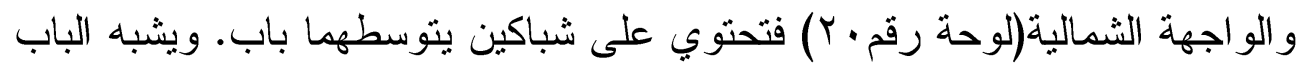

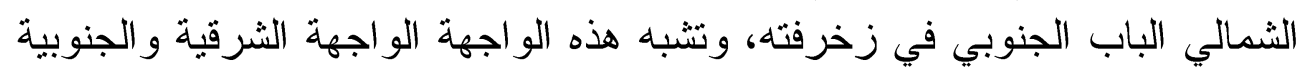
فيما تبقى حتى المقاسات. أما الو اجهة الغربية(لوحة رقم ابل) فهي تحتوي على ثلاث فتحات شبابيك ثشبه

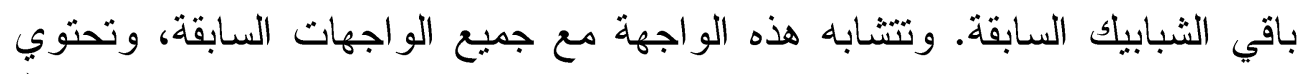
هذه الواجهة على لوحة حديثة كتب عليها في سطرين: السطر الأول:"لا إله إلا الله

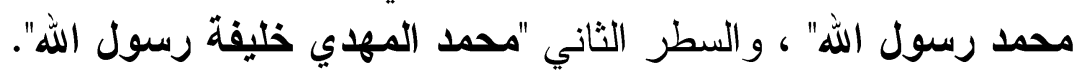

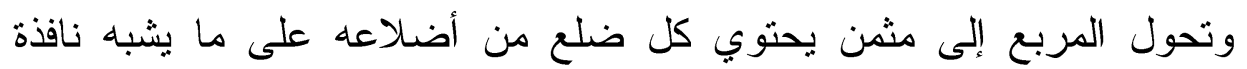
ثلاثية تحتوي بداخلها على قندلية بسيطة. تتكون من قمريتين مستطلتين، يعلو هما

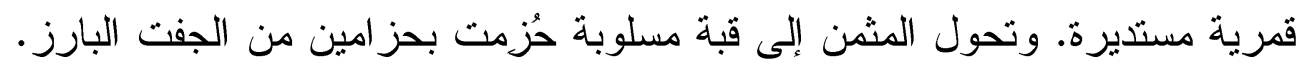

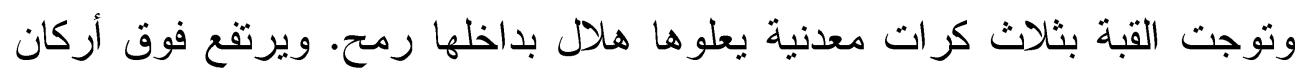

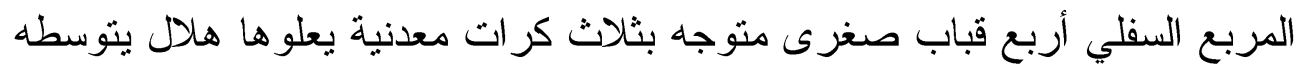
رمح. ونزتكز هذه القباب على أعمدة، حيث حملت كل قبة على أبلى أربعة منها. 
وأحبطت القبة حاليًا بسور تغلق عليه بوابة واحدة في الجهة الغربية(لوحة

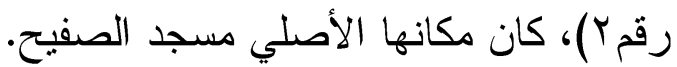
وصف القبة من الاخلي: مانها:

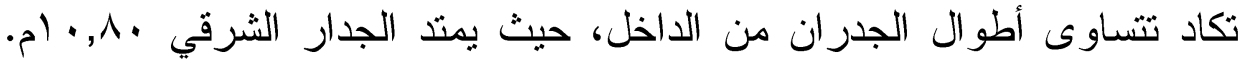

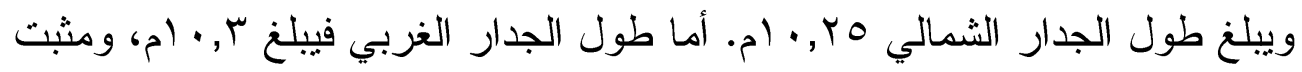

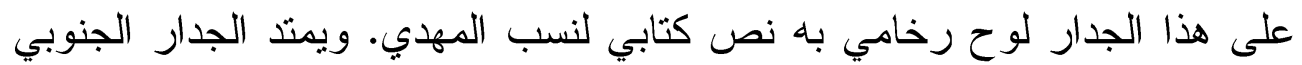

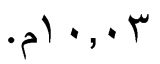

\section{بعد الضريح والمقصورة عن الجدارن}

احتوت القبة حاليًا على ضريح يضم رفات بعض الفرة أفراد أسرة المهدي. ويعلو

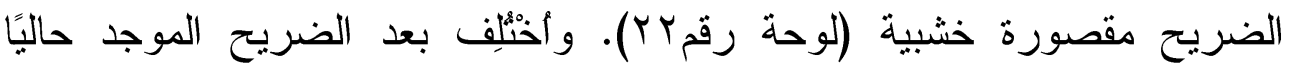

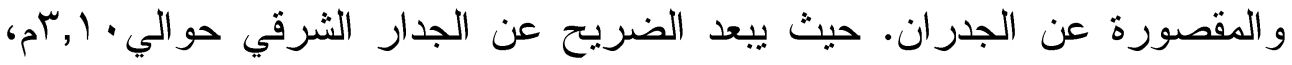

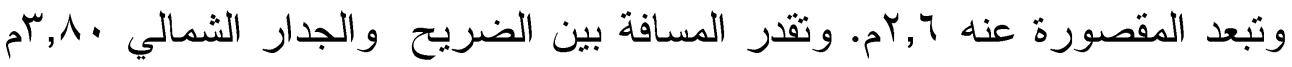

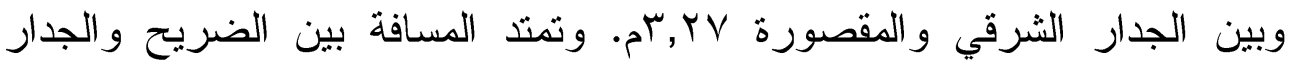

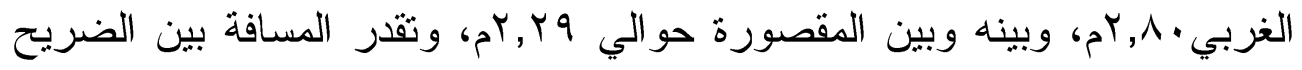

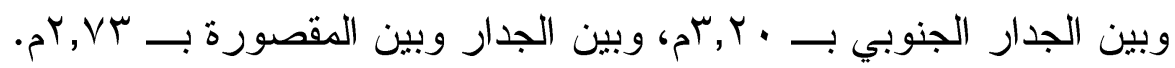

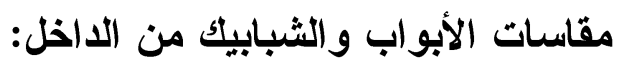

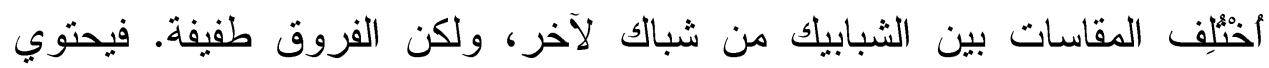

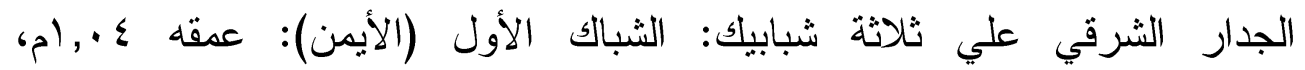

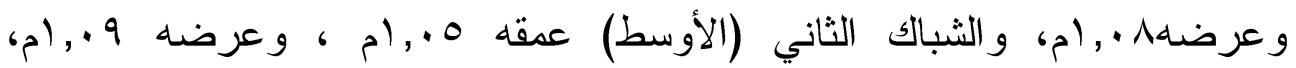

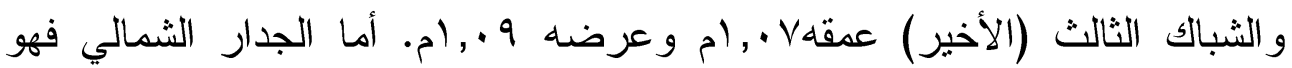

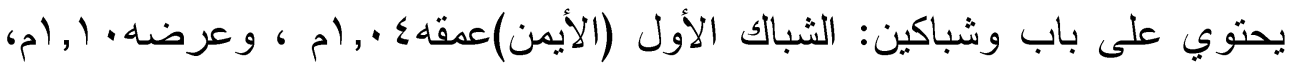

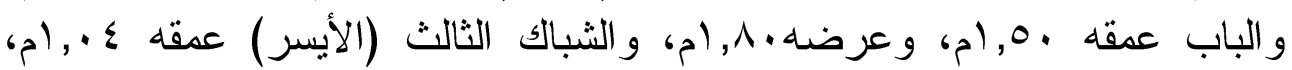

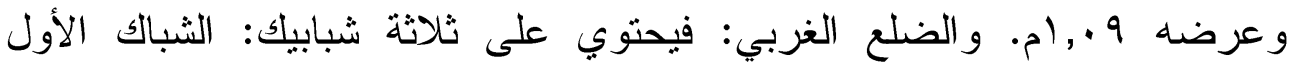

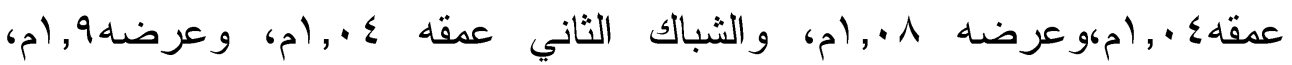

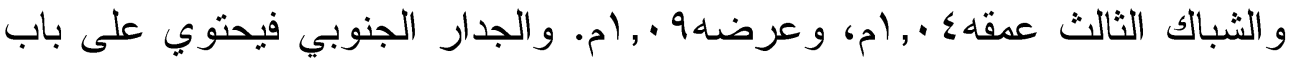

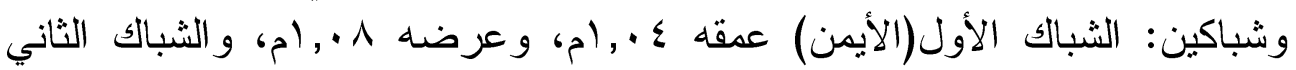

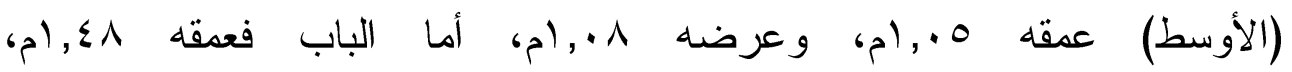

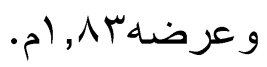

طول المسافات بين الثبابيك في جدران القبة:

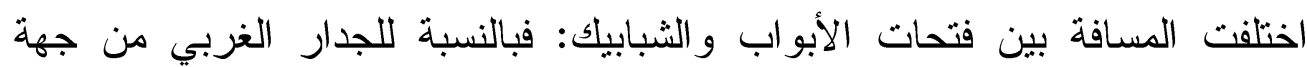

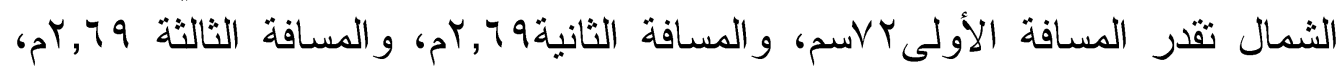

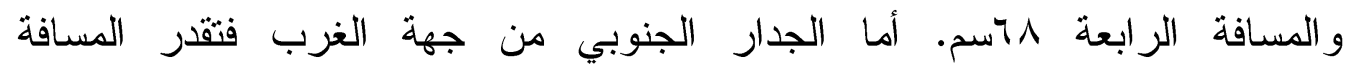




\section{الماملامح العمرانية والمعمارية لمدينة أم درمان الأثرية}

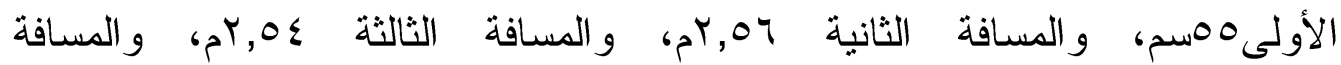

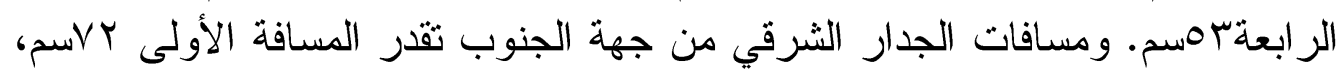

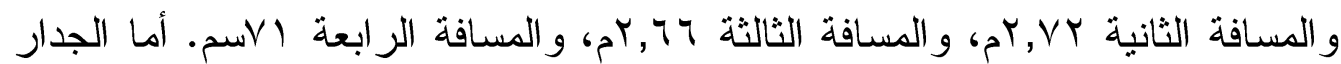

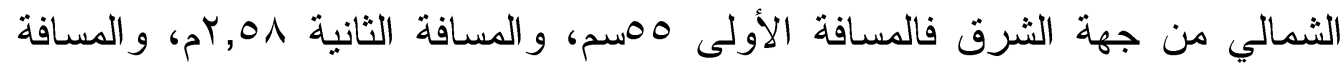

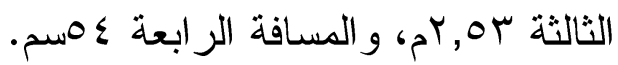

\section{ب-المنشآت السكنية :}

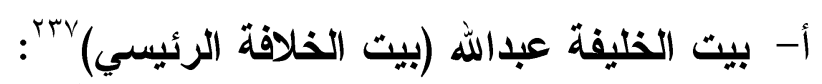

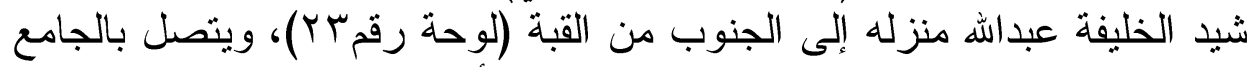

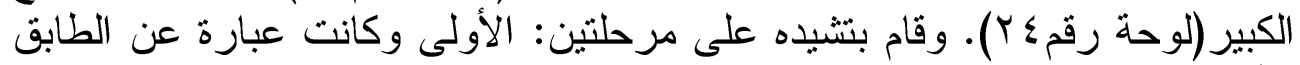

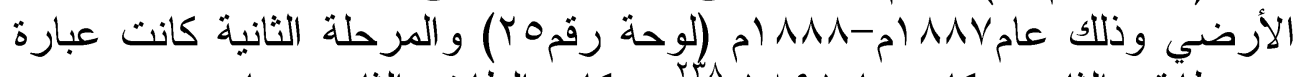

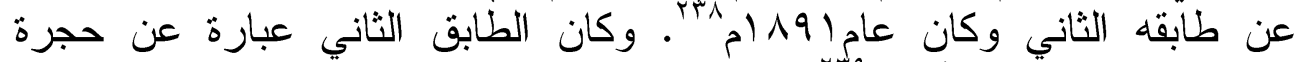

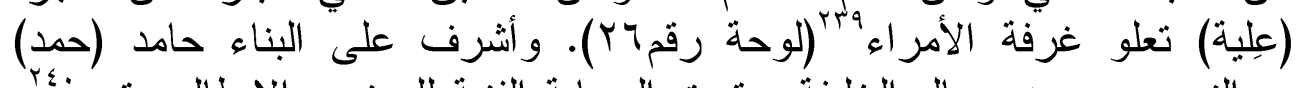

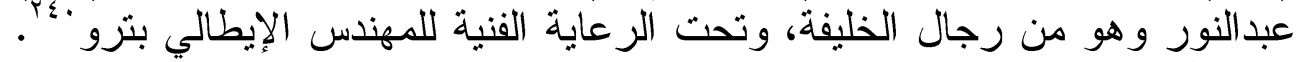
ويقال أن الخليفة هو الذي وضن رون تخطيطه بنفسه. وسيد بالطوب الأحمر الذي جلب الذب بعضي فضه من الذبه الموقع الأثري في سوبا شرق.

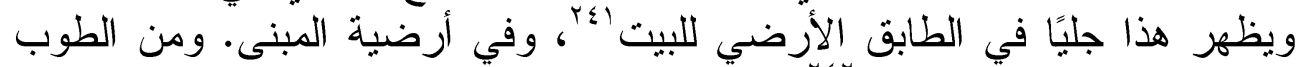

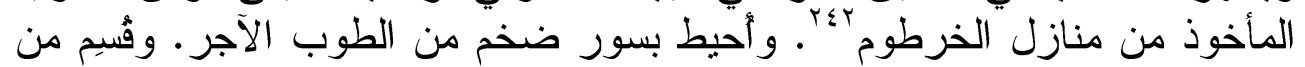

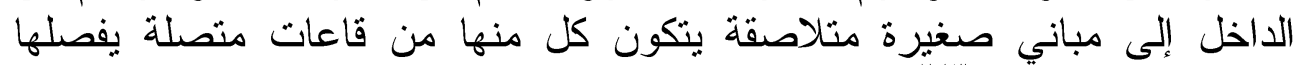

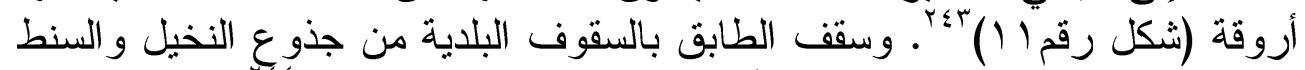

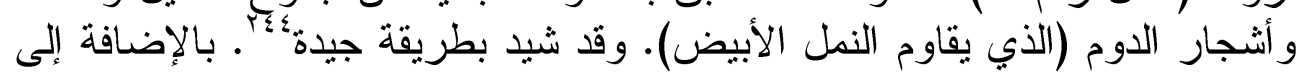

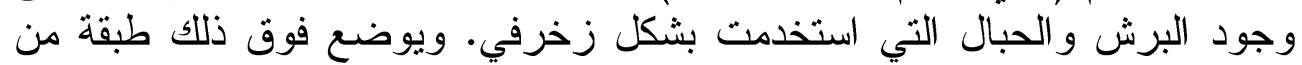

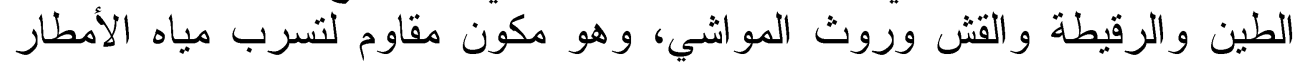

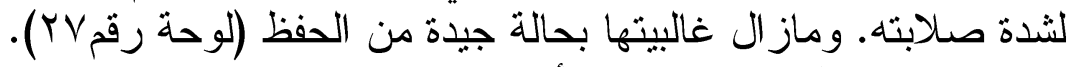

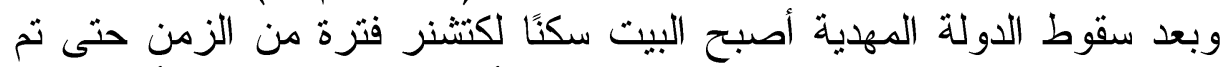

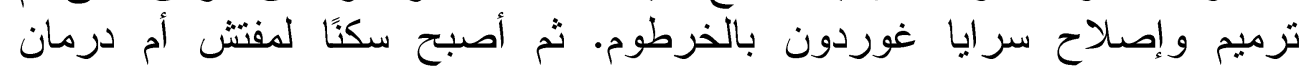

بrrr بيت الخليفة هو موضوع بحث بعنوان " متحف بيث الخليفة عبداله بأم درمان دراسة آثارية

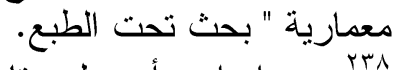

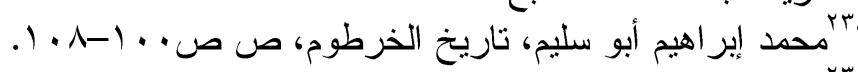

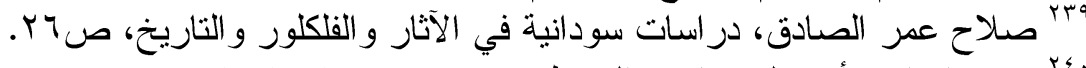

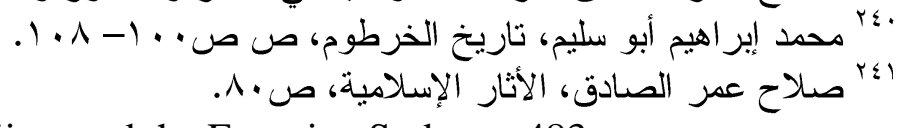

${ }^{242}$ F.R.Wingate,Mahdiism and the Egyptian Sudan,p. 483.

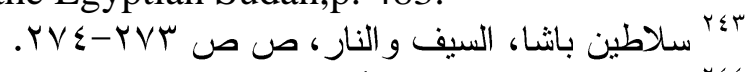

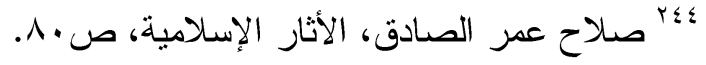




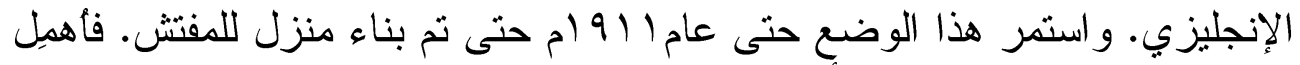

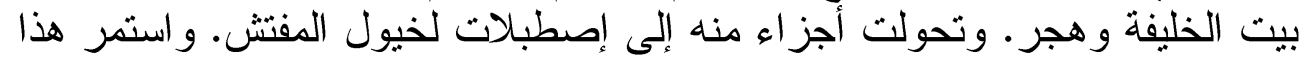

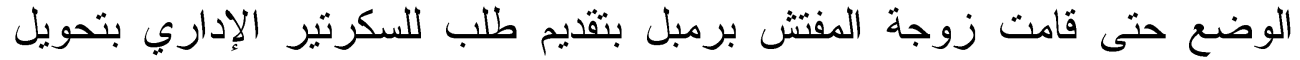

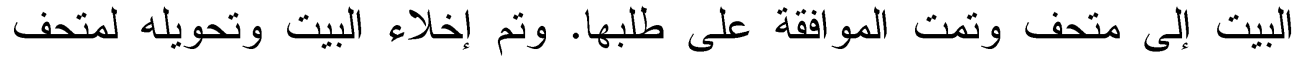

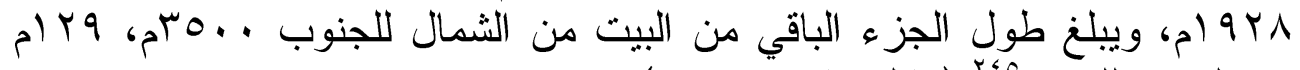

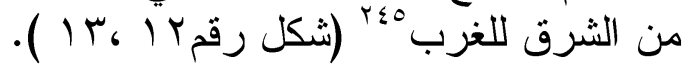

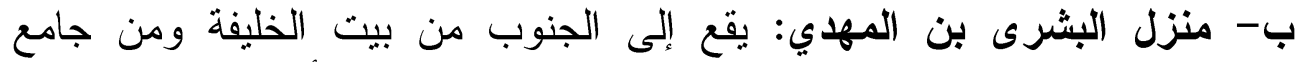

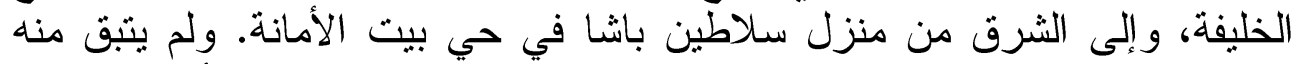

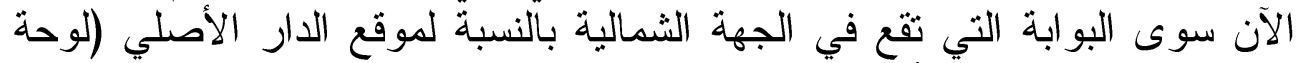

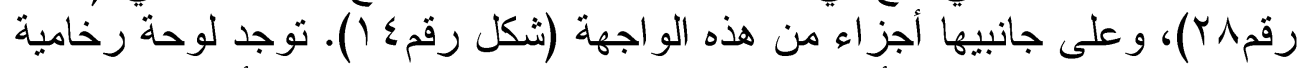

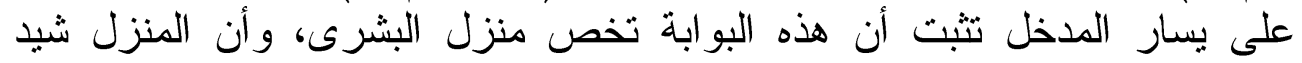

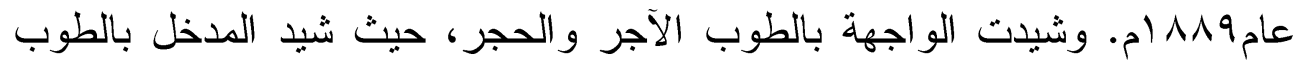

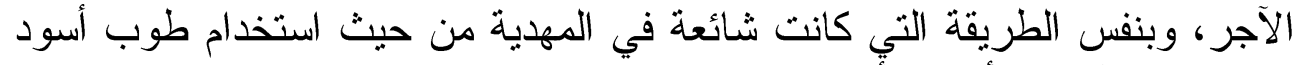

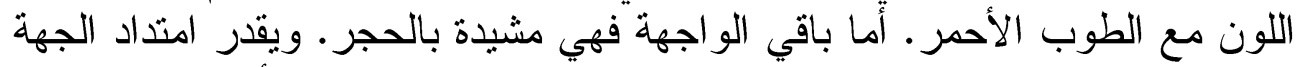

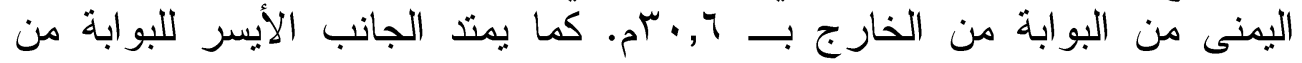

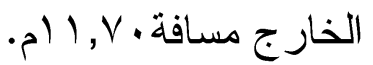
ويظهر استخدام لطوب مختلف عن مادة البناء سُّ به فتحنين مستطيلتين ربما

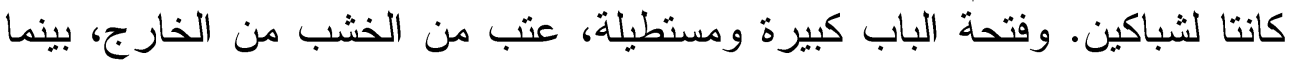

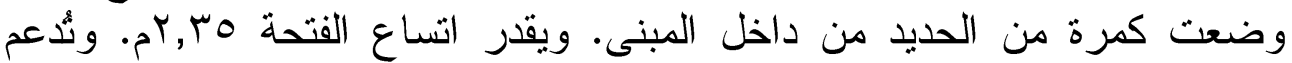

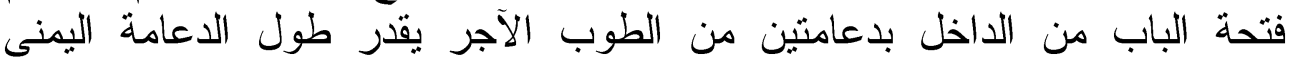

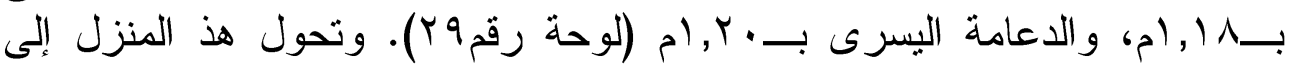

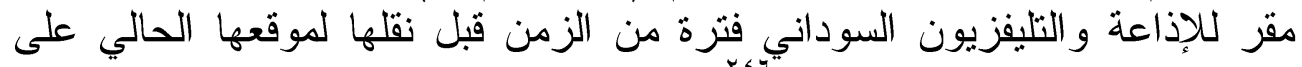

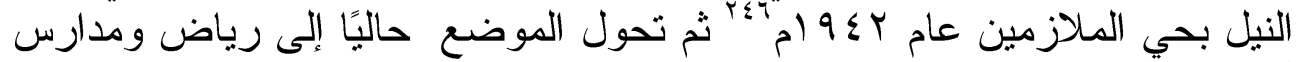

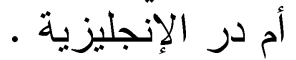
ج - منزل عثمان شيخ الدين ابن الخليفة عبدالله: يقع إلى الشرق من بن بيت الخليفة.

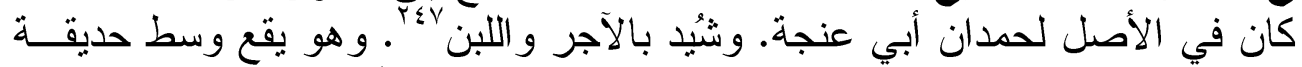

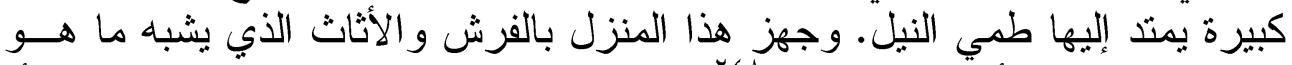

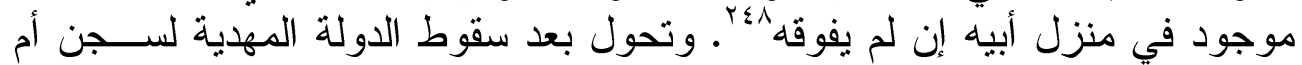

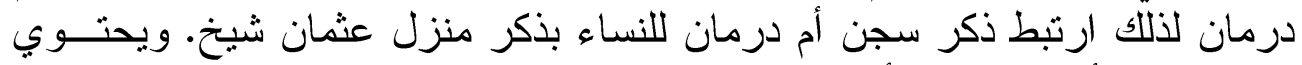

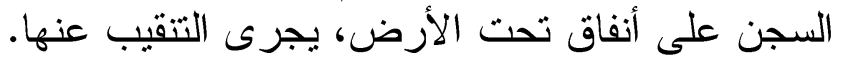

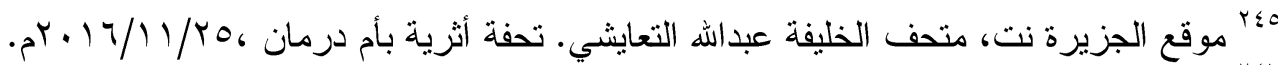

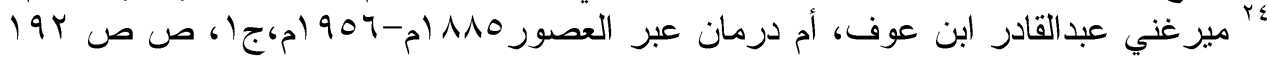

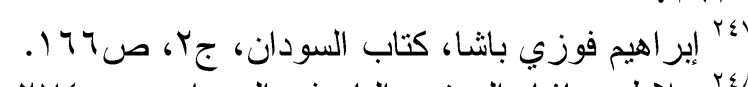

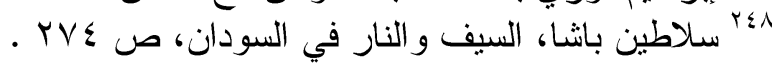




\section{الملامح العمرانية والمعمارية لمدينة أم درمان الأثرية}

وقد رمم سور السجن أكثر من مرة بنفس مادة البناء، التي استخدمث في جميــع

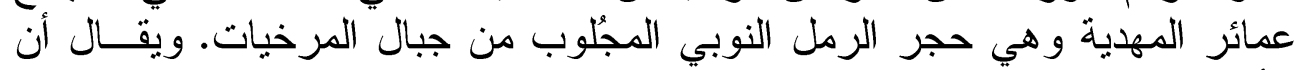
الأنصار كانو ايققون صف و احد ممتد من جبل المرخيات حتى مكان التشبيد، ويقوم

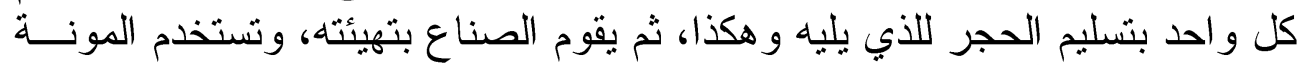
من تر اب مدينة أم درمان. وماز ال السجن بحتوي على بعض الحجرات التي ترجع

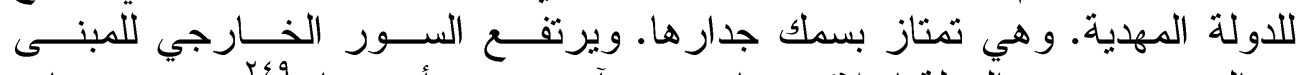

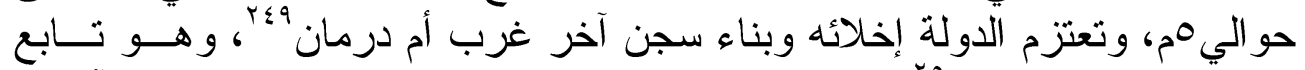

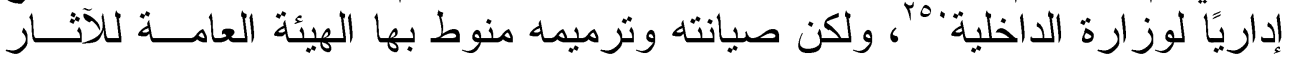

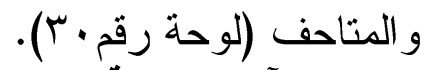
ع -المنشآت الحربية واحنة والتحصينية :

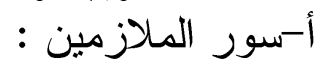

كان الخليفة عبدالله يخشى على حياته بعد ثورة الخليفة شريف وأثباعه. فيهي بداية عام/19 ام بدأ بتشييد سور يحيط بالقسم الأوسط من المدينة الذي يسكنه. ويضم إلبي جوار منزله منزل أخيه بعقوب، ومنازل الأعيان، ومساكن حرسه

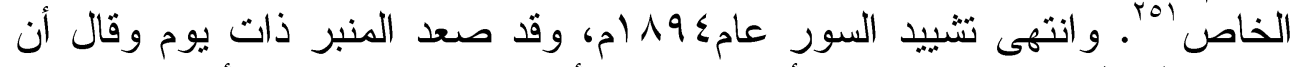

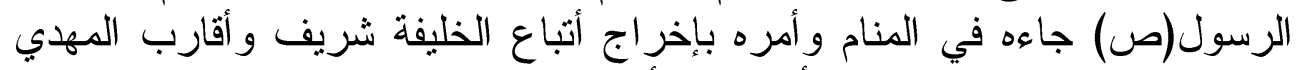

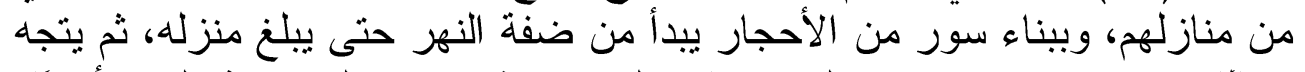
شمالّا حتى يصبح غربي منزله وشرقي المسجد، ثم ينتهي إلى ضفة النه أنهر أيضنًا، كما قال أن الرسول (صن) أمره أن لا يسكن في داخله سوى سون الجهادية و البقارة.

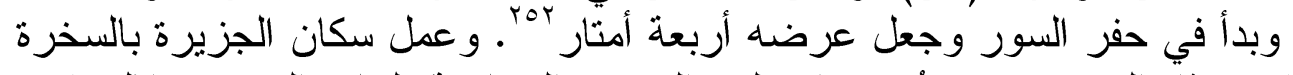
في هذا السور حيث أرغِمِوا على الهجرة الجماعية لبناء السور خلاء فله فترة

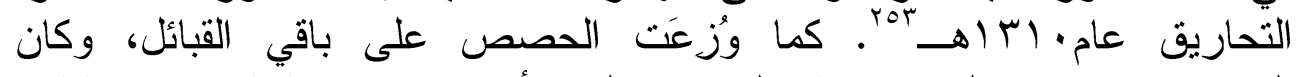
المصريون ممن عملوا في بناء السور وعلى رأسهم إبر اهيم باشا فوزي. فكانوا

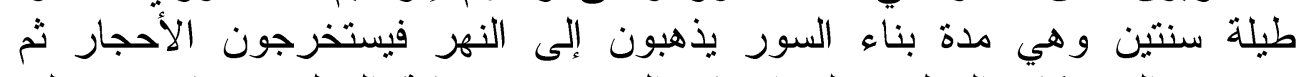

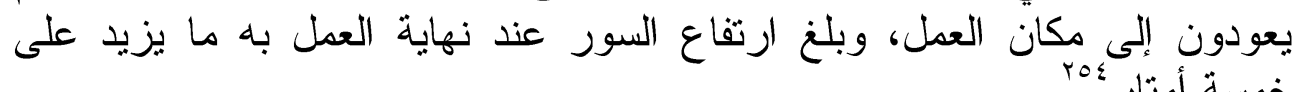

وكان هذا السور بمتذ من الجانب الشرقي في اتجاه النيل مسافة تقدر بخمسمائة

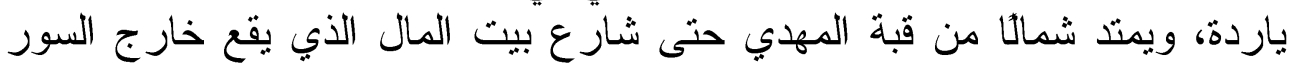
مسافة تقدر بثمنمائة ياردة. ويمتد من الجانب الغربي حتى الجامع الكبير الذي كان

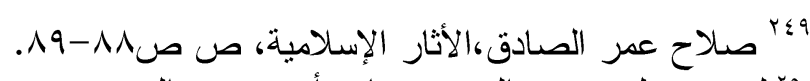

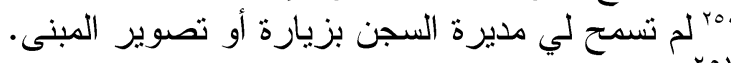

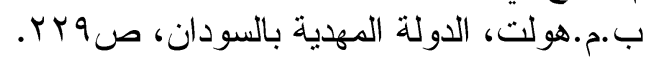
ror

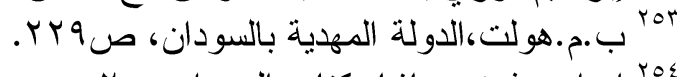

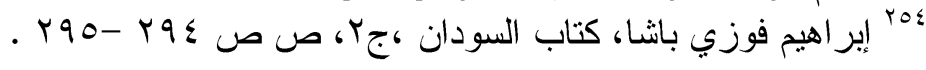




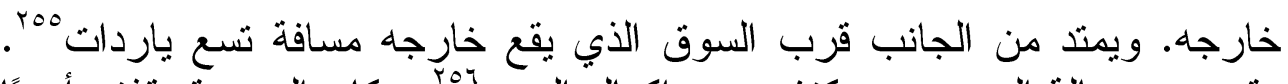

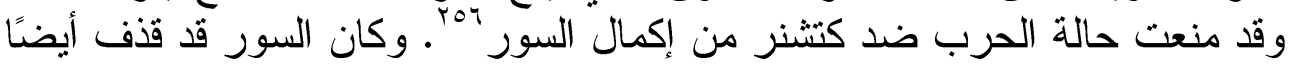

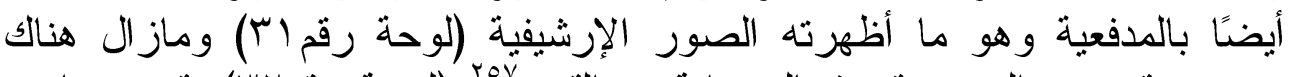

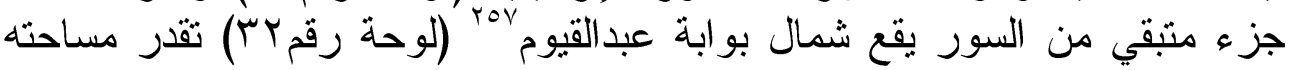

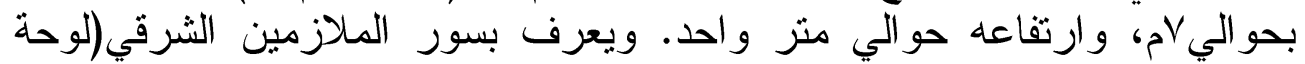

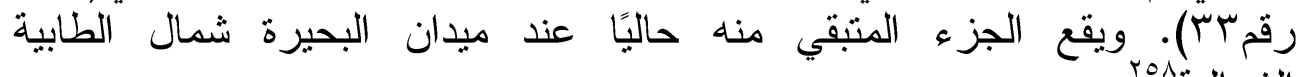

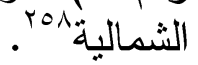

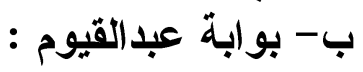

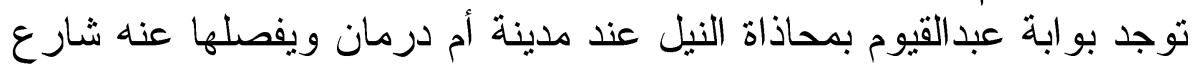

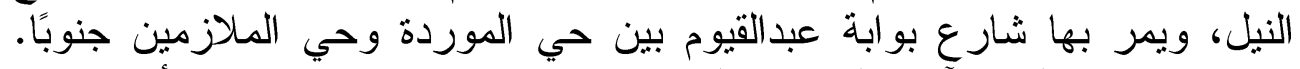

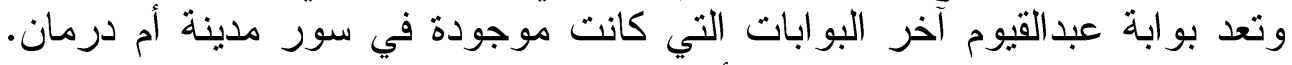

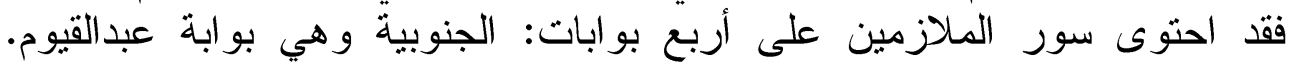

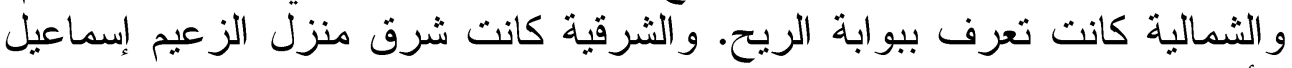

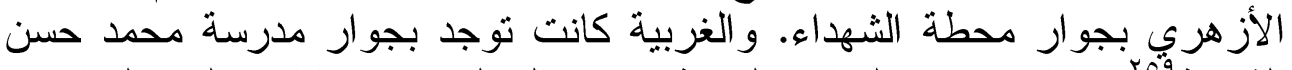

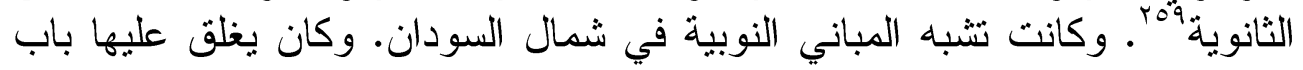

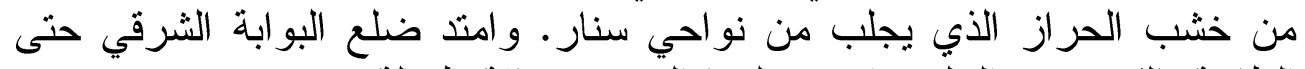

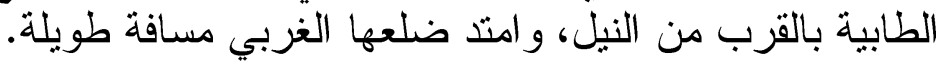

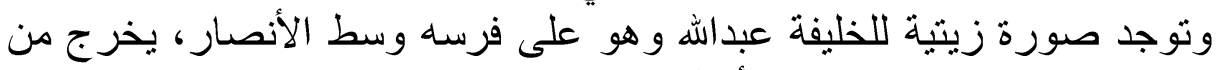

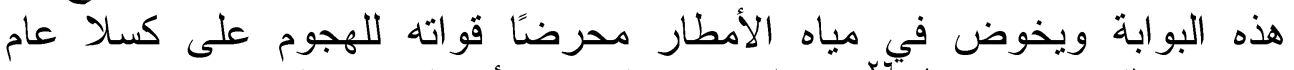

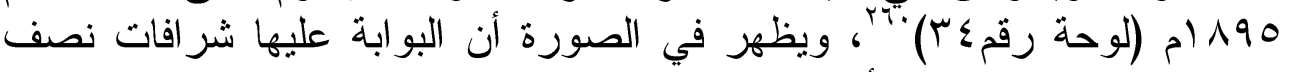

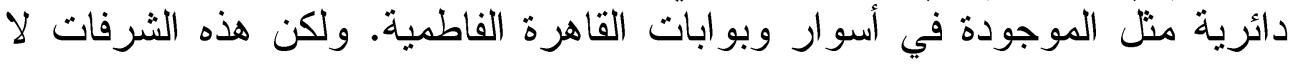

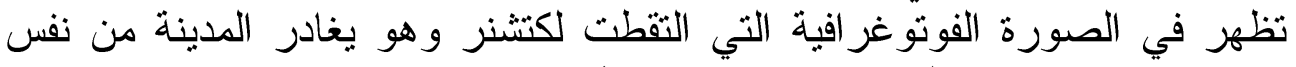

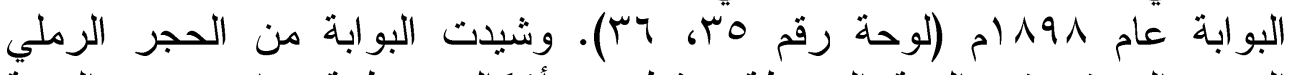

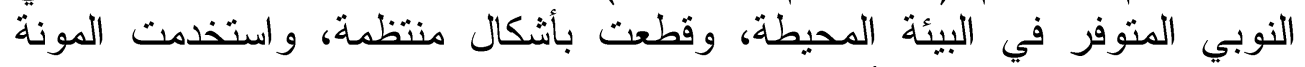

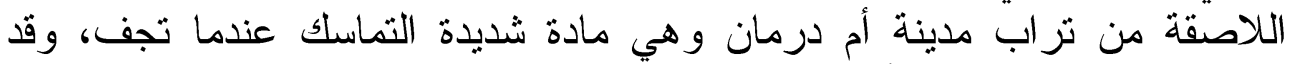

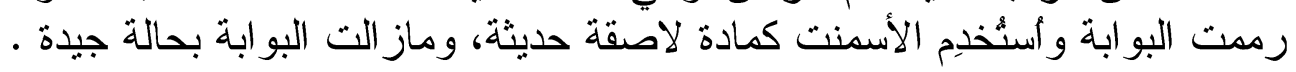

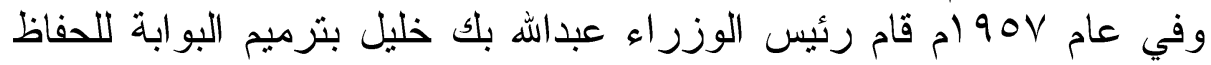

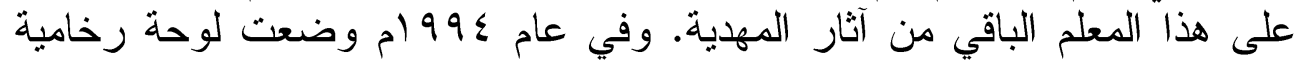

فيفيان أمينة ياجي، الخليفة عبداله حياته وسياسته، صس صـ ا. .

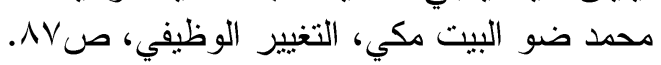

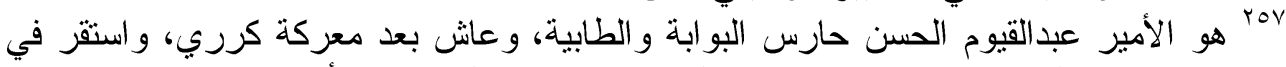

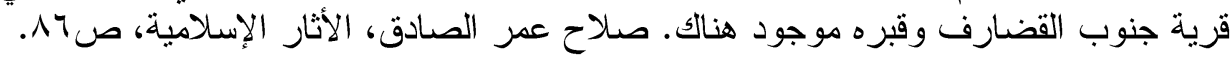

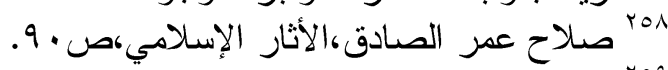

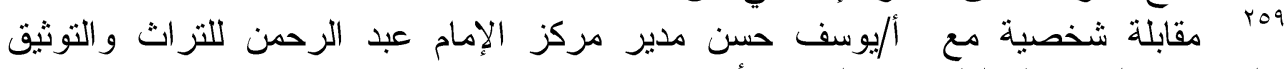

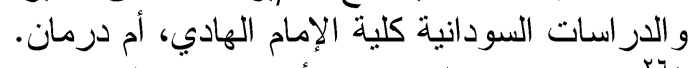

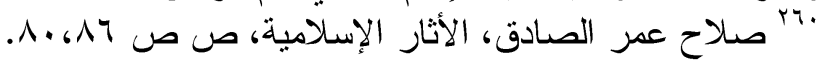




\section{الماملامح العمرانية والمعمارية لمدينة أم درمان الأثرية}

نقش عليها أن البوابة رمدت بالتعاون بين الهيئة القومية للآثار و المتاحف وبين

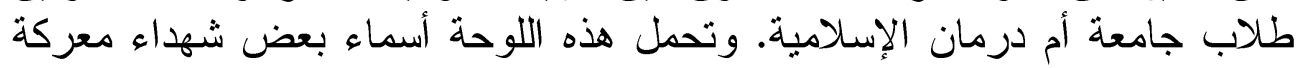

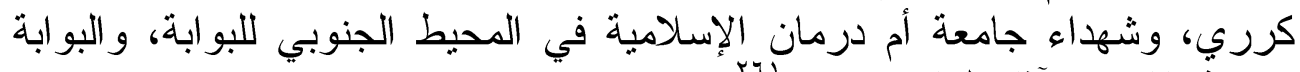

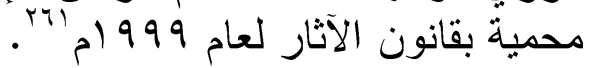

\section{- مصف البوابة الحالي:}

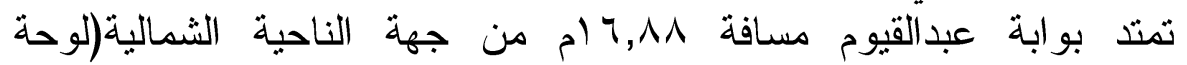

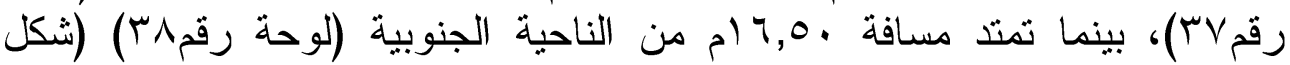

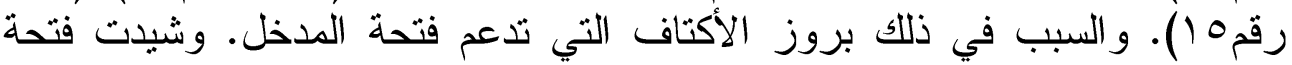

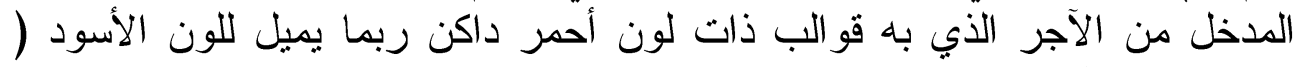

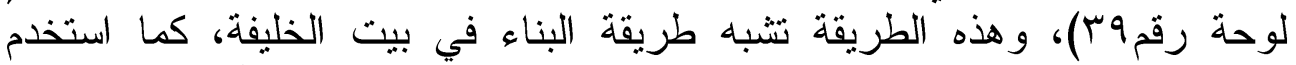

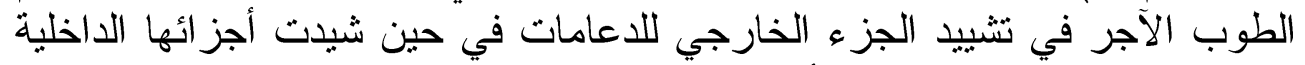

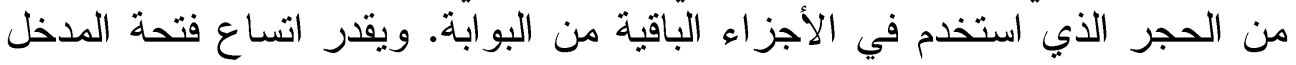

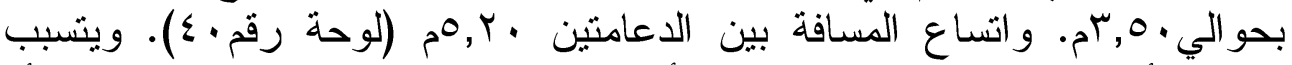

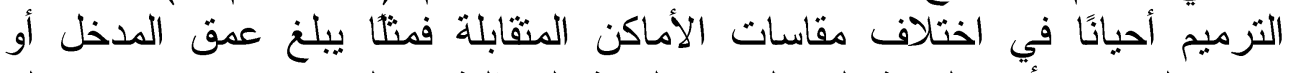

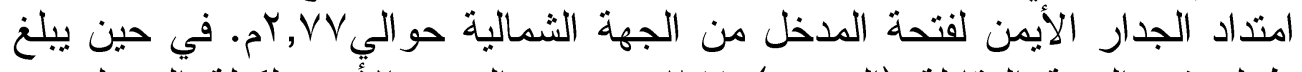

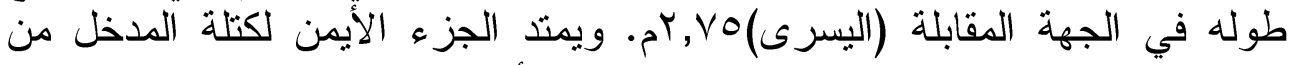

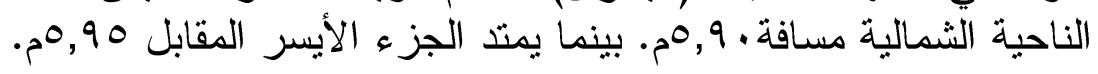

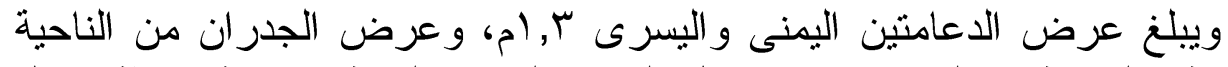

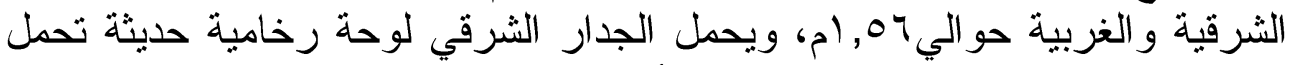

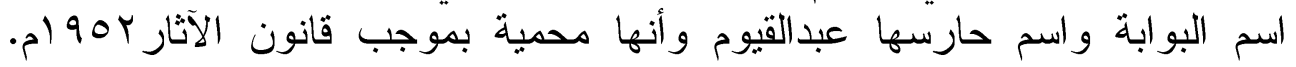

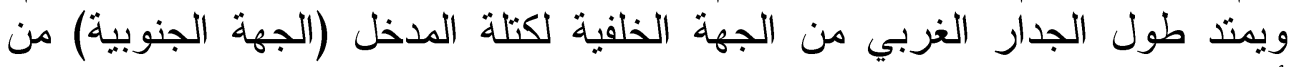

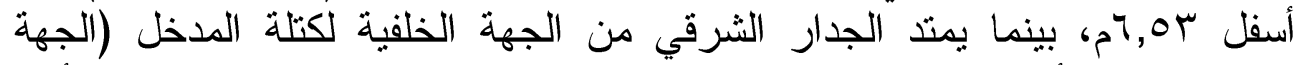

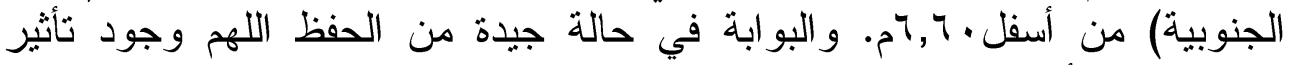

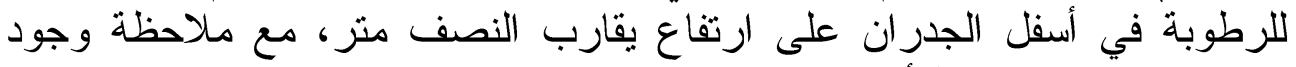
تجويف ناتج عن سقوط أحجار في نهاية الو اجهة الجنوبية من الناحية النية الغربية.

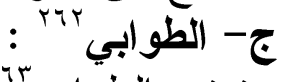

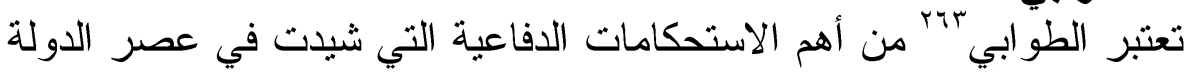

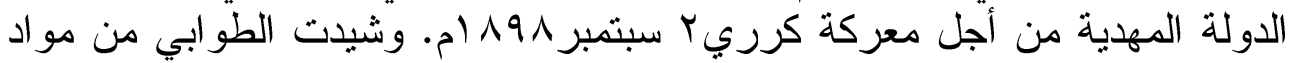
بناء غاية في البساطة، ومتوفر غالبيتها في التربة المحيطة بكل طابية، وهي التراب ابن

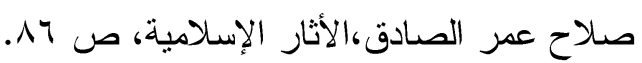

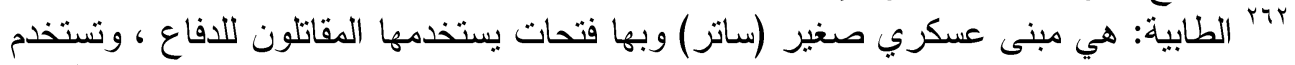

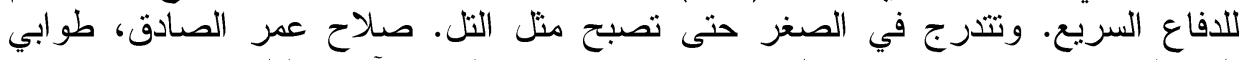

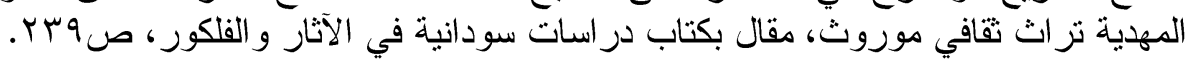

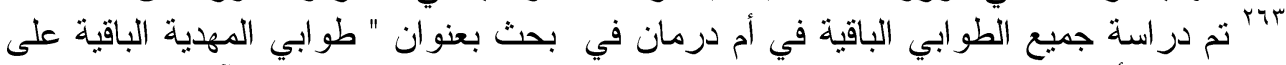

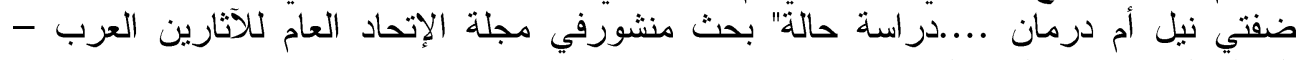

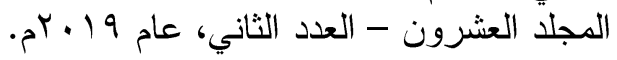




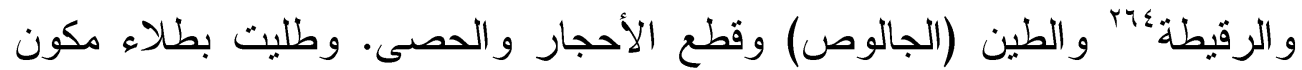
من الطين والقش و الرقيطة وروث المواشي، وهو طلاء يمتاز بصلابنه ومقاومته لتسرب مياه الأمطار .

شيدت الطوابي إما مستديرة و إما طولية، وتتكون الأخيرة من جزء أوسط نصف مستدير أو حدوي يلتقي في نهايته بجناحين يمتذ أحدهما يمينًا و الآخر يسارًا.

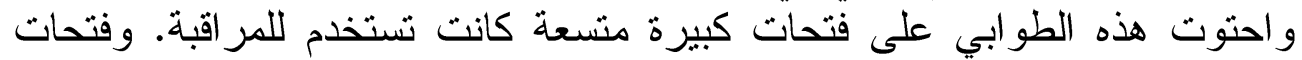

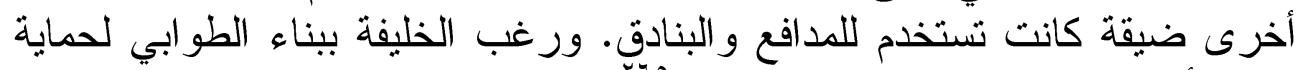

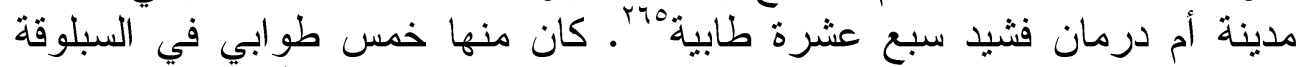

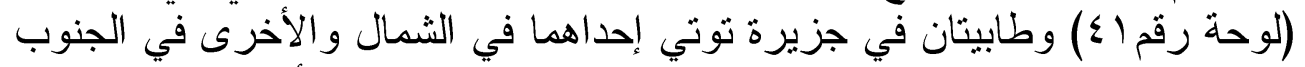

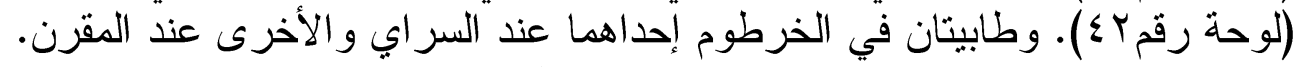

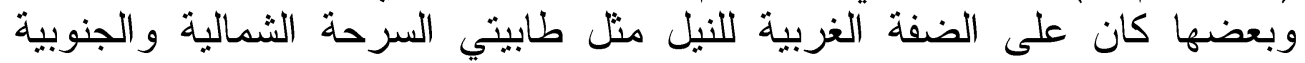

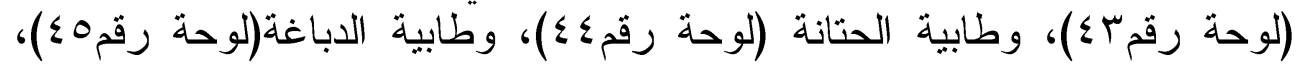

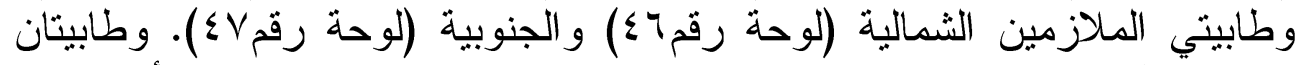

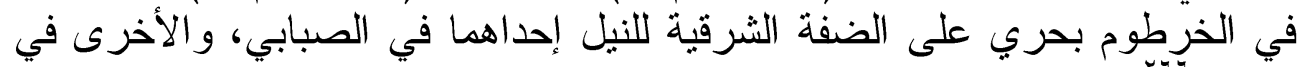

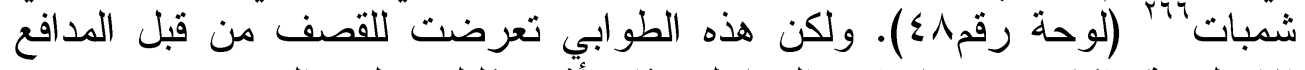

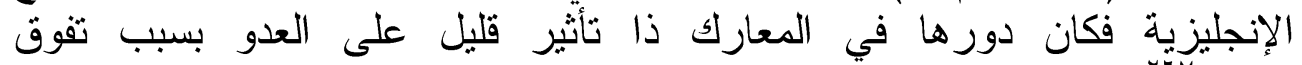

$$
\text { أ-بيث الأمانة (الترسانة الحكومية : }
$$

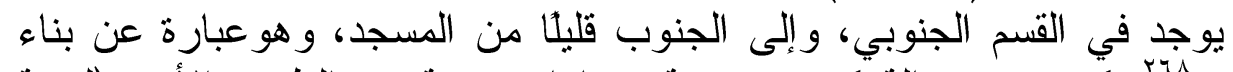

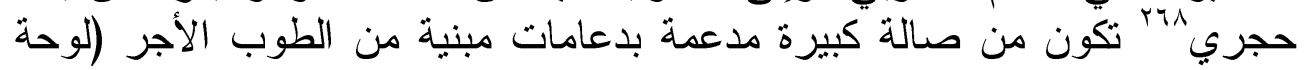

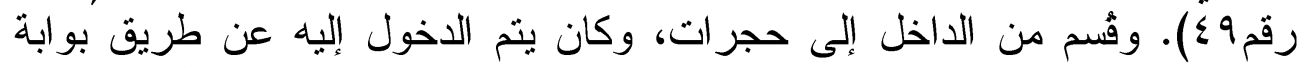

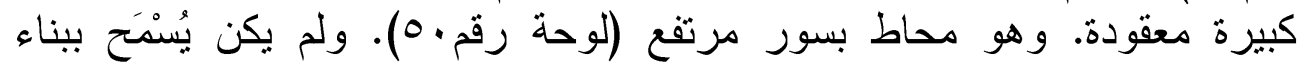

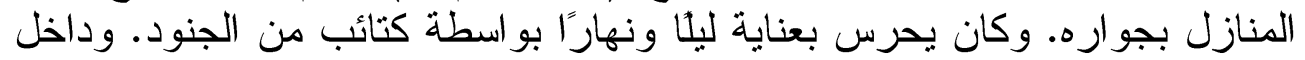

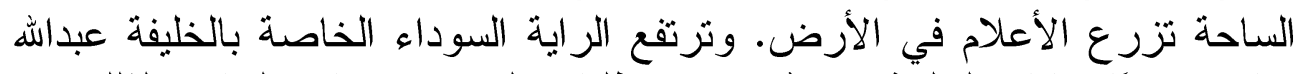

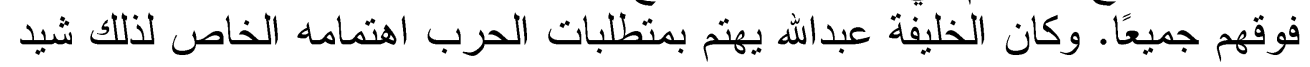

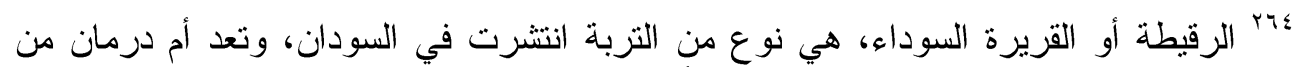

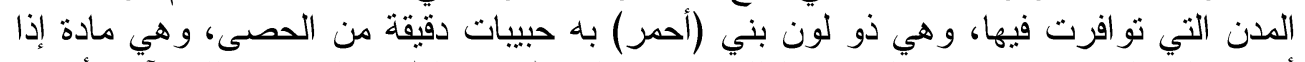

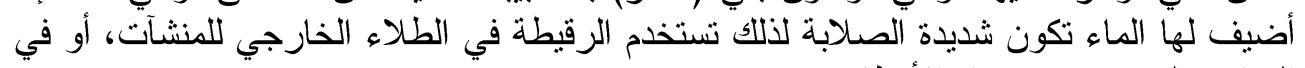

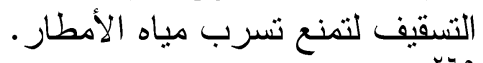
roro

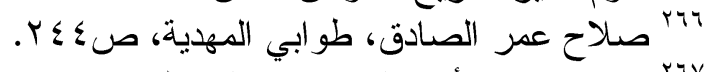

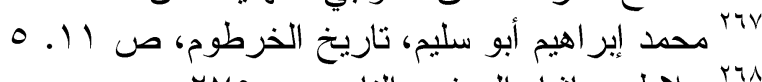

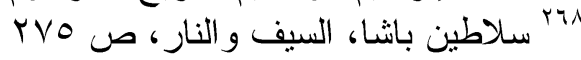




\section{الماملامح العمرانية والمعمارية لمدينة أم درمان الأثرية}

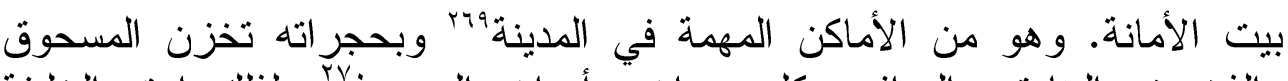

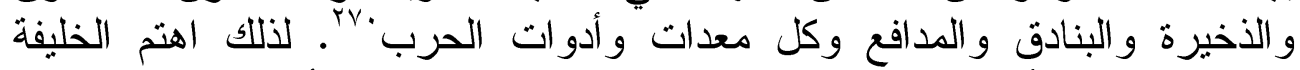

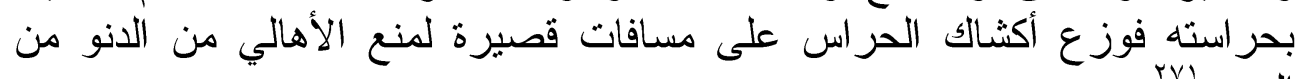

وهو مبنى مستطيل الشكل، شيدت جدرانه مرتفعة وسميكة شيدت من الحجر

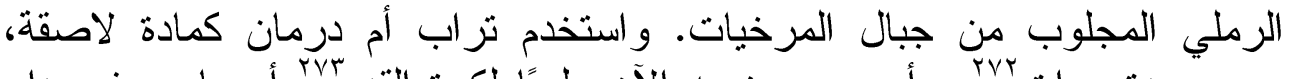

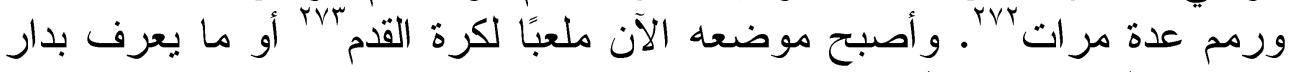

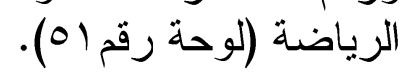

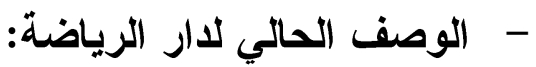
وتبقى من المبنى الأسوار الخارجية فقط. والئه وهو مستطيل ذو مساحة كبيرة (شكل

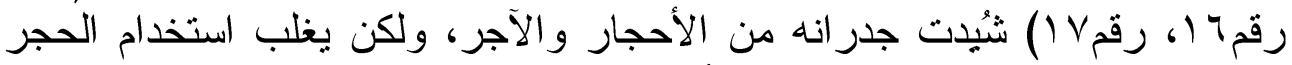

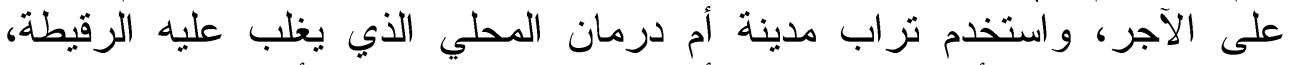

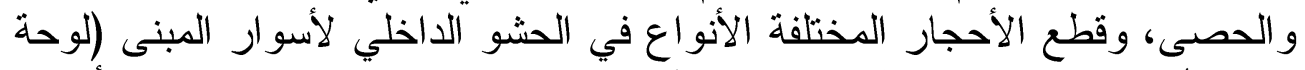

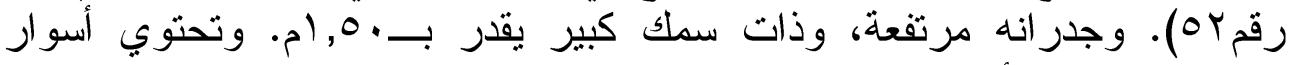

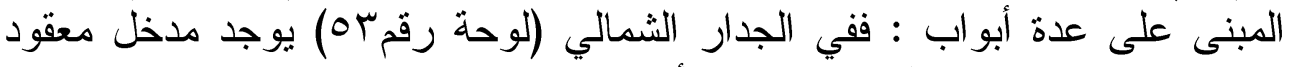

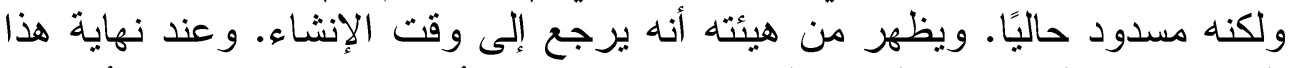

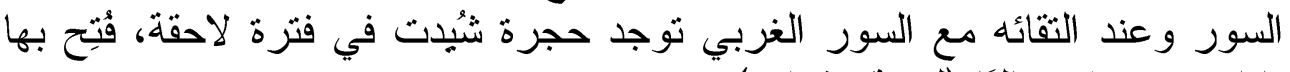
بابان مسدودان حاليًا (لوحة رعة رقمع م).

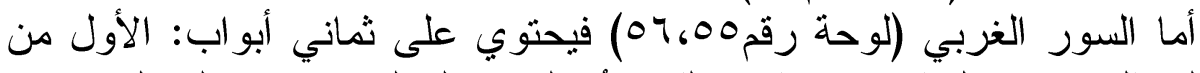

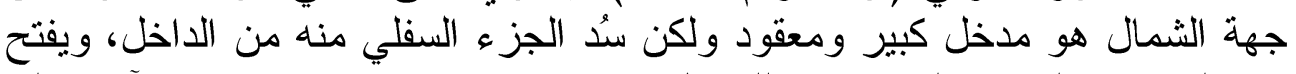

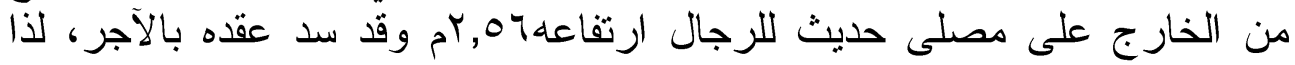

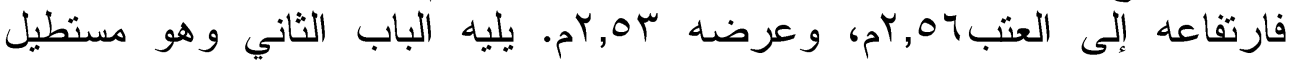

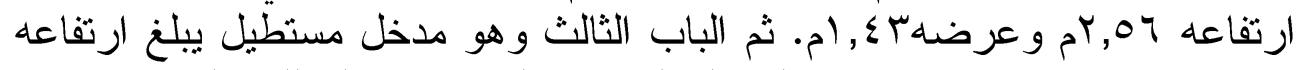

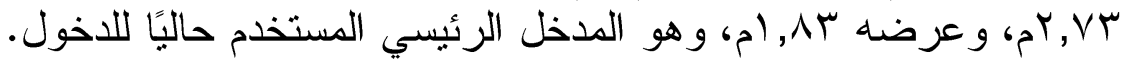

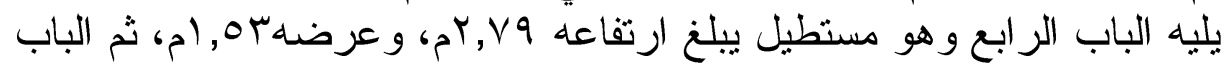

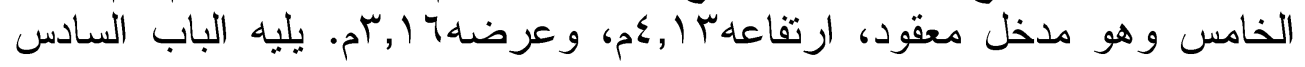

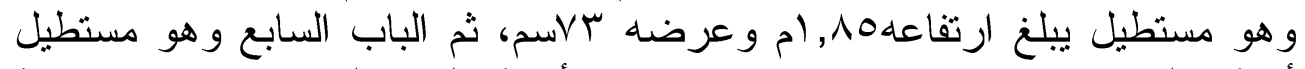

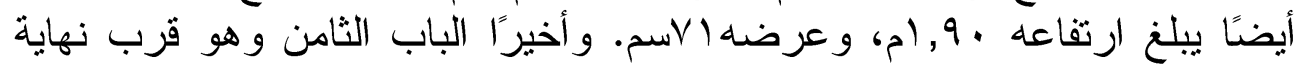

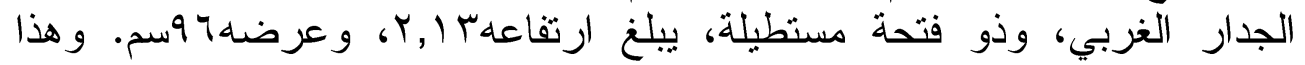

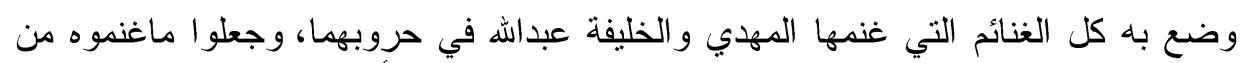

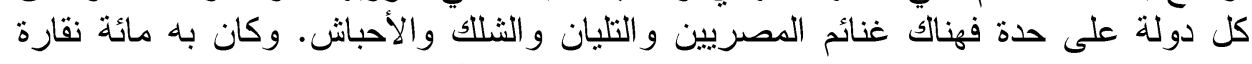

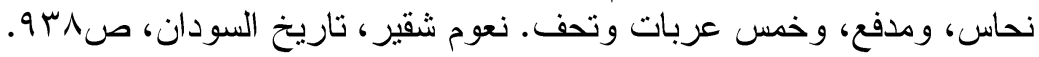
${ }^{270}$ Major F.R Wingate, Ten years, p.281.

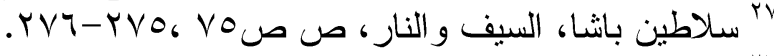

$$
\begin{aligned}
& \text { rVr }
\end{aligned}
$$

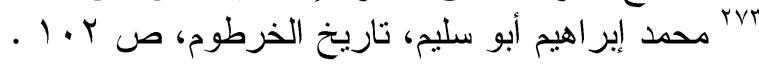


الباب يستخدم حاليًا لحر اس المبنى حيث يؤدي هذا الباب إلى إثغالات وحجرات

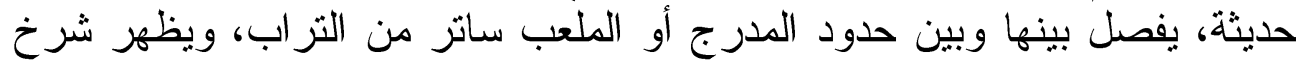

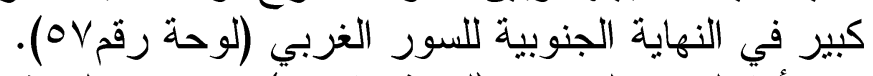

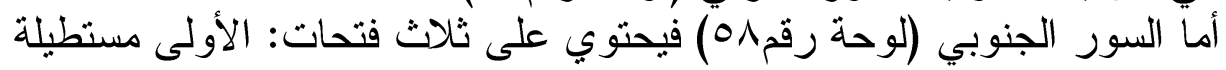

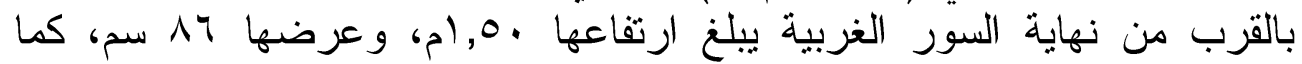

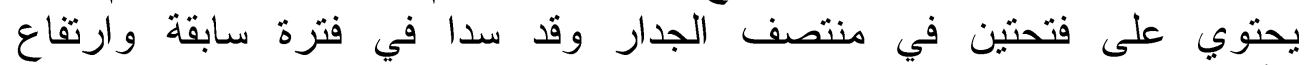

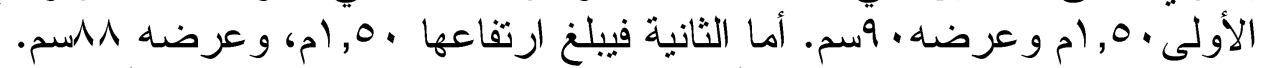

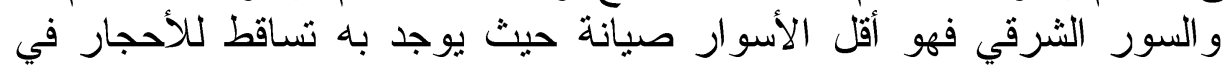
زاوية التقائه مع السور الجنوبي(لوحة رقمهوه) وكان لهذا التساقط فضل في معرفة

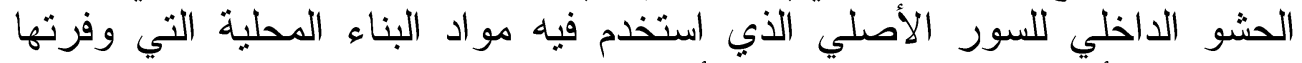

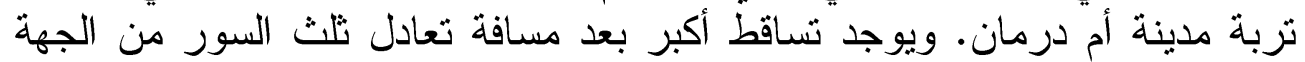

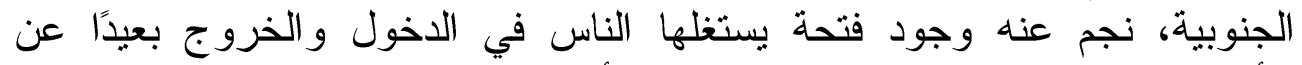

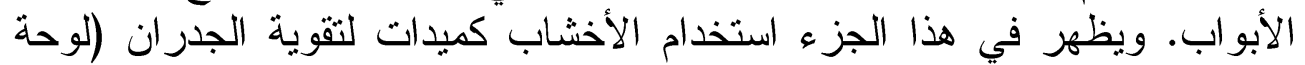

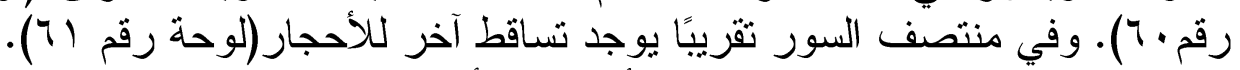

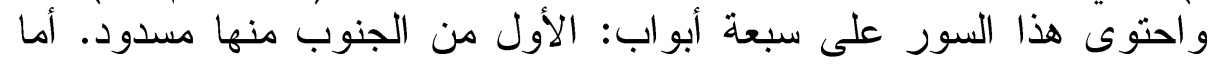

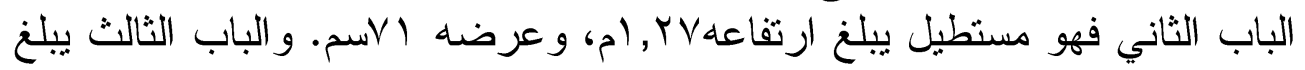

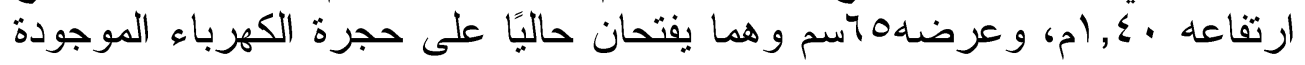

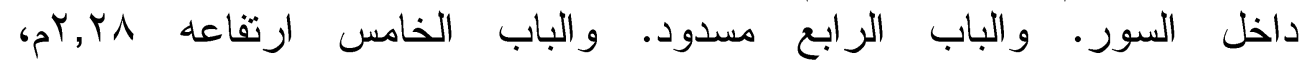

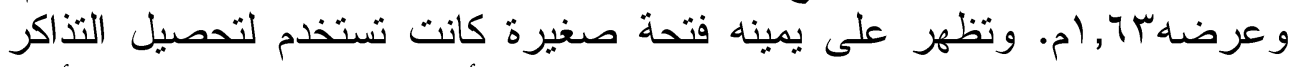

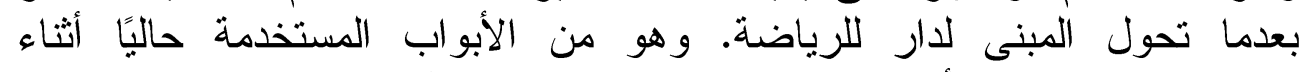

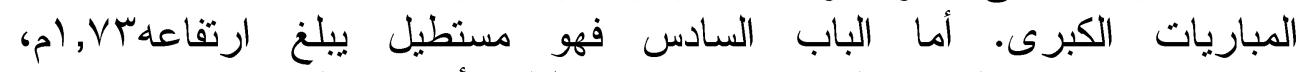

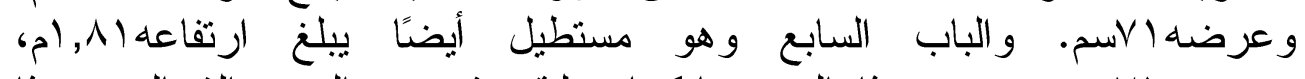

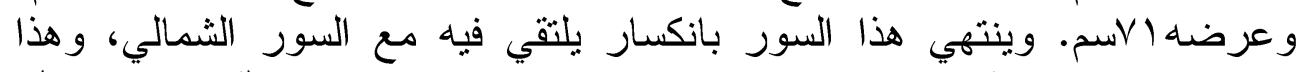

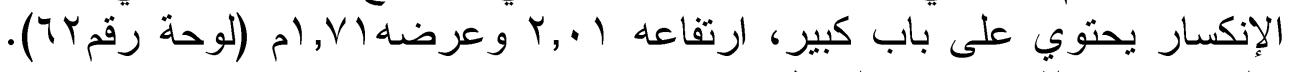

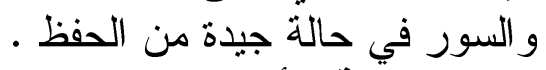

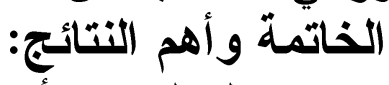

فضل المهدي تأسيس معسكره في أم درمان التي لا يفصلها النهر عن التمبن

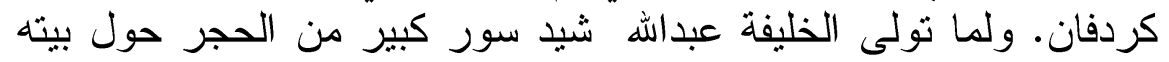

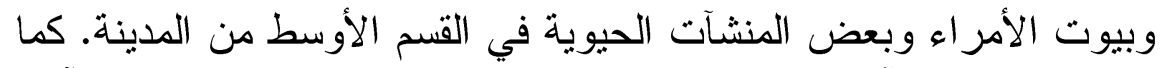
شيد الخليفة منشآت عديدة من دينية ومدنية وعسكرية واستخدم الآجر

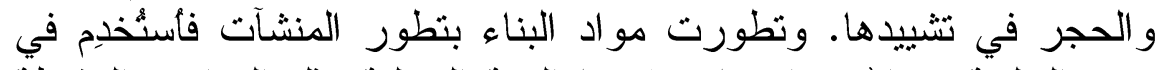

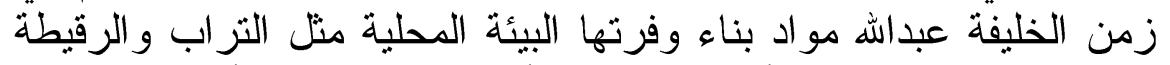

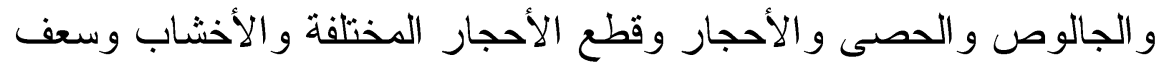
النخل. - الوصر

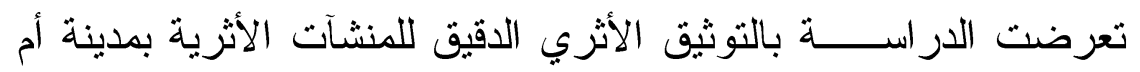

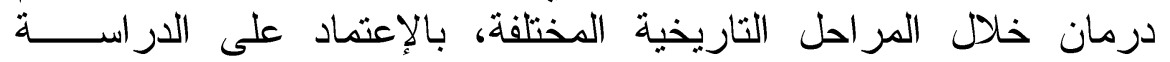




\section{الماملامح العمرانية والمعمارية لمدينة أم درمان الأثرية}

الآثارية، وأرشيف الصور القديمة، وأثثتت الدر اســـــة التعديلات المختلفة

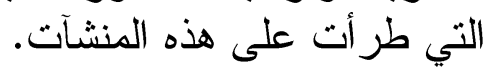

تحكمت الدو اعي الأمنية في اختيار المنات موضع مدينة أم درمان كمكان يستقر فيه المهدي بجنوده.

جمعت المنشآت في المدينة بين التقاليد المحلية الموروثة، وبين المداثي الحداثة السائدة في ذلك العصر خار جات في القطر السوداني. هيدت أبو اب السور المحيط بقبة الإمام المهدي مرتفعة عن السور .

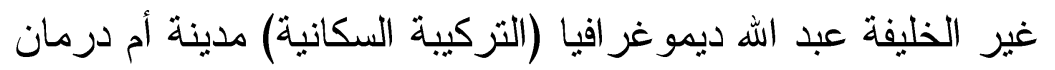
بتهجيزه للقبائل المناصرة لله عنوة. تبقى من قبة المهدي (الأصلية) التي شيدها الخليفة عبدالله جدران المربع السفلي.

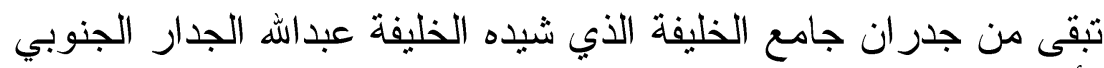
بأكمله و الجزء من الجنوبي الشرقي من السور الثرقي و الملاصق لبيت الخليفة. استطاع البناء توظيف مو اد البناء المتوفرة في المدينة كل حسب ملأئمته لوظيفة المبنى الذي شُئ بهـ. (التوصبات :

ثُوصي الدر اسة بالحفاظ على التراث الثقافي و المادي و المحلي للمدينة. تسجيل المنشآت الباقية فيها و العمل على العئ ادراجها في فائمة التزاث العالمي لليونسكو .

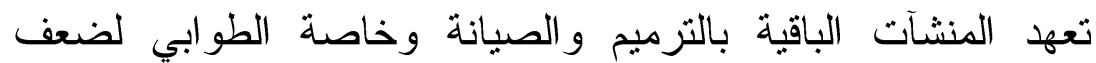

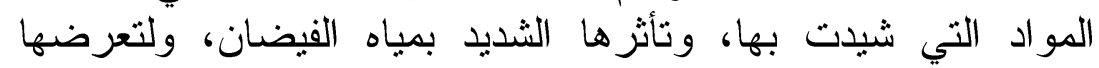
للزحف النباتي وللتعديات البشرية.

\section{قائمة المصادر و المر اجع :}

أولا المصادر : (1)

ا-إيراهيم فوزي باشا، كتاب السودان بين يدي غوردون وكتشنر،

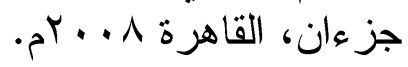
Y- إسماعيل عبدالقادر الكردفاني، سعادة المستهدي في سيرة الإنه الإمام

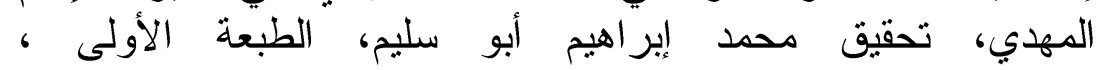

$$
\text { الخرطوم }
$$

ب-سلاطين باشا، السيف و النار في السودان، تعريب جريدة البلاغ،

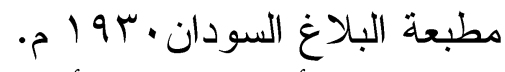
ع- عبدالمحمود أبو شامة، من أبا إلى تسلهابي حروب المهو حياة الإمام المهدي،

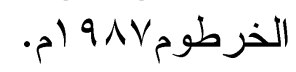


0-نعوم شقير، تاريخ السودان، تحقيق د محمد إبر اهيم أبوسليم، بيروت

$$
\text { ثانيا- المراجع العربية و المعربة: }
$$

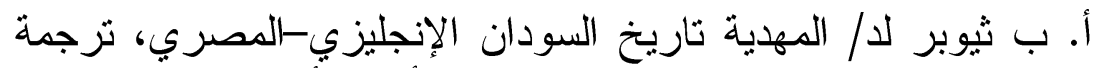

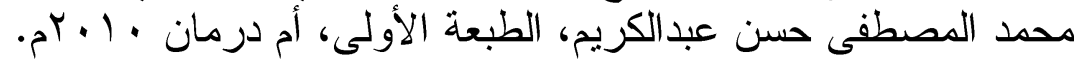

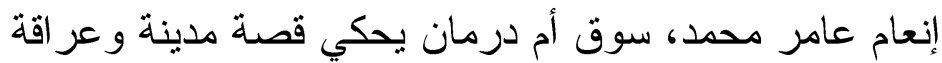

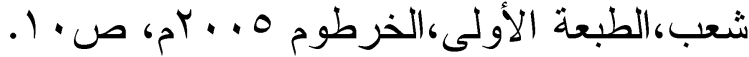

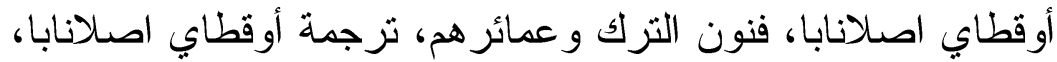

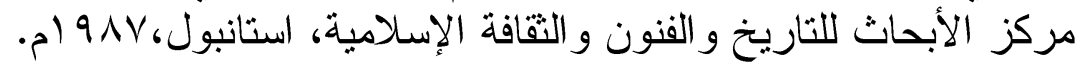

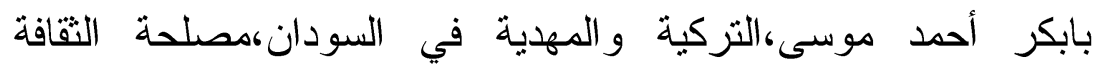
للطباعة و النشر كد.ت عوست التر

ب.م.هولت ،الدولة المهدية بالسودان،رجمة جميل جبه عبيد، دار الفكر

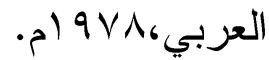

روبن نيلاند، حروب المهدية ،ترجمة عبدالقادر عبدالرحمن ، أبوظبي r...

ريتشارد هِل، معجم تز اجم أهل السودان،ترجمة سيف الدين عبدالحميد

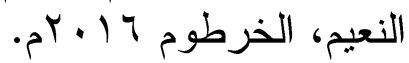

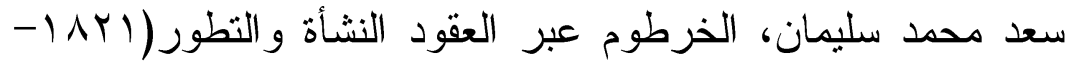

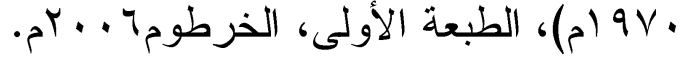

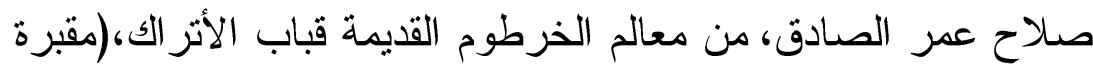

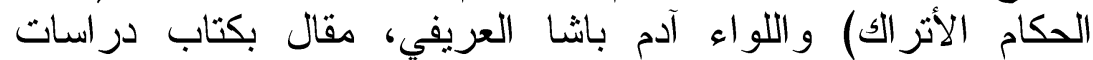

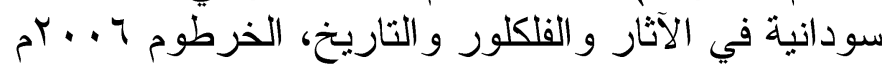

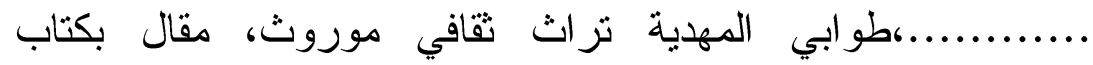

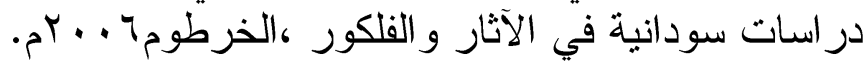

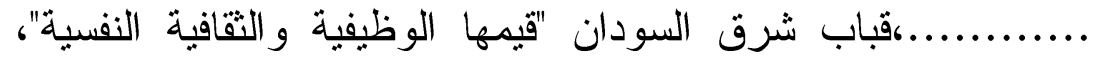

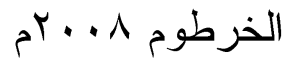

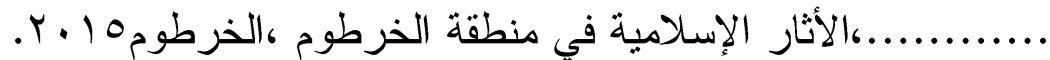
في معركائ...........

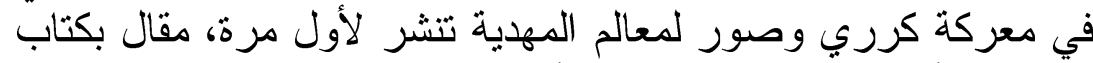

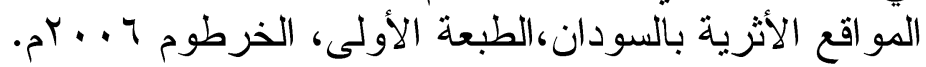

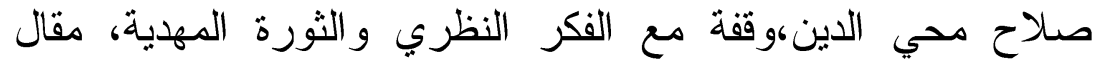

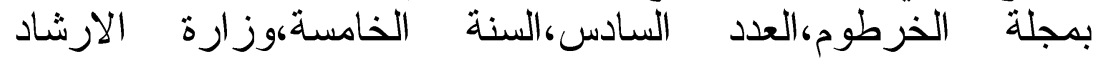

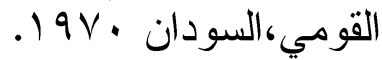

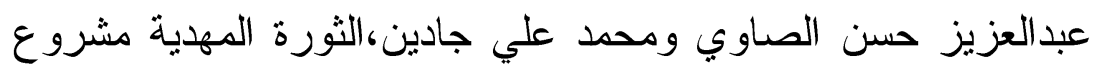

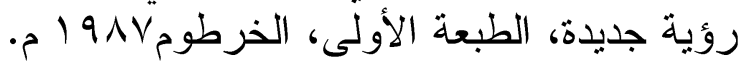




\section{الملامح العمرانية والمعمارية لمدينة أم درمان الأثرية}

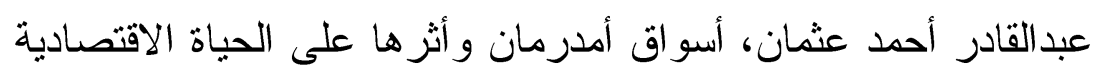

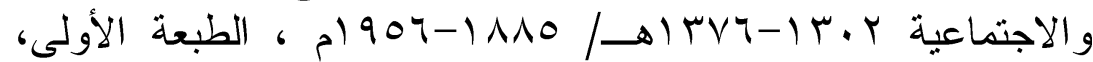

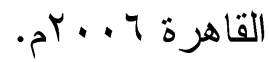

عبدالله حسن زروق، التصوف و أثره في المجنمع، الخرطوم 10 • بـ.

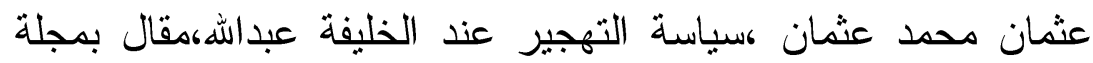

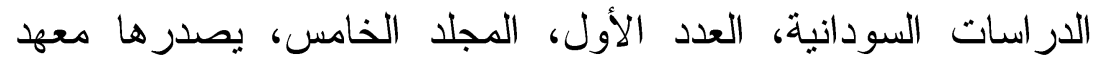

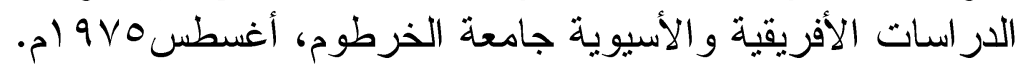

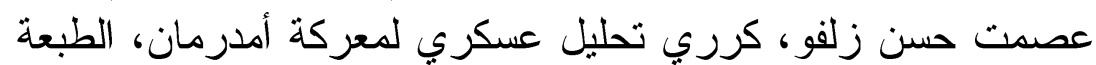

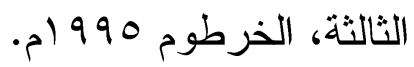
فيفيان أمينة ياجي، الخليفة عبداله حياته وسياسته، ترجمة مكي بشير مصطفى، الخرطوم 11 أ.

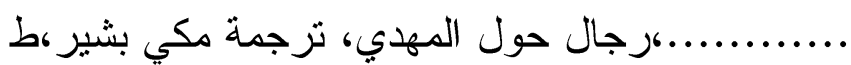

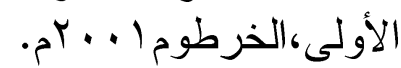

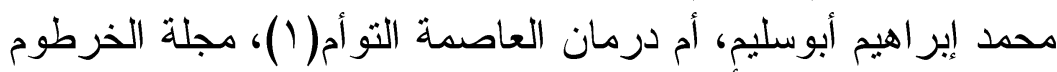

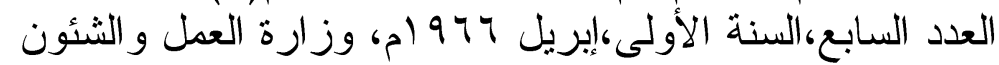

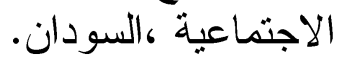

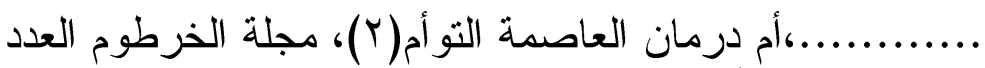

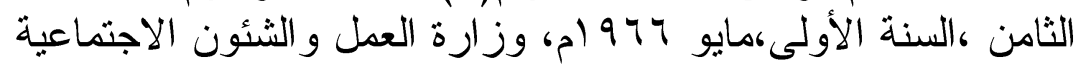
، السودان.

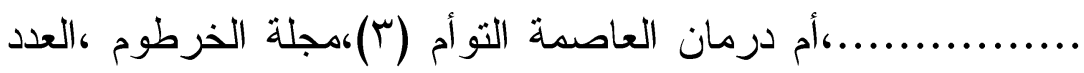

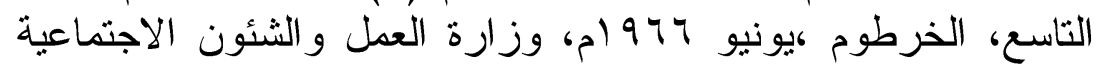
،السودان.

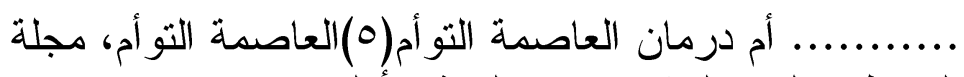

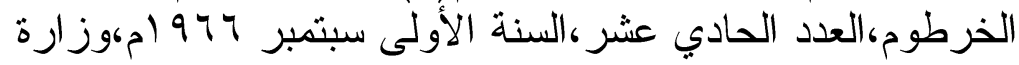

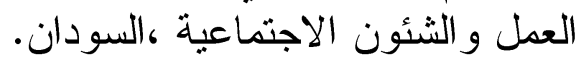

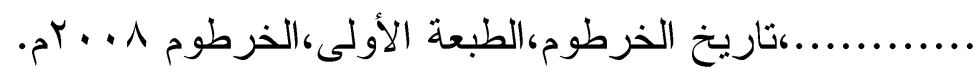

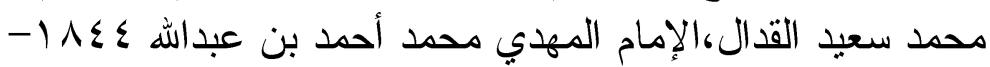

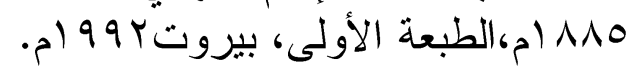

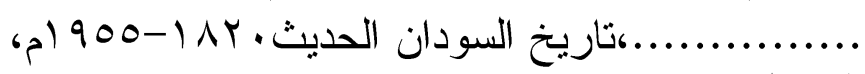

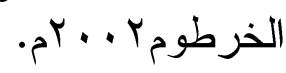
محمد ضو البيت مكي،التغيير الوظيفي لإستخدامات الأرض و الآثار

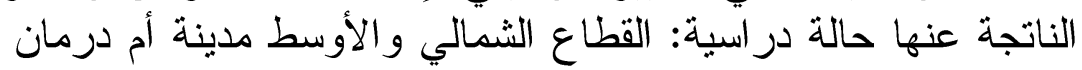

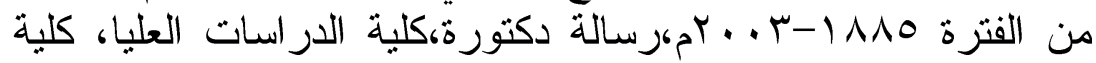

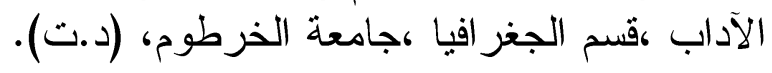




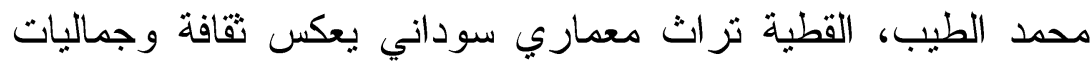

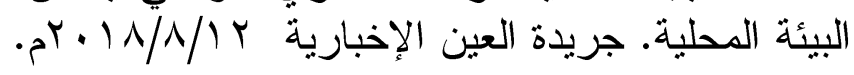

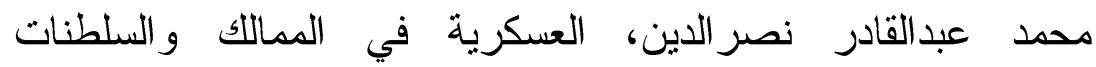

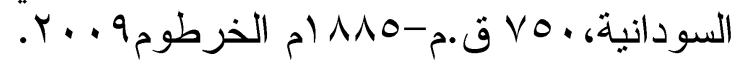

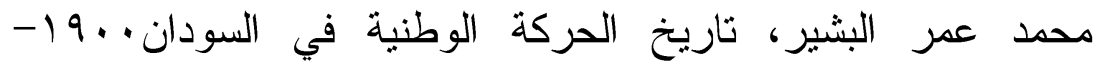

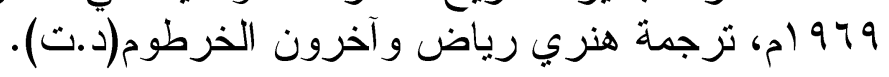

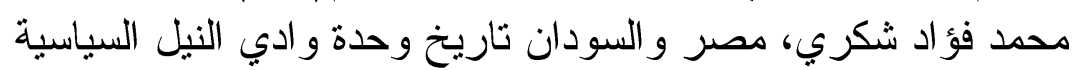

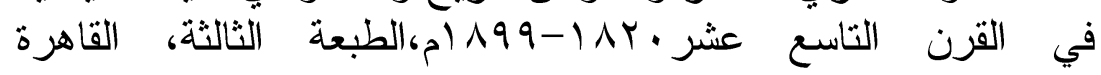

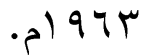

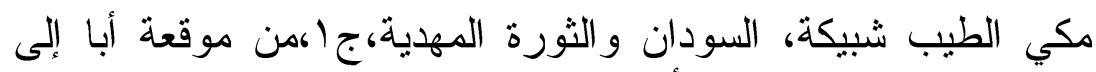

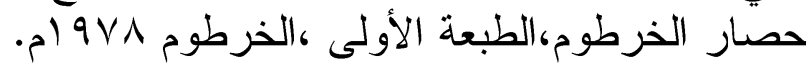

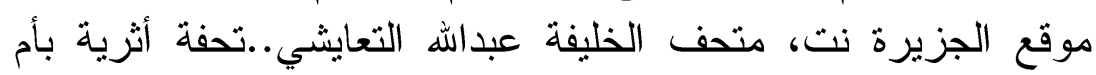

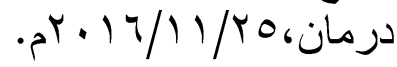

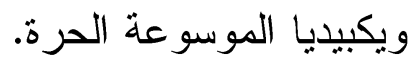

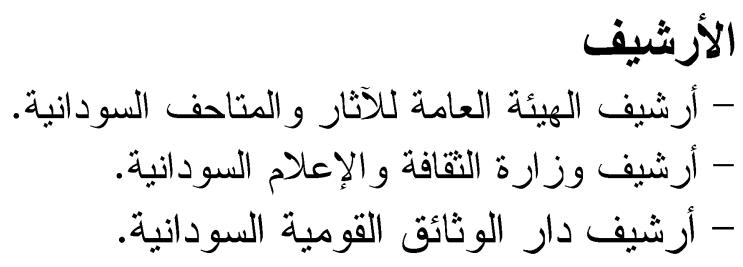

ثانيا المراجع الأجنبية :

- Hill, Richard. "Biographical, Dictionary of the AngloEgyptian Sudan." Oxford,1951.

- Hill, Richard." the Sudan memoirs of Carl Christian Giegier pasha", the British academy,1984.

- Holt, P. M. "a modern history of the Sudan from the Funj sultanate to the present day.", London,1963.

- Rehfisch, F. "a sketch of the early history of Omdurman." Sudan notes and records, no.45, vol, xlv,1964.

- Rehfisch, F."Omdurman during the Mahdiya", Sudan notes and recordes, no.48,vol, xlv111, 1967.

- Voll, John Obert." Historical dictionary of the Sudan." London, 1978.

- Steevens, G.W. "with Kitchener to Khartoum." twentysecond edition, New York, 1898. 
- Burleigh,Bennet. "Khartoum campaign 1898,or the reconquest of the Soudan", London, 1899.

- R.A Bermann, the Mahdi of Allah a drama of the Sudan,New York, 1932

- Wingate, F.R. Mahdiism and the Egyptian Sudan,second edition, London and Edinburgh,1968.

- Wingate, F.R. Ten years captivity in the Mahdi's camp 1882-1892 from the original manuscripts of father Joseph Ohrawalder, London, 1986.

- Reid, J.A. some notes on the Khalifa Abdullahi from contemporary Sudanese sources, Sudan notes and recordes,no.21,vol, xxi, 1938.

- Spencer,J. Trimingham ,Islam in the Sudan, London,1965.

- Compton, Piers. the last days of General Gordon,London, 1974.

- Archer, Thomas. the war in Egypt and the Sudan ,an episode in the history of the British empire, vol,2.London 1886.

- https:// Commons.wikimedia.org. 10/3/2017

\section{مراجع المواقع الإيكترونية :}

- https://www.wikimedia.org. 7/3/2017

- https://Sudaneseonline.com 17/4/2107

- http:// www.Anasudani.net 1/3/2017 


$$
\text { لوحات بحث مدينة أم درمان }
$$




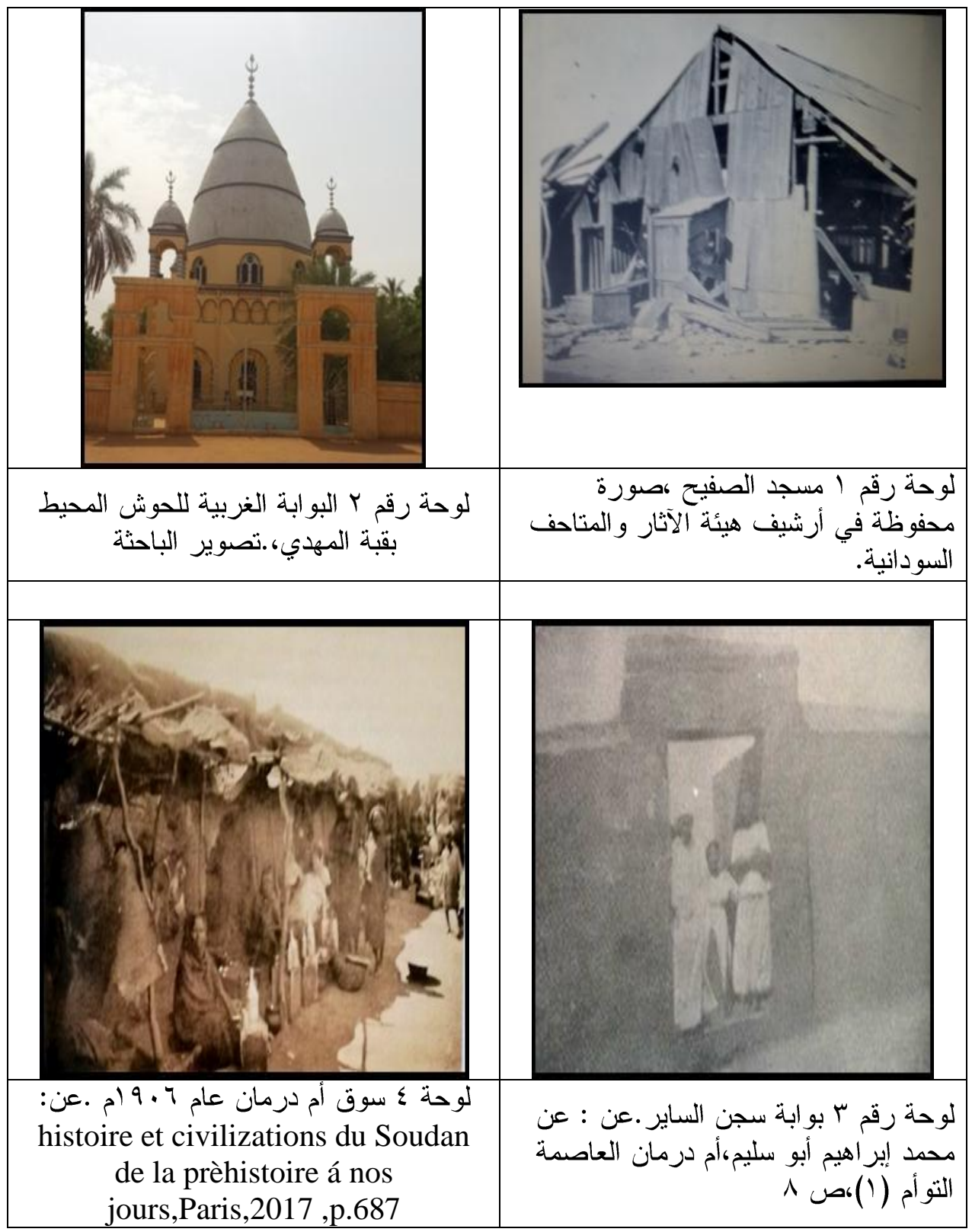




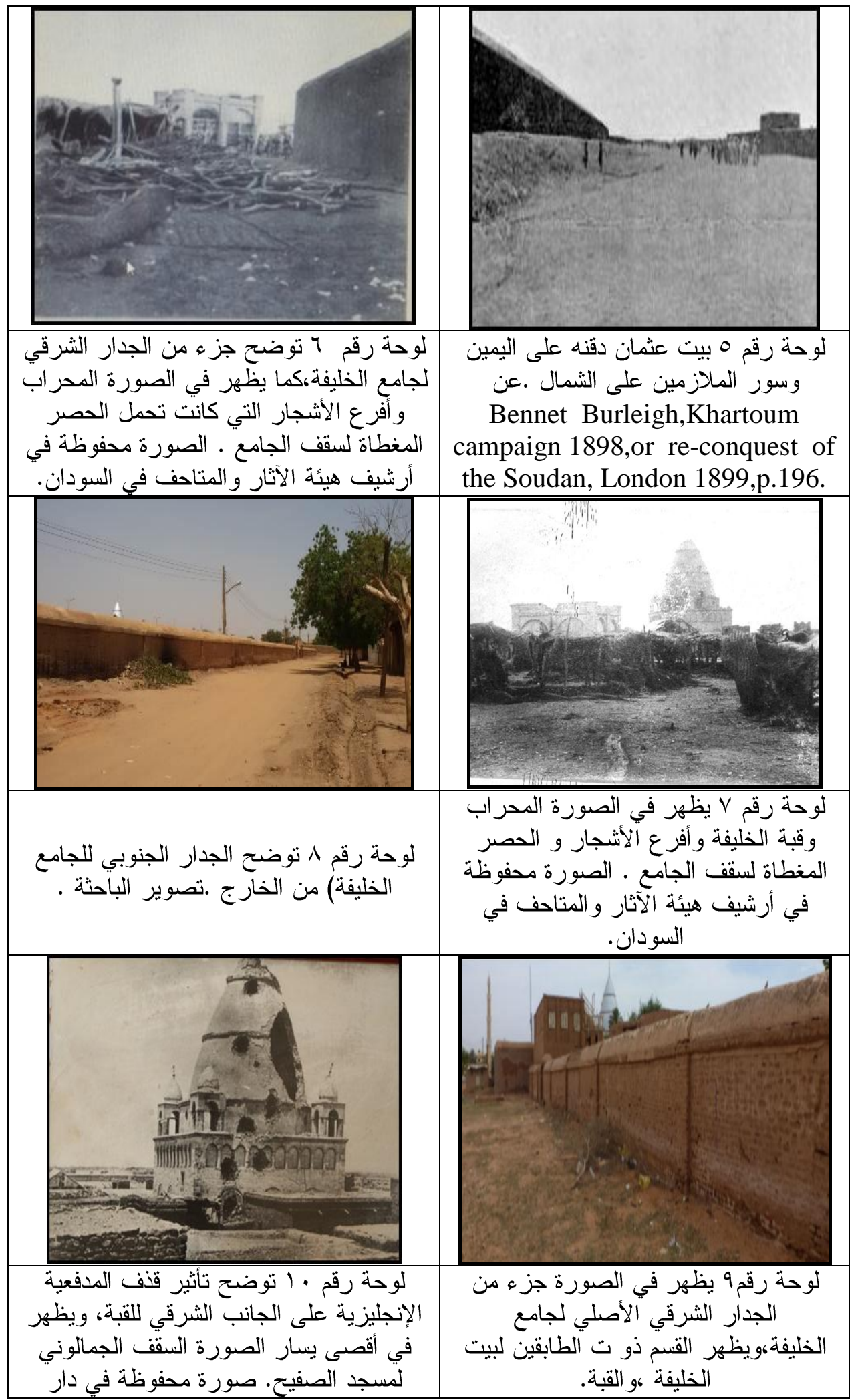




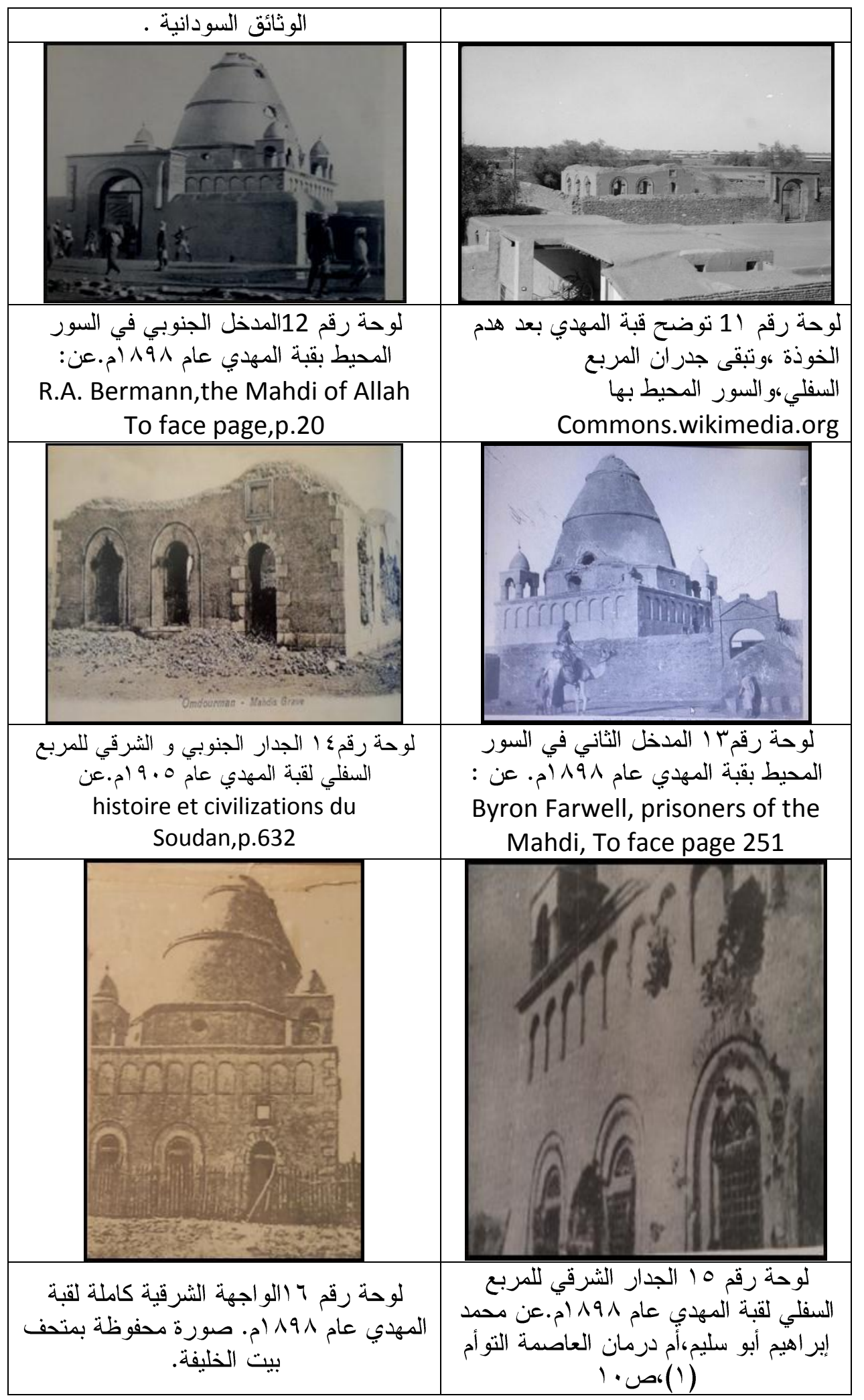




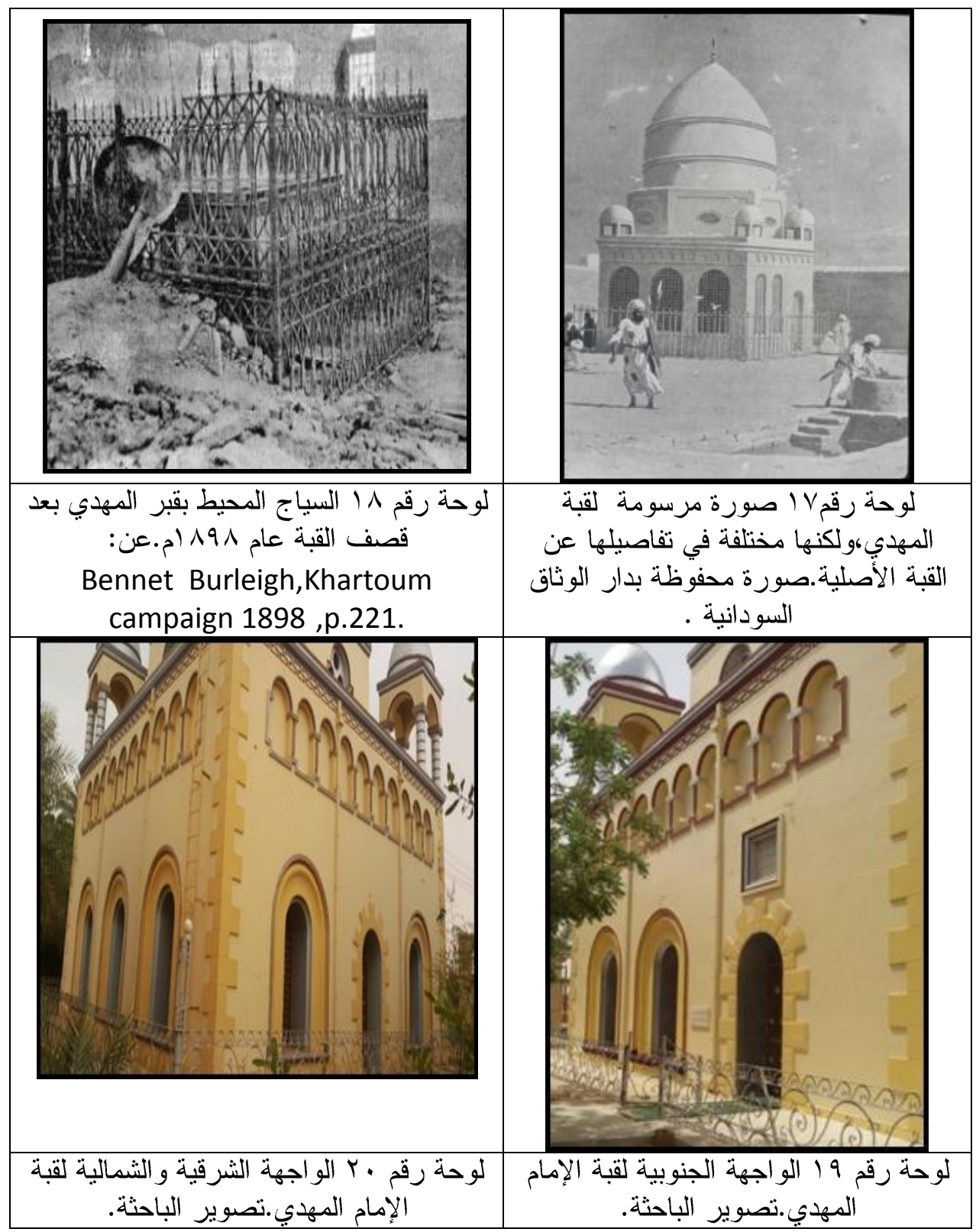


الملامح العمرانية والمعمارية لمدينة أم درمان الأثرية

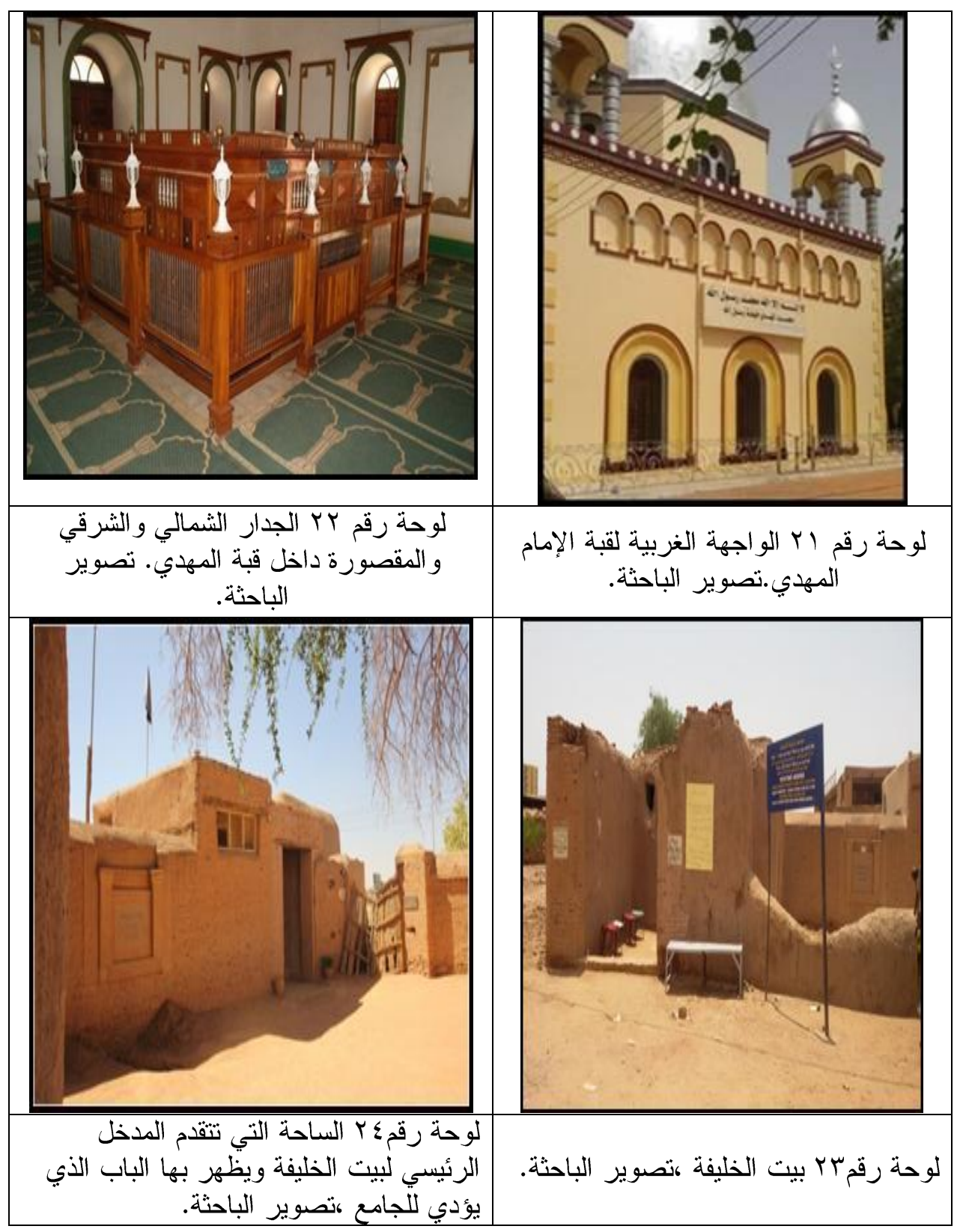




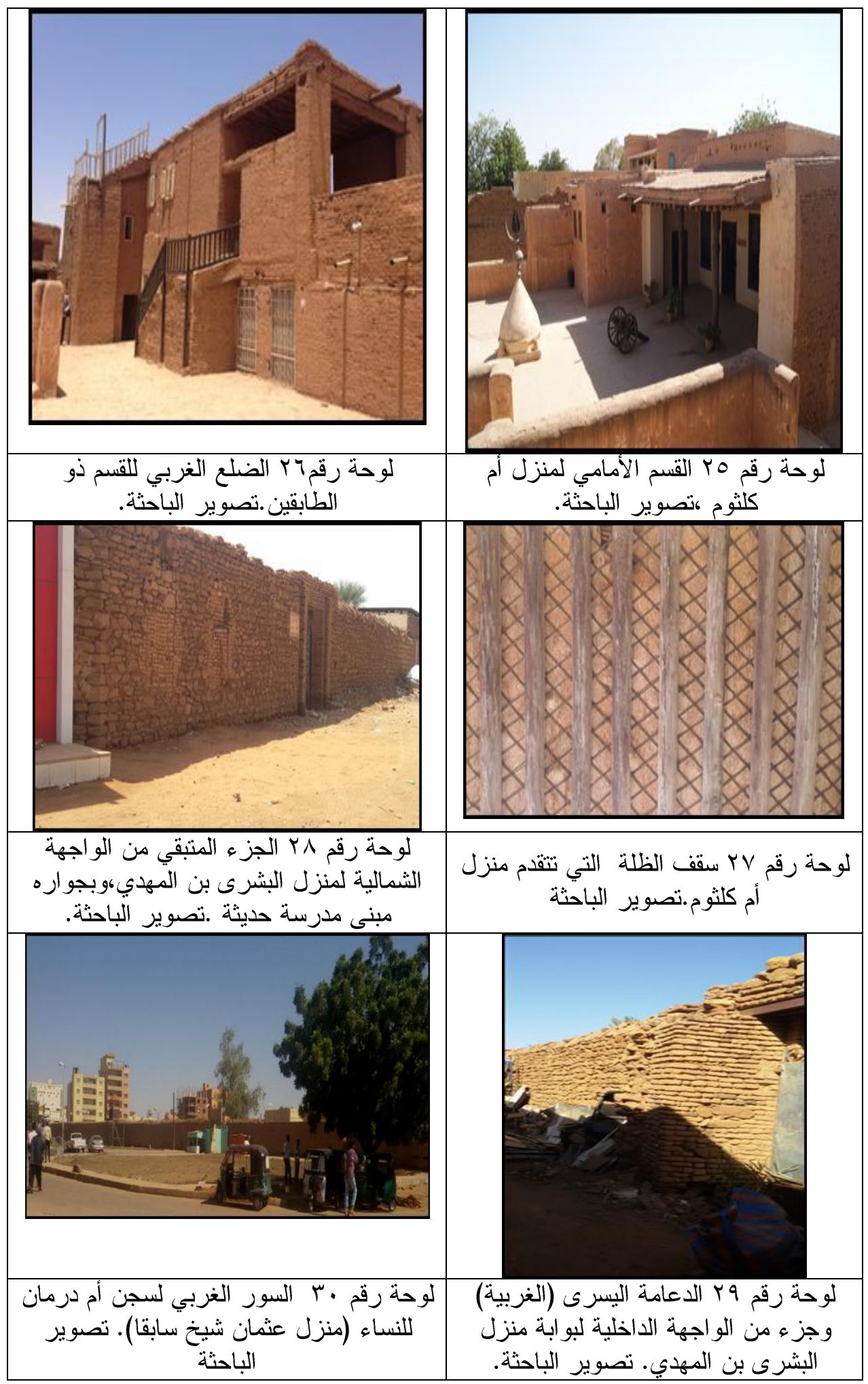




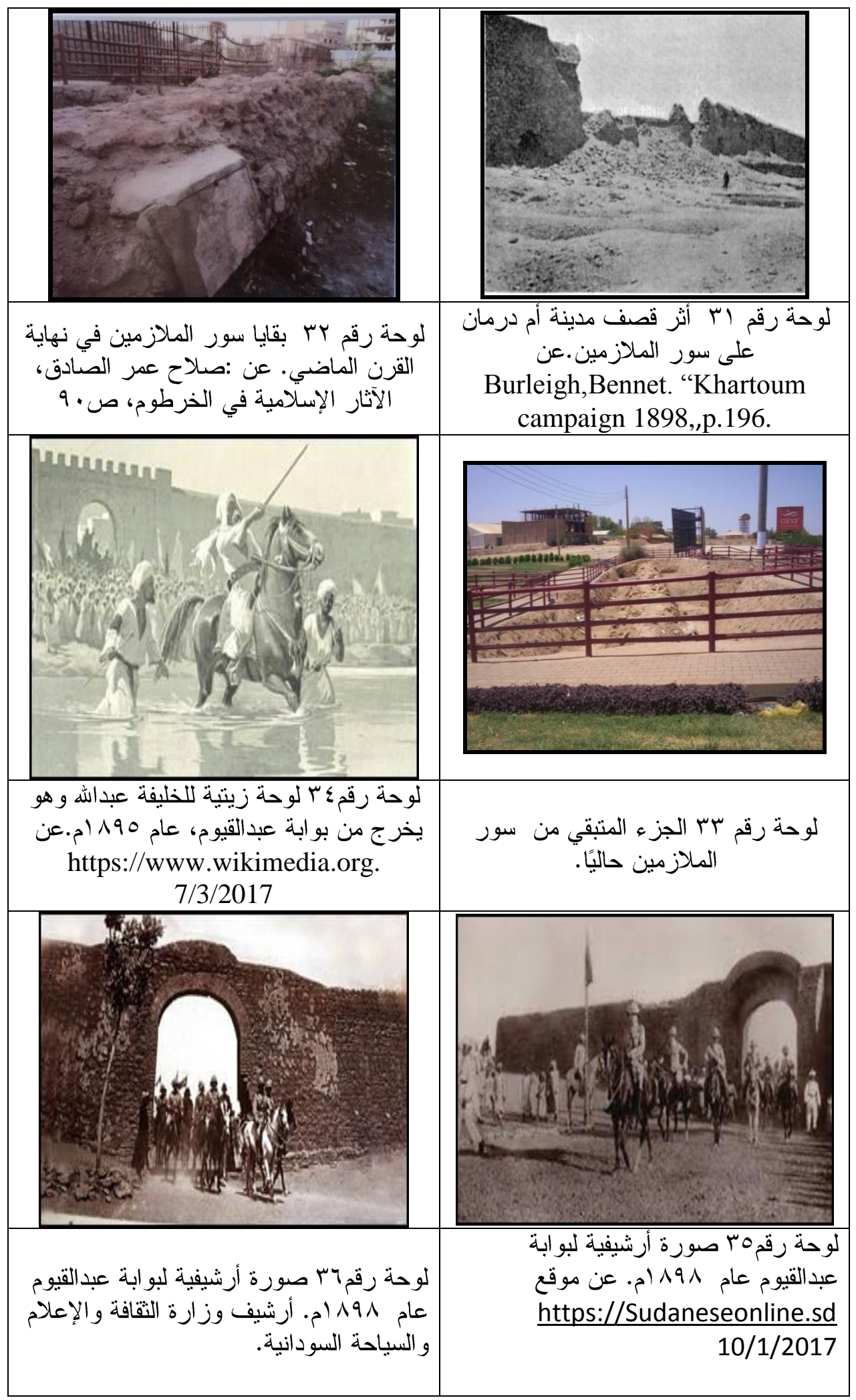


الملامح العمرانية والمعمارية لمدينة أم درمان الأثرية

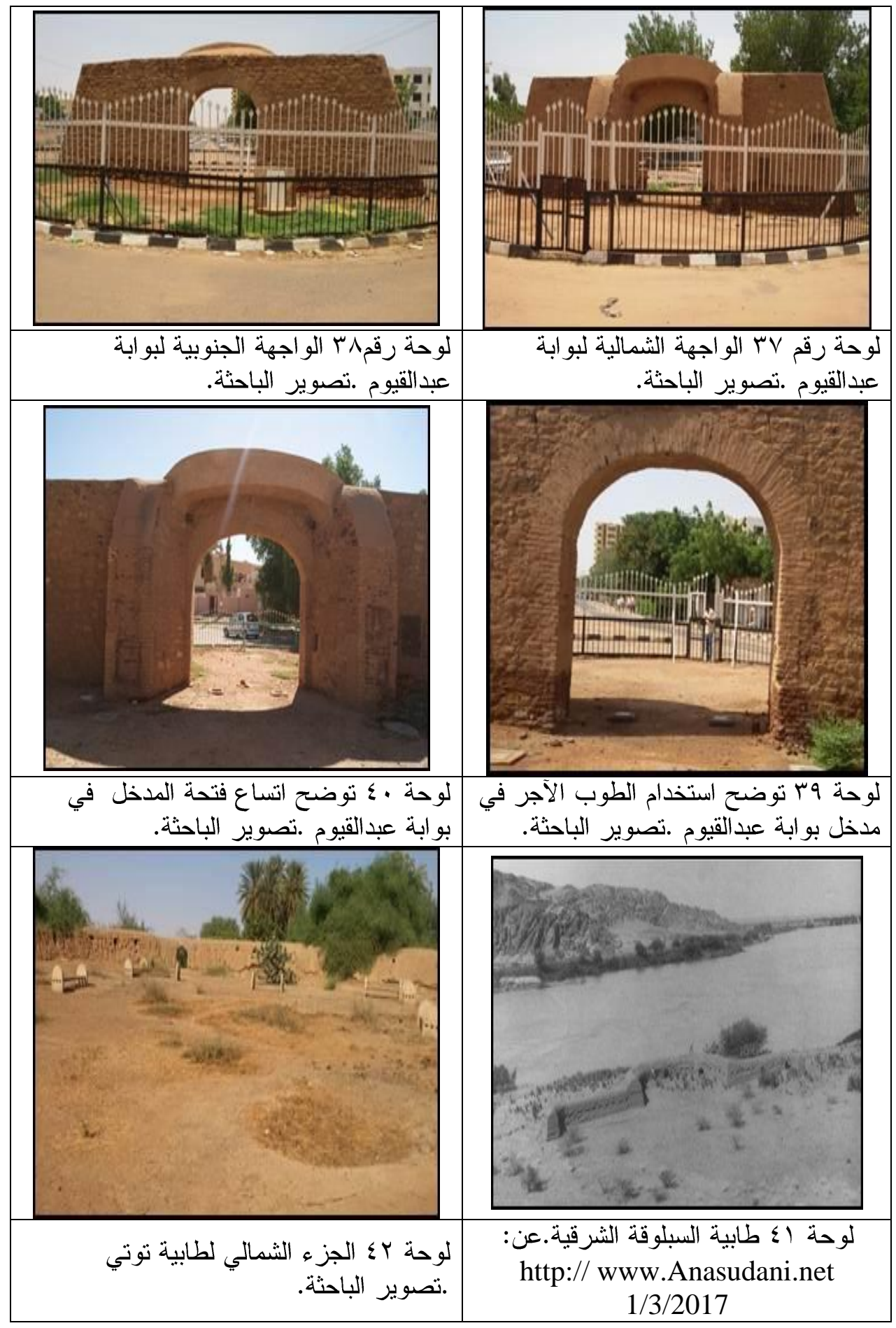


الملامح العمرانية والمعمارية لمدينة أم درمان الأثرية

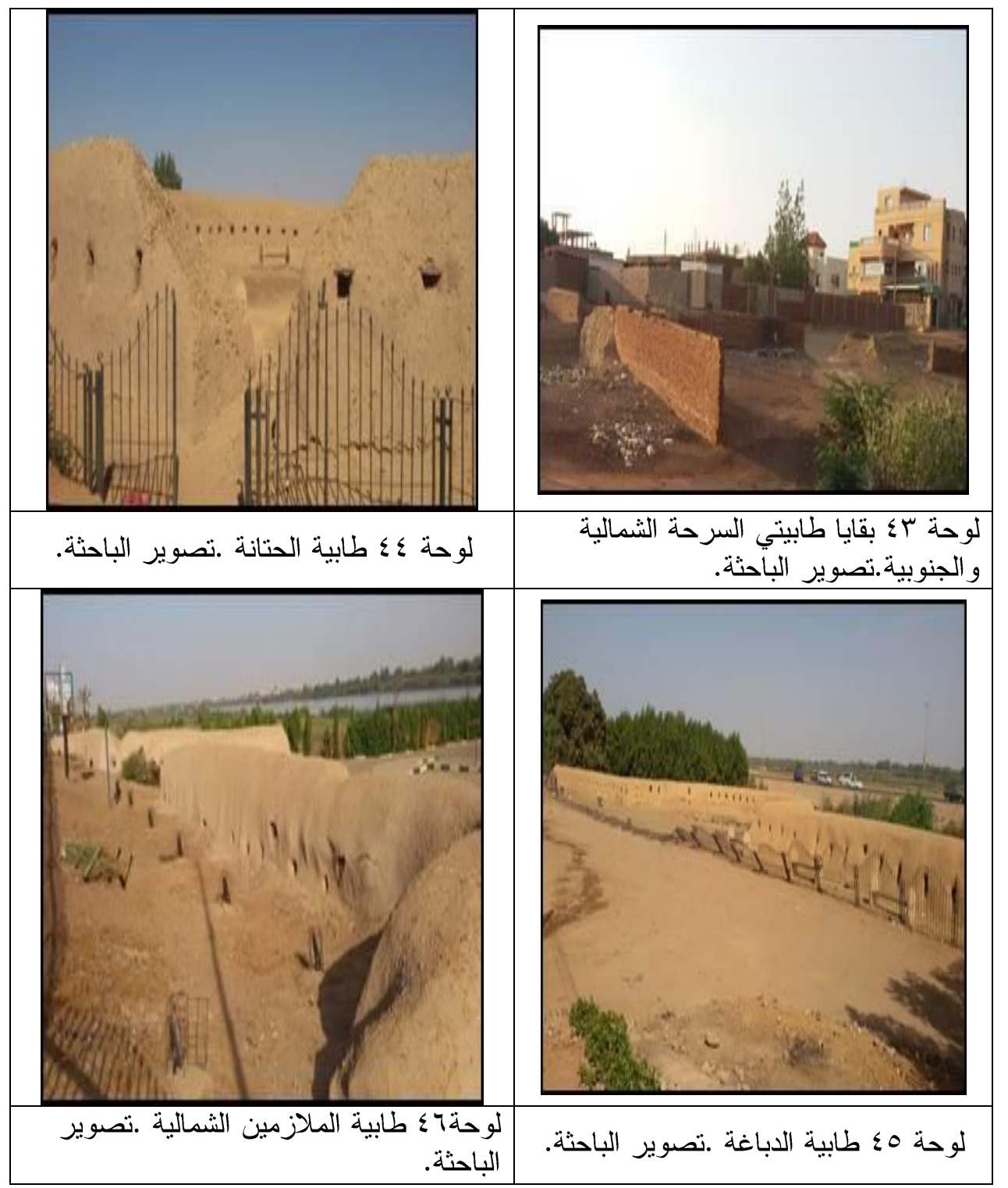




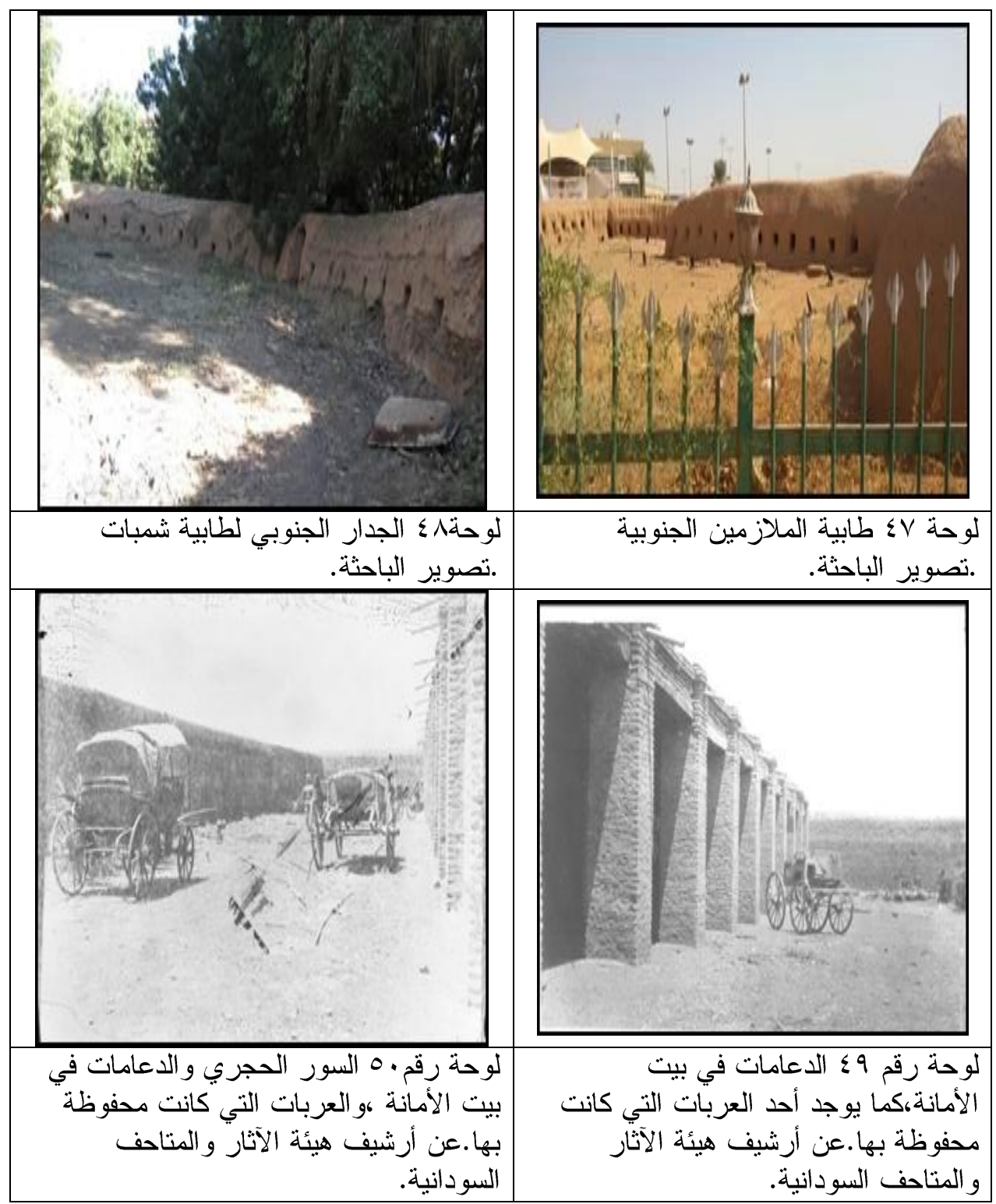


الملامح العمرانية والمعمارية لمدينة أم درمان الأثرية

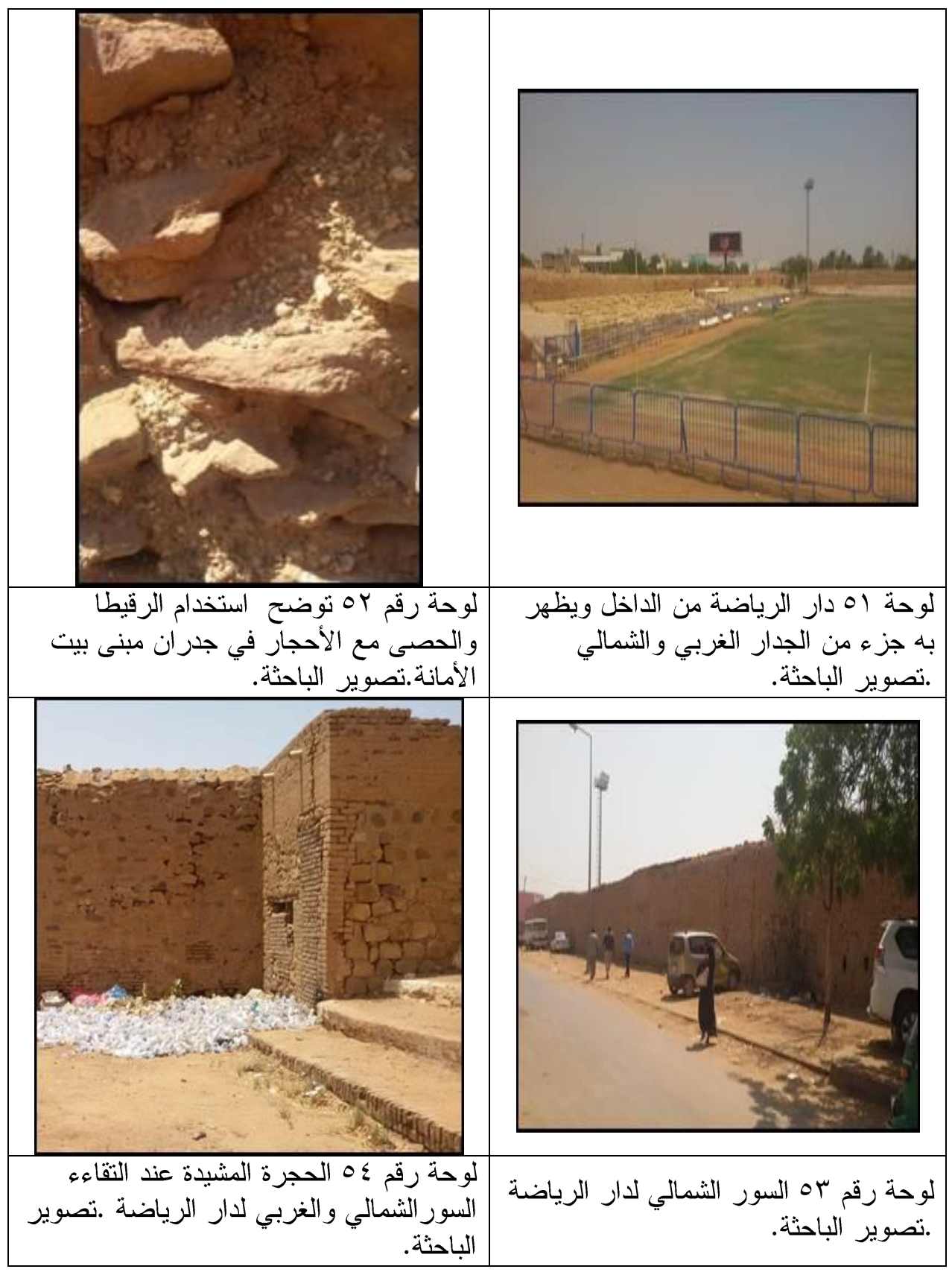




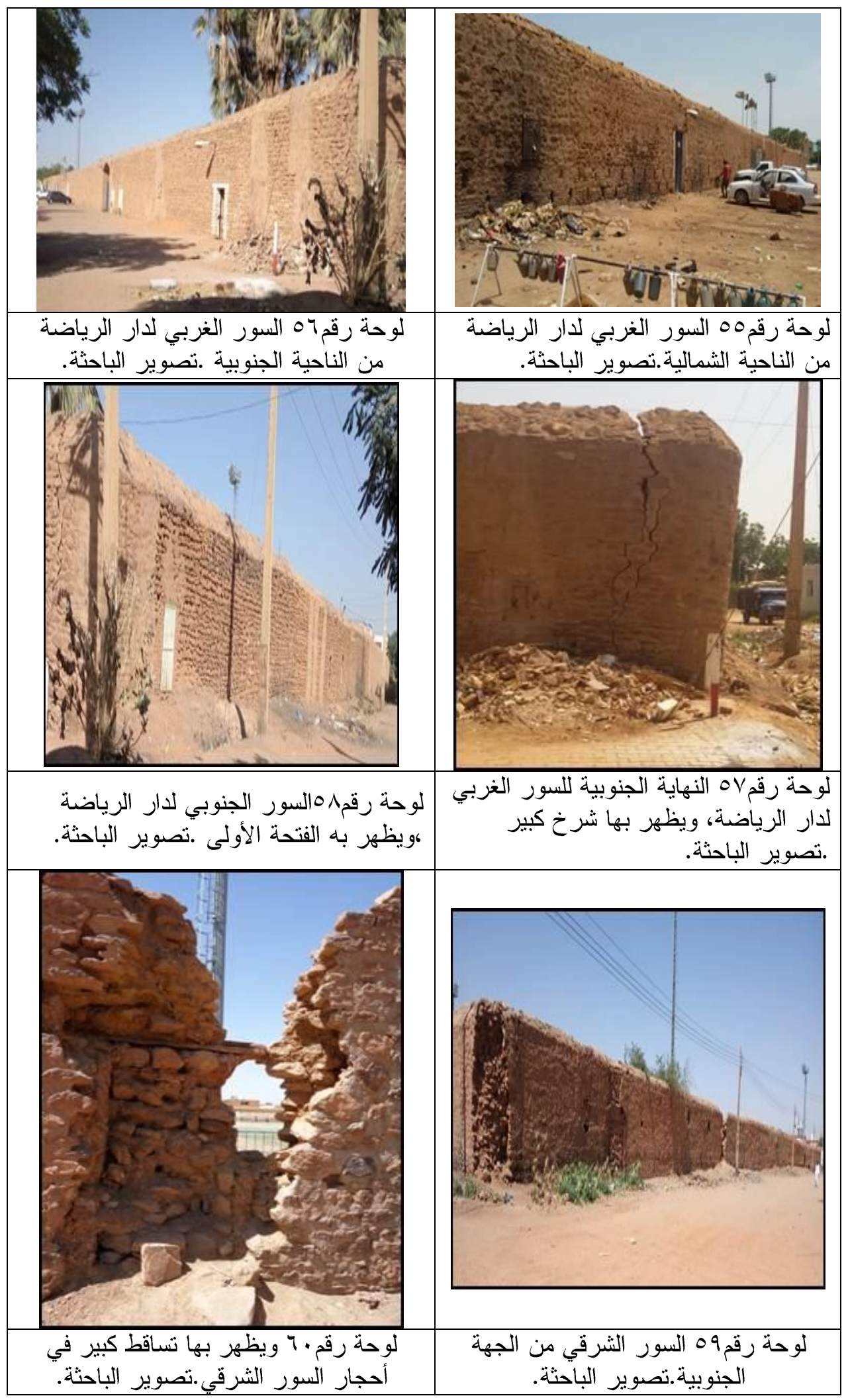




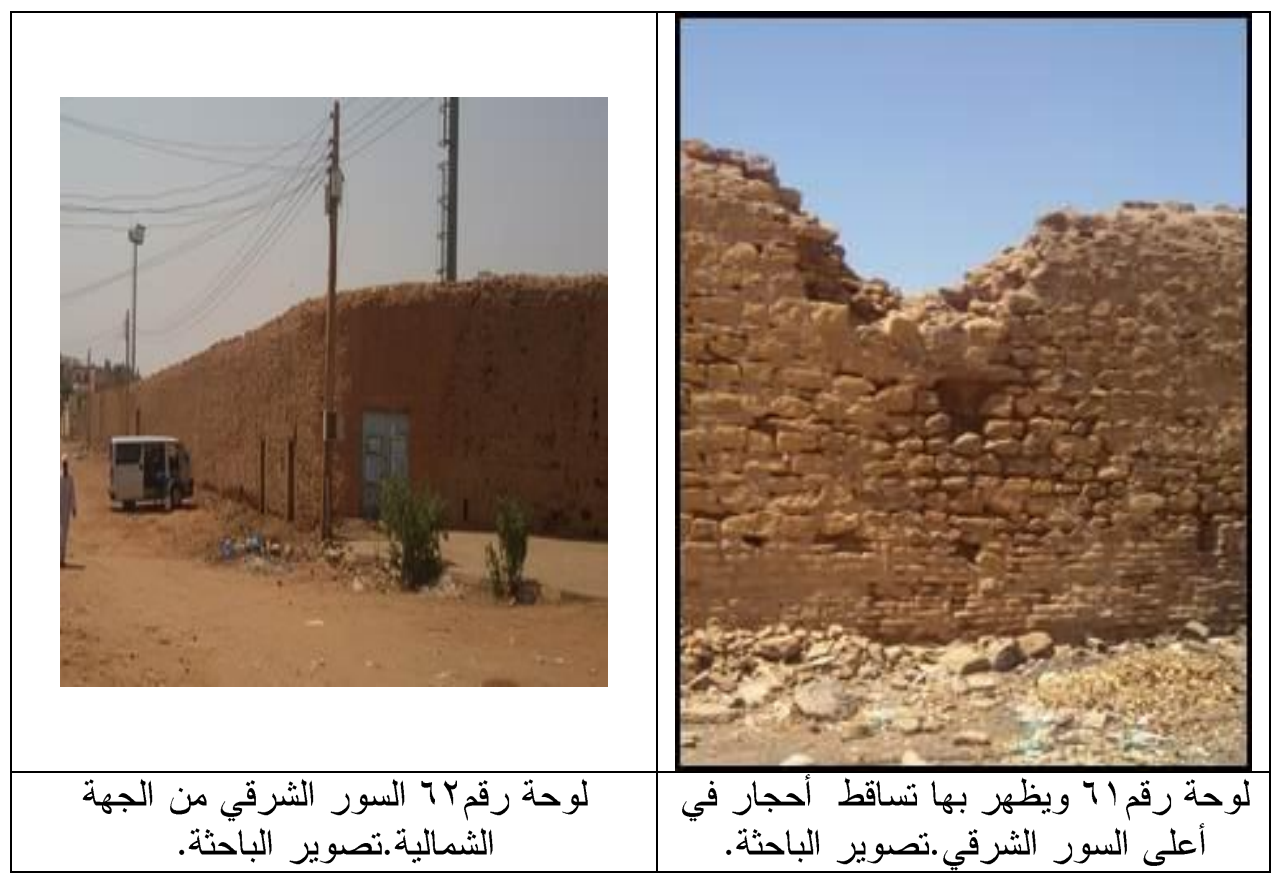

\section{أشكال بحث مدينة أم درمان}

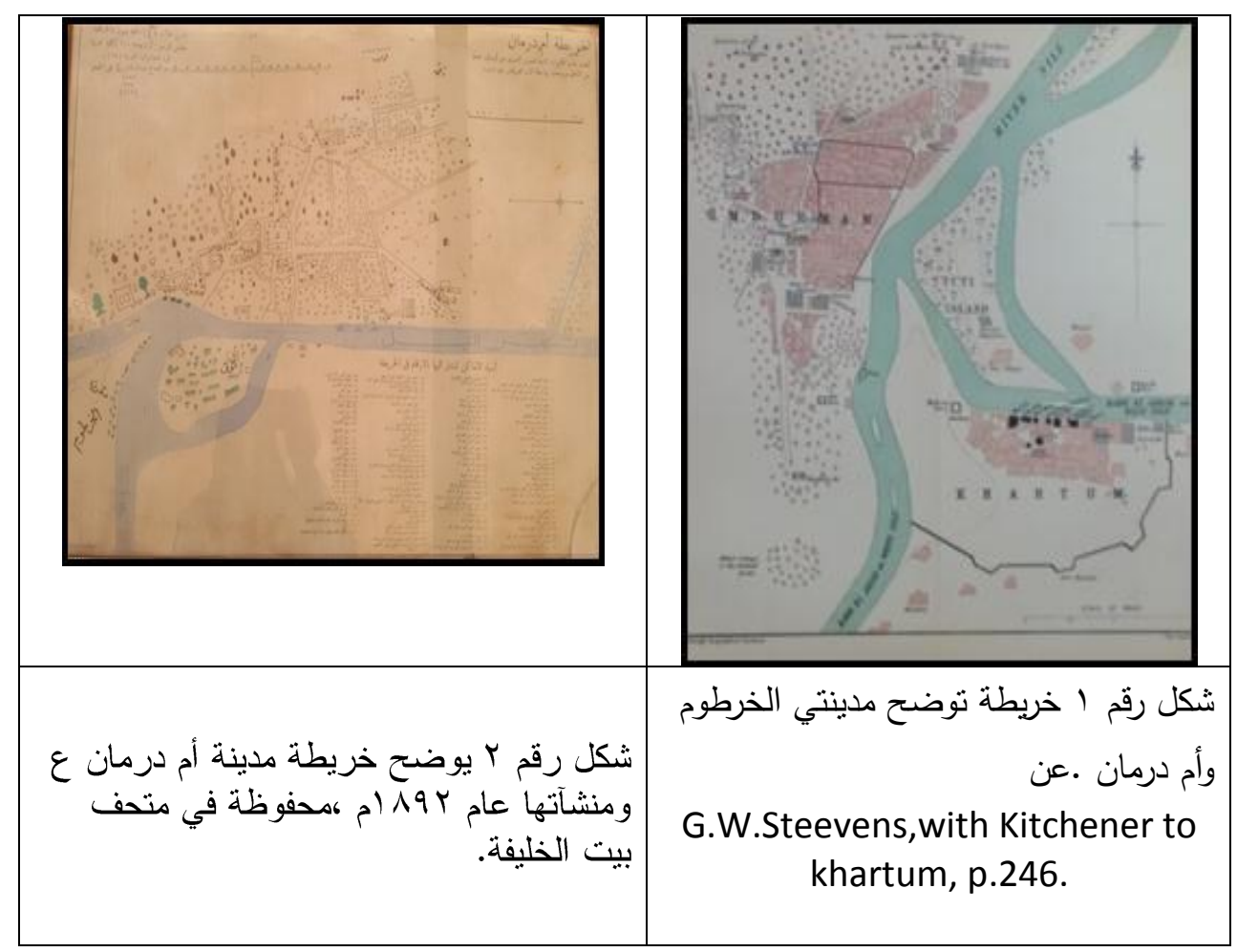




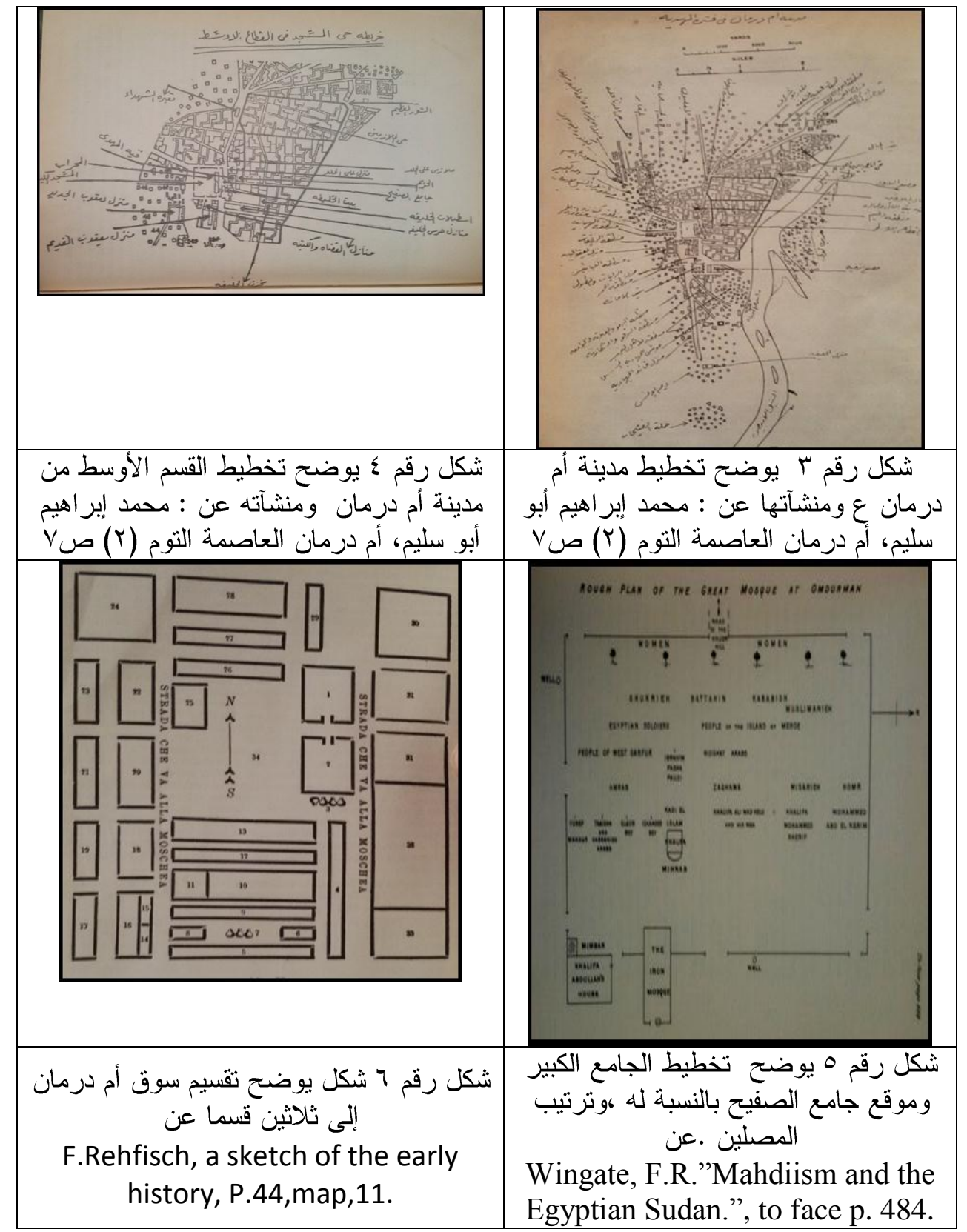




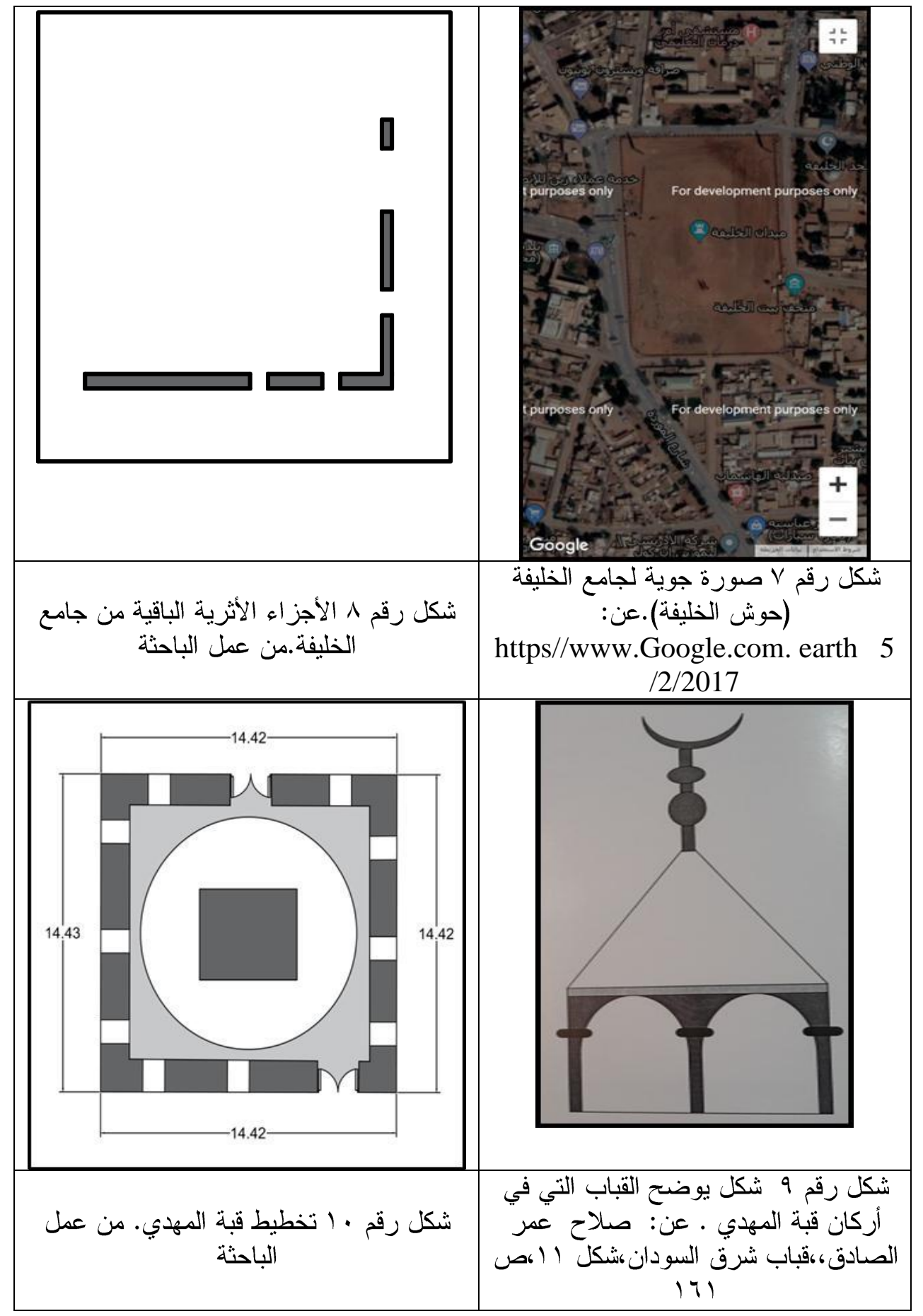


الملامح العمرانية والمعمارية لمدينة أم درمان الأثرية

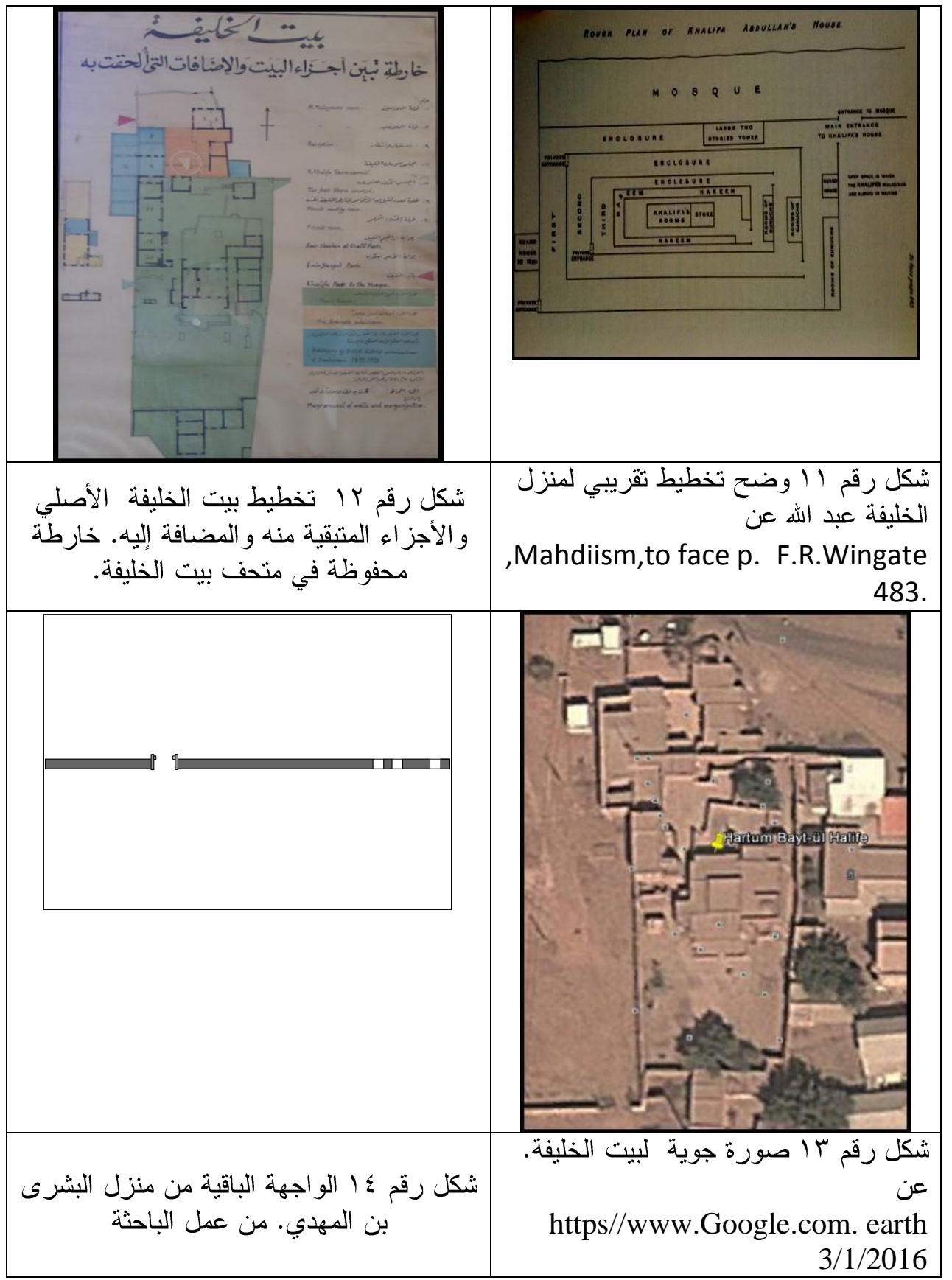


المالامح العمرانية والمعمارية لمدينة أم درمان الأثرية

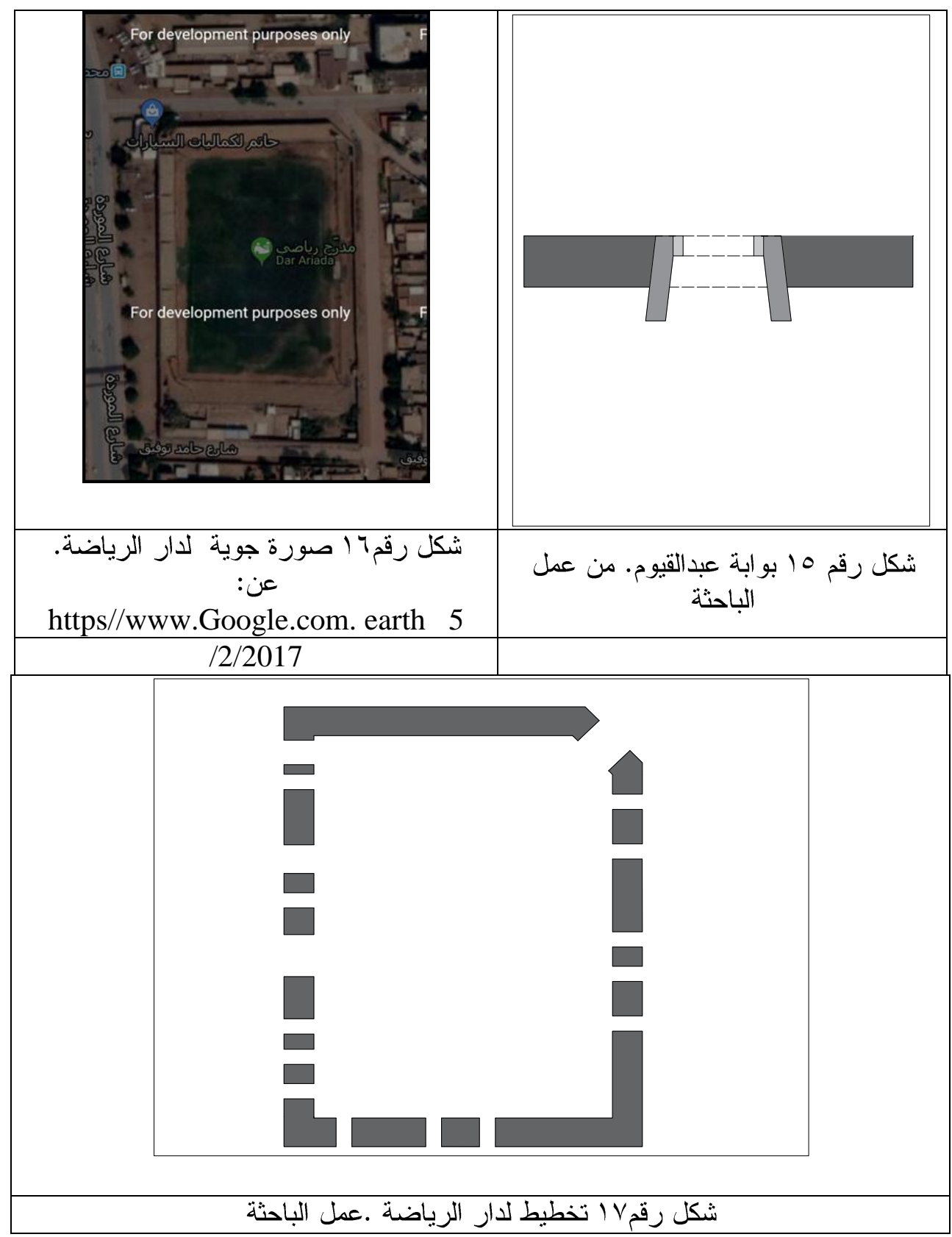

